\title{
Stability Analysis of Bleeder Entries in Underground Coal Mines Using the Displacement-Discontinuity and Finite-Difference Programs
}

\author{
Xu Tang \\ West Virginia University
}

Follow this and additional works at: https://researchrepository.wvu.edu/etd

Part of the Mining Engineering Commons

\section{Recommended Citation}

Tang, Xu, "Stability Analysis of Bleeder Entries in Underground Coal Mines Using the DisplacementDiscontinuity and Finite-Difference Programs" (2014). Graduate Theses, Dissertations, and Problem Reports. 8160.

https://researchrepository.wvu.edu/etd/8160

This Thesis is protected by copyright and/or related rights. It has been brought to you by the The Research Repository @ WVU with permission from the rights-holder(s). You are free to use this Thesis in any way that is permitted by the copyright and related rights legislation that applies to your use. For other uses you must obtain permission from the rights-holder(s) directly, unless additional rights are indicated by a Creative Commons license in the record and/ or on the work itself. This Thesis has been accepted for inclusion in WVU Graduate Theses, Dissertations, and Problem Reports collection by an authorized administrator of The Research Repository @ WVU. For more information, please contact researchrepository@mail.wvu.edu. 
Stability Analysis of Bleeder Entries in Underground Coal Mines Using the Displacement-Discontinuity and Finite-Difference Programs

\author{
Xu Tang \\ Thesis submitted \\ to the Benjamin M. Statler College of Engineering and Mineral Resources \\ at West Virginia University \\ in partial fulfillment of the requirements for the degree of \\ Master of Science in \\ Mining Engineering
}

\author{
Approved by \\ Brijes Mishra, Ph.D., Chair \\ Yi Luo, Ph.D. \\ Felicia F. Peng, Ph.D. \\ Department of Mining Engineering \\ Morgantown, West Virginia \\ 2014
}

Keywords: Stability, Bleeder entry, Bleeder pillar, Bleeder roof, Vertical stress, Safety factor, Displacement-discontinuity, Finite-difference 


\title{
ABSTRACT \\ Stability Analysis of Bleeder Entries in Underground Coal Mines Using the Displacement-Discontinuity and the Finite-Difference Programs
}

\begin{abstract}
Xu Tang
The stability of bleeder entries is essential for both mine ventilation and personnel travelling through the entries. Therefore, it is imperative that bleeder pillars remain stable and bleeder entries safe during their service life. Surprisingly, there are few published investigations on ground control issues in the bleeder entries. This thesis is an attempt to analyze the ground control problems in bleeder entries especially, the structural integrity of the bleeder entry. Two numerical programs (a) displacement discontinuity programLaModel and (b) the finite difference program-FLAC were used to investigate these problems. Modeling results from the LaModel program indicated that the vertical stresses in bleeder pillars would first increase and then remain unchanged during retreat mining. The active longwall did not influence the stress concentrations and safety factors in the bleeder pillars of the adjacent mined-out panel in multiple longwall panels. The vertical stress concentration on bleeder pillars increased with depth. For detailed analysis of roof, pillar and floor of the mine entry simulation was performed in the finite difference program-FLAC. For realistic analysis, coal was assigned as strain-softening material and the gob was simulated with double yielding material. Results showed that the roof displacement in bleeder entries increased during second mining. The stability of the bleeder entry was affected by the behavior of the gob and active mining zone.
\end{abstract}




\section{ACKNOWLEDGEMENTS}

\section{Take Me Home, Country Roads!}

This is where my journey begins in West Virginia. After two years study in Morgantown, lots of memories were, are and will always be preserved here: the WVU Stadium, PRT (Personal Rapid Transit), Creative Art Center, Recreation Center, WVU library, Mineral Resource Building, Pineview, WVUCSSA, Christian \& Missionary Alliance (CMA) Church, Cheat Lake, Metropolitan Theater, and so on. These are the places where I have experienced American culture, where I have shared my joys and sorrows with my friends, where I have learned how to live my life, and where I have found my true passion.

First, I would like to express my gratitude to my supervisor, Dr. Brijes Mishra. I want to thank him for his trust, encouragement, and guidance during my time at West Virginia University.

I would like to thank my committee members, Dr. Yi Luo and Dr. Felicia F. Peng, for their support and invaluable suggestions during the research.

I also thank the West Virginia State Coal and Energy Research Bureau (CERB), which provided funding, guidance, and support.

I would also like to give my sincerest thanks to my friends and colleagues in the mining engineering program: Kaifang Li, Yu Xiong, Yuting Xue, Meng Zhang, Shrey Arora, Christopher Newman, Jian Yang, Mingming Li, Ming Fan, Wan Wang, Xinyang Wang Peng Zhang, and other graduate students.

Last, I want to thank my family, and the people who helped me. Without their support, I could not have made it here in Morgantown. 


\section{TABLE OF CONTENTS}

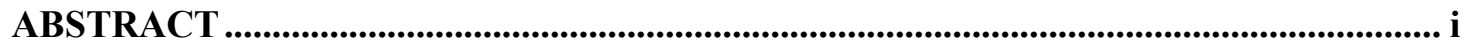

ACKNOWLEDGEMENTS........................................................................................................ ii

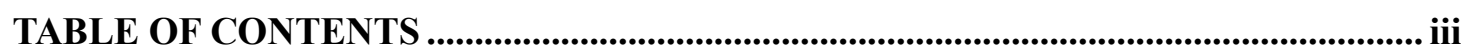

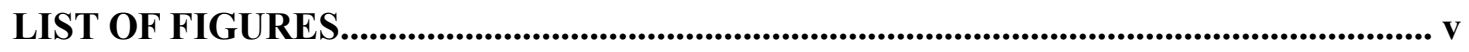

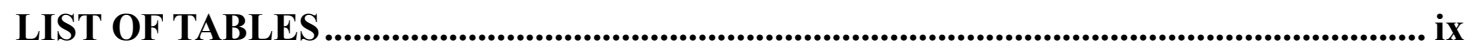

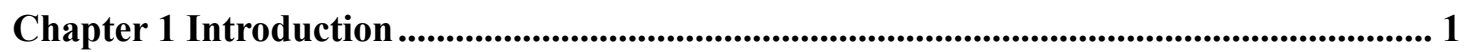

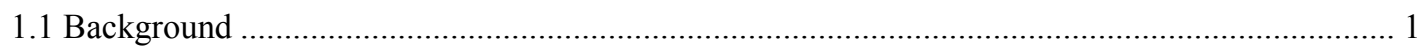

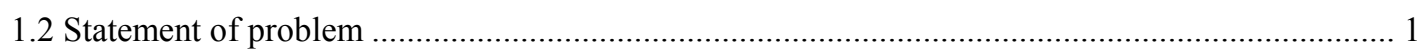

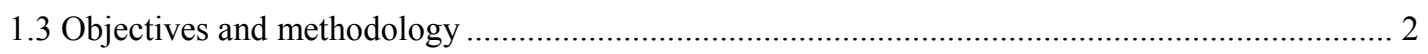

Chapter 2 Literature review ...................................................................................................................... 4

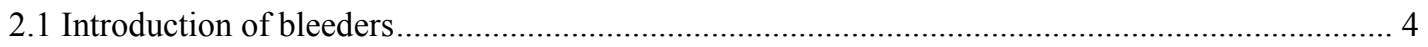

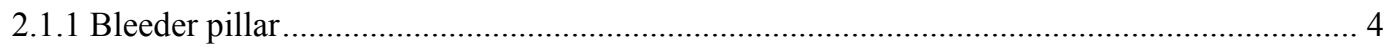

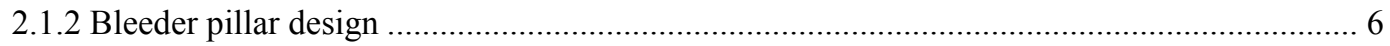

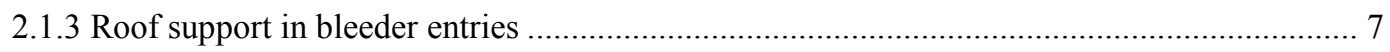

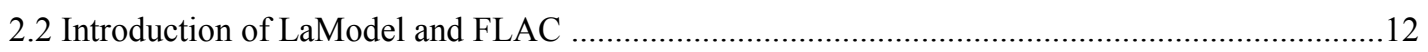

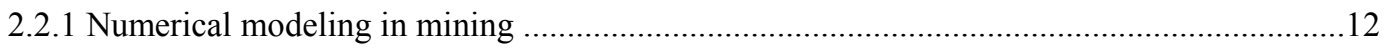

2.2.2 Development of displacement-discontinuity LaModel code................................................14

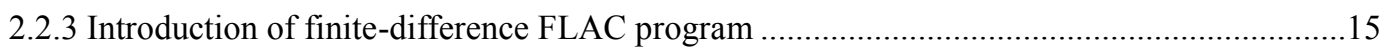

Chapter 3 Stability analysis of bleeder pillars by LaModel ................................................. 17

3.1 Effects of overburden thickness and adjacent longwall faces ....................................................17

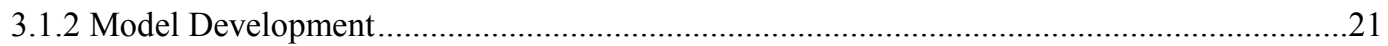

3.1.3 Stress development and safety factors for bleeder pillars in mining scenario 1 ....................23

3.1.4 Stress development and safety factors for bleeder pillars in mining scenario 2 .....................26

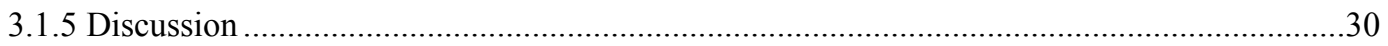

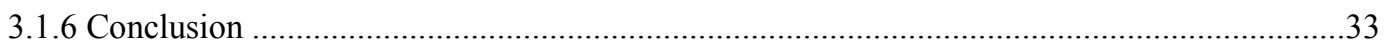

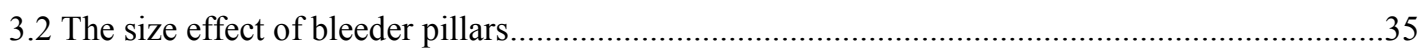

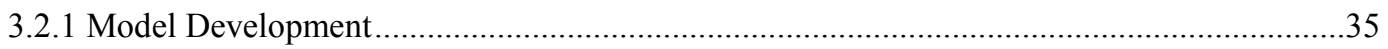

3.2.2 Stress distribution and safety factor in bleeder pillars in mining scenario 1 ..........................37

3.2.3 Stress distribution and safety factor in bleeder pillars in mining scenario 2 ..........................4

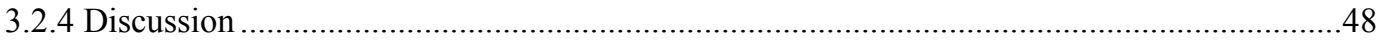


Chapter 4 Roof stability analysis of bleeder entries by FLAC ........................................50

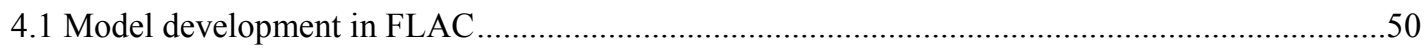

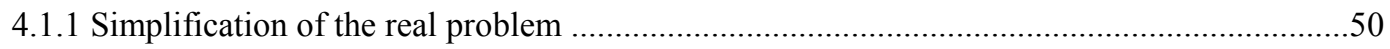

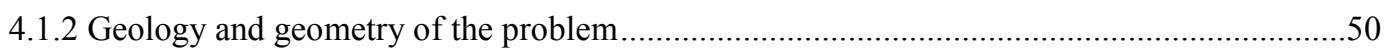

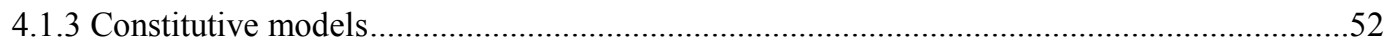

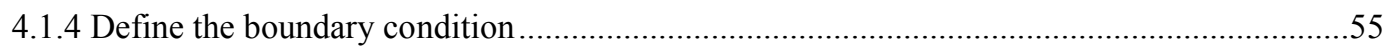

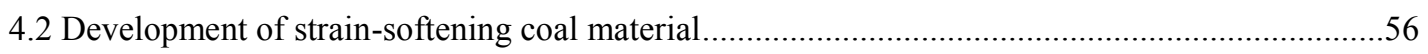

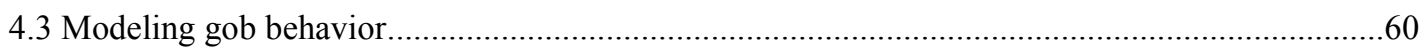

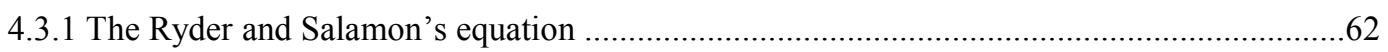

4.3.2 Discussion on the confidential interval of Salamon's equation ............................................64

4.3.3 Confirmation of the confidence interval of Salamon's equation.............................................66

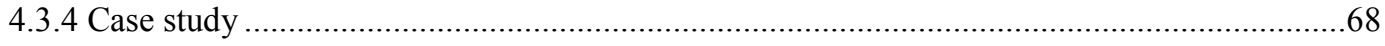

4.4 Roof deformation analysis in bleeder entries …………............................................................

4.4.1 Model development........................................................................................................

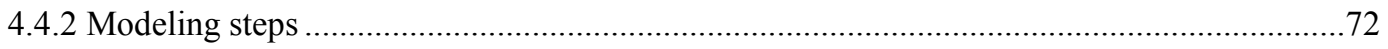

4.4.3 Roof and floor displacement analysis of bleeder entries ..........................................................75

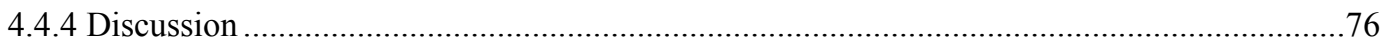

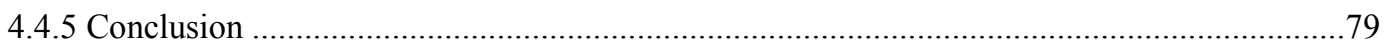

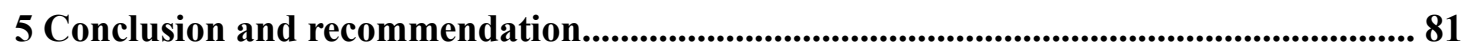

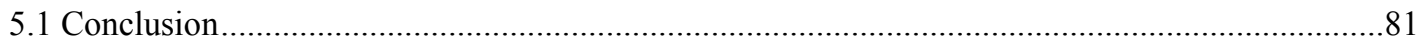

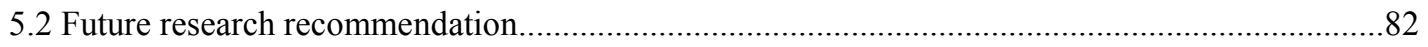

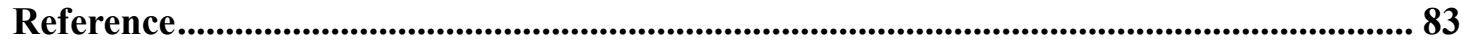

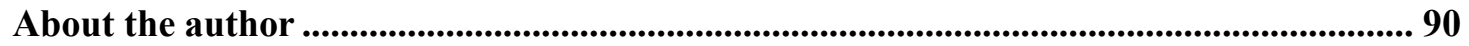




\section{LIST OF FIGURES}

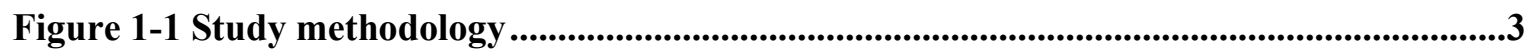

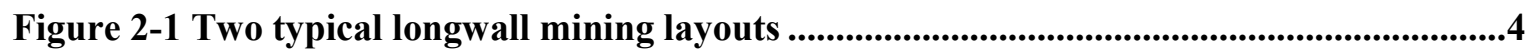

Figure 2-2 Coal pillar classification in underground coal mines..............................................5

Figure 2-3 Three-entry system in bleeder area ....................................................................................6

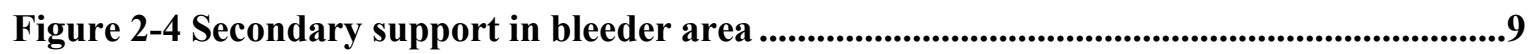

Figure 2-5 Wood cribs in bleeder area (C. Mark, 2002).....................................................10

Figure 2-6 Prosetter and Cluster support in underground mine (Strata web, 2014) ...............10

Figure 2-7 Can support and the Prestressing Units (T.M. Barczak, 2006) ................................11

Figure 2-8 Pumpable support in longwall tailgate (T. M. Barczak, 2008) ...............................12

Figure 2-9 Numerical method for modeling ….......................................................................................13

Figure 2-10 General solution procedure of FLAC (Itasca, 2011).........................................16

Figure 3-1 Schematic of laminated overburden (Heasley, 1998) ............................................18

Figure 3-2 The laminated abutment stress fitted the empirical formula (Heasley, 1998)........18

Figure 3-3 Two modeling layouts by LaModel...................................................................22

Figure 3-4 The vertical stress $(1,3,7$ steps) and pillar stress SF (1, 3, 7 steps) in bleeder pillars under 500ft overburden during retreat mining process ............................... 25

Figure 3-5 Development of the vertical stress and SF with advancing longwall face ..............26

Figure 3-6 The vertical stress (1, 3, 7 steps) and pillar stress SF (1, 3, 7 steps) on bleeder area for multiple panels under $\mathbf{1 5 2 . 5}$ m overburden during retreat mining process .....29

Figure 3-7 Vertical stress and SF plots in bleeder pillars of multiple panels with advancing longwall face ..................................................................................................................................... 30

Figure 3-8 Abutment loading development process during retreat mining (modified after Peng, 2008) .................................................................................................................................. 31

Figure 3-9 Vertical stress concentration in gob area (Peng 2007) ............................................32

Figure 3-10 Vertical stress and SF plots in bleeder pillars under different overburden with advancing longwall face........................................................................................................ 33 
Figure 3-11 Layouts of bleeder pillars in mining scenario 1

Figure 3-12 Layouts of bleeder pillars in mining scenario 2 ..............................................36

Figure 3-13 Layout of bleeder area with $60 \times 90 \mathrm{ft}$ pillars .....................................................38

Figure 3-14 Layout of bleeder area with $60 \times 40 \mathrm{ft}$ pillars ....................................................38

Figure 3-15 Development of vertical stress in bleeder pillars (a-1 to a-3 and A-1 to A-3) during retreat mining process.................................................................................... 39

Figure 3-16 Development of SF in bleeder pillars (a-1 to a-3 and A-1 to A-3) during retreat mining process............................................................................................................................ 40

Figure 3-17 The development of total vertical stress in bleeder pillars (A-1, A-2, A-3) at 1, $2,5,10$ steps during retreat mining process ............................................................... 40

Figure 3-18 The development of stress SF in bleeder pillars (A-1, A-2, A-3) at 1, 2, 5, 10 steps during retreat mining process...............................................................................................41

Figure 3-19 The development of total vertical stress in bleeder pillars (a-1, a-2, a-3) at 1, $2,5,10$ steps during retreat mining process 42

Figure 3-20 The development of stress SF in bleeder pillars (a-1, a-2, a-3) at 1, 2, 5, 10 steps during retreat mining process. 42

Figure 3-21 Development of vertical stress in bleeder pillar (b-s and B-s) during retreat

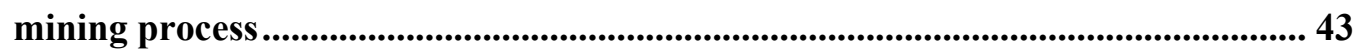

Figure 3-22 Development of vertical stress in bleeder pillar (b-s and B-s) during retreat

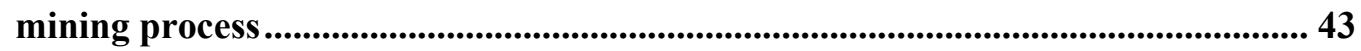

Figure 3-23 Bleeder area supported by different sizes of bleeder pillars .................................44

Figure 3-24 Development of vertical stress in bleeder pillar for 1, 2 and 10 steps....................45

Figure 3-25 The development of vertical stress in bleeder pillars (F-1, F-2, F-3, F-4, F-5) at 1,

2,5,10 steps during retreat mining process . .45

Figure 3-26 The development of vertical stress in bleeder pillars (D-1, D-2, D-3) at 1, 2,5,10 steps during retreat mining process 46

Figure 3-27 Development of vertical stress in bleeder pillars (C-1, D-1,E-1,F-1,G-1,H-1) during retreat mining process. 
Figure 3-28 Development of stress SF in bleeder pillar (C-1, D-1, E-1, F-1, G-1, and H-1) during retreat mining process.................................................................................................. 47

Figure 3-29 Distribution of induced vertical stress behind gob ...........................................48

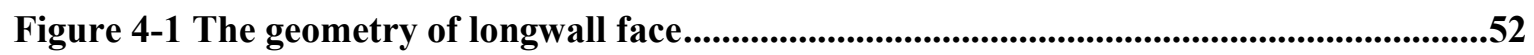

Figure 4-2 The Mohr-Coulomb failure criterion in FLAC (Itasca, 2011) ...............................53

Figure 4-3 The stress-strain curve of strain-softening model in FLAC (Itasca, 2011) .............54

Figure 4-4 The relation between pressure and volumetric strain of double yielding model in

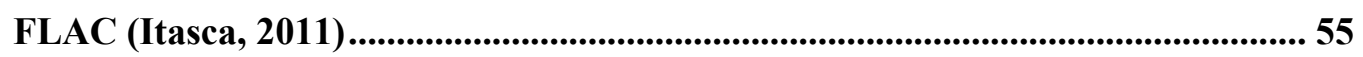

Figure 4-5 Typical stress-strain curves for coal under different width-to-height ratios ..........56

Figure 4-6 Comparison between the peak strength of pillar under various $\mathrm{W} / \mathrm{H}$ ratios with the results obtained by Bieniawski's equation and Salamon's equation.................. 58

Figure 4-7 The stress-strain curves of pillars modeled by FLAC with various W/H ratios....59

Figure 4-8 Variation of initial tangent modulus with rock strength and bulking factor (H.

Yavuz, 2003) ..................................................................................................................................... 63

Figure 4-9 The relation between initial tangent modulus and vertical stress for different

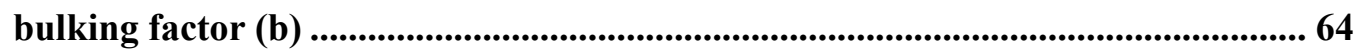

Figure 4-10 The confidence interval or boundary of Salamon's equation.................................66

Figure 4-11 The calibration process of double yielding model in FLAC ................................67

Figure 4-12 The conformation process of double yielding model in FLAC.............................68

Figure 4-13 Comparison between model results and Salamon's model for gob material ........70

Figure 4-14 Modeling procedures.............................................................................................................71

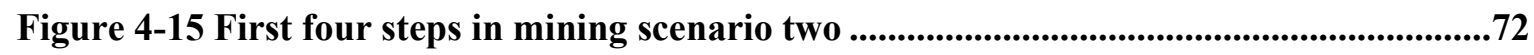

Figure 4-16 Displacement monitoring point of bleeder roof during retreat mining process .. 72

Figure 4-17 The physico-mechanical properties of the overburden rock strata .....................73

Figure 4-18 The geostatic state of model-YY stress contour....................................................73

Figure 4-19 The YY stress contour after creating bleeder entries and setup room.................74

Figure 4-20 The YY stress contour in tenth mining steps .....................................................74 
Figure 4-22 Y displacement of each monitor point in the floor in bleeder entries during the retreat mining process .............................................................................................................. 76

Figure 4-23 Displacement vectors around three bleeder entries ...........................................76

Figure 4-25 Y displacement of each monitor point of the roof in bleeder entries with FLAC steps during the retreat mining process .................................................................... 78

Figure 4-26 Y displacement of each monitor point of the roof in bleeder entries with FLAC steps during the retreat mining process ................................................................................... 78

Figure 4-27 Stress state around bleeder entries in retreat mining step 10 .................................79 


\section{LIST OF TABLES}

Table 2-1 Type of roof bolts in the U.S. coal mines (Peng, 2008)...........................................8

Table 3-1 Input material properties in the LaModel program...................................................23

Table 3-2 Input values for rock mass properties produced by LaModel Wizards Results.....23

Table 3-3 Input material properties in the LaModel program....................................................36

Table 4-1 The simplified stratigraphic column of overburden strata ......................................51

Table 4-2 The relation between strain and cohesion ......................................................................57

Table 4-3 The mechanical properties of strain-softening coal .....................................................58

Table 4-4 Bulking factor of broken rock ............................................................................................64

Table 4-5 Reasonable coefficient for Ryder and Salamon's equation.....................................65

Table 4-6 Five cases for calibrated double yielding model by FLAC...........................................68

Table 4-7 Physical-mechanical parameter of double yielding model in FLAC .........................69

Table 4-8 Relation between plastic volumetric strain and cap pressure of double yielding model in FLAC ......................................................................................................... 70 


\section{Chapter 1 Introduction}

\subsection{Background}

Coal mining has always been a hazardous occupation all over the world, even though highly modern mechanized methods have been employed. Accidents in underground coal mine consist of gas, flooding, roof fall, fire and haulage (Peng, 2008). Gas accidents usually include coal and gas outburst and methane explosion. The high concentration of methane in the coal seam is one of the triggers inducing gas accidents. The emission of methane and its accumulation in worked-out areas always plagues the safety production in the coal mining industry, which may be caused by improperly installed sensors, improper local ventilation, and other mine ventilation issues.

In order to avert methane accumulation and provide a safe working environment for miners, the underground coal mine ventilation system must provide enough fresh air to underground coal mines and ensure that all pillared areas are ventilated, including the mined-out area (Stefanko, 1972). At the far end of gob, there are a set of roadways connecting the tailgate and headgate of the panel; these are called bleeders, and are used to dilute and exhaust the return air from mining face and mined-out area. Generally, bleeders include the pillared area (including internal airflow paths), bleeder entries,

bleeder connections, and all associated ventilation control devices that control the air passing through the pillared area (Tisdale, 1996; Urosek, 2002). Bleeders usually serve a twofold purposes: 1) they continuously drain air-methane mixtures from the gob area away from active pillared areas into the mine return; 2) they relieve expansion of gob contamination such as blackdamp due to atmospheric pressure drop, directing it into the return (Krickovic, 1973). Because of the complexity of mined-out areas, bleeder areas have always been one of the most challenging and uncertain areas in mine ventilation systems.

\subsection{Statement of problem}

Effective bleeder systems control the air passing through the bleeder, dilute any methaneair mixtures and other gases, dusts, and fumes from active workings and the worked-out area. These noxious gases are routed to the surface of the mine through a return airway. 
Because of its effectiveness, both state and federal mine regulations recommended the usage of bleeder system. Furthermore, the federal mine regulations are specific concerning the implementation of bleeder systems in underground coal mines. CFR (Code of Federal Regulation) 75.334 address situations where the bleeder system can be implemented during a retreat mining operation. CFR 75.323(e) limits the methane in the bleeder split of air to $2.0 \%$ immediately before it enters another split of air. The weekly examination requirements can be found in CFR 75.364 (a-2) that, a certified person shall evaluate the effectiveness of bleeder systems under given conditions, and at least one entry of each set of bleeder entries used as part of the bleeder system shall be traveled in its entirety every 7 days. There are also other clauses established for the requirement of air quality and ventilation management in the bleeders.

One of the key questions, which the regulators have often asked, is how to ensure the safety of working or traveling in bleeder entries where only one travelable entry in and out of the area exists?

Bleeders located at the far end of gob area show edge and roof failure posing hazards for mine personnel travelling in these entries. Furthermore, caving of rock stratum associated with retreat mining results in the stress concentration on the pillars in bleeders, which will reduce the stability of bleeder pillars. One practical and straightforward technique is to implement additional roof supports or other measures to ensure bleeder entries and pillars are as safe as multiple travelable entries in and out of the areas. The forefront and key thing for this method is to evaluate whether the bleeder pillars and bleeder entries are stable or not. However, there are no published researches about the evaluation of bleeder area from design to maintenance. Prior research focused on improving ventilation and removal of dust (Krickovic, 1973; Tisdale, 1996; Mucho, 2000; Urosek and Francart, 2002; Oswald and Prosser, 2006). Therefore, this thesis will focus on the stability analysis of the bleeder pillars and roof condition of bleeder entries from the point of ground control.

\subsection{Objectives and methodology}

The main goal of this study is to 1) evaluate the stability of bleeder pillars, and 2) evaluate the roof condition in bleeder entries. The methodology used for this thesis is 
shown in Figure 1-1.

In the first part, the displacement-discontinuity laminated model, LaModel, was used to evaluate the stability of bleeder pillars. The development of vertical stress on bleeder pillar is discussed during the longwall retreat mining operation. The safety factor of bleeder pillars will also be discussed with regard to engineering application. The effect of overburden thickness and the adjacent mining face on the vertical stress development of bleeder pillars will be studied. Then the size effect on the design of bleeder pillars in the bleeder area will be investigated.

In the second part, the finite difference FLAC was used to model the roof deformation of bleeder entries during retreat mining process. The strain-softening coal material was calibrated and applied in the model. The double yielding model in FLAC was used to model gob behavior in the mined-out area. Finally, the deformation of roof in bleeder entry was studied during retreat mining process.

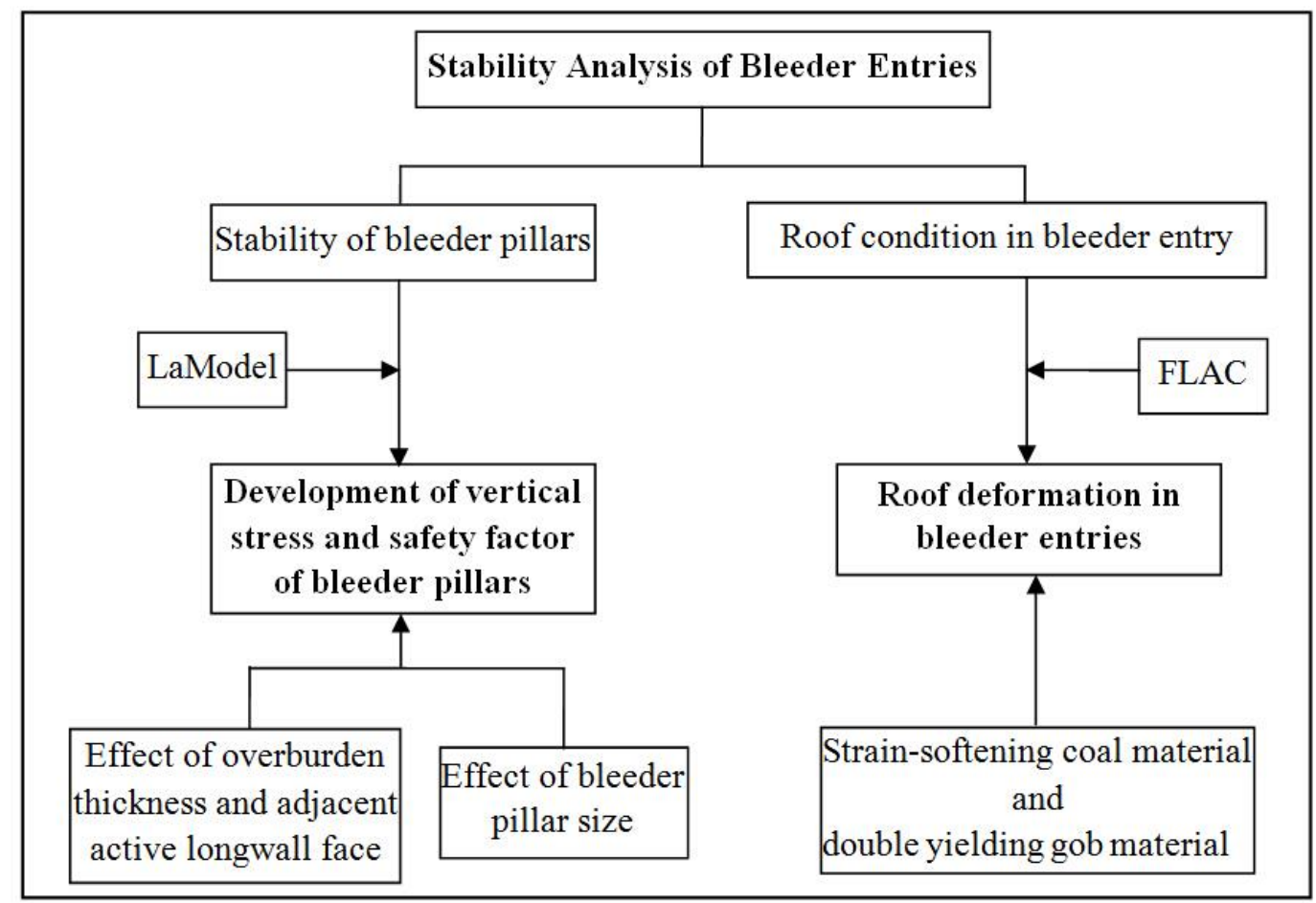

Figure 1-1 Study methodology 


\section{Chapter 2 Literature review}

\subsection{Introduction of bleeders}

\subsubsection{Bleeder pillar}

A coal pillar is a block of coal left in its natural state to support the weight of overburden and to protect the integrity of the entries and crosscuts adjacent to it, thereby allowing miners to extract coal between pillars and to travel safely (Peng, 2008). Coal pillars are fundamental and very important structures in U.S. underground coal mines.

With respect to a pillar design objective, coal pillar can be classified into two groups: chain pillar and barrier pillar (Peng, 2008). Chain pillars are the most common support pillars, which are composed of pillar rows aligned at different locations such as the main, submain, panel, gateroads and bleeder entries, as shown in Figure 2-1. Barrier pillar are usually large coal blocks left to protect surface or subsurface structures from being damaged or affected by mining activity. Barrier pillars are left to ensure that the travel ways, beltlines, ventilation, and power traversing these entries are not adversely affected by mining activities. These pillars are also left at the far inby end of an extracted longwall panel to protect bleeder entries and setup room before the longwall face retreats.

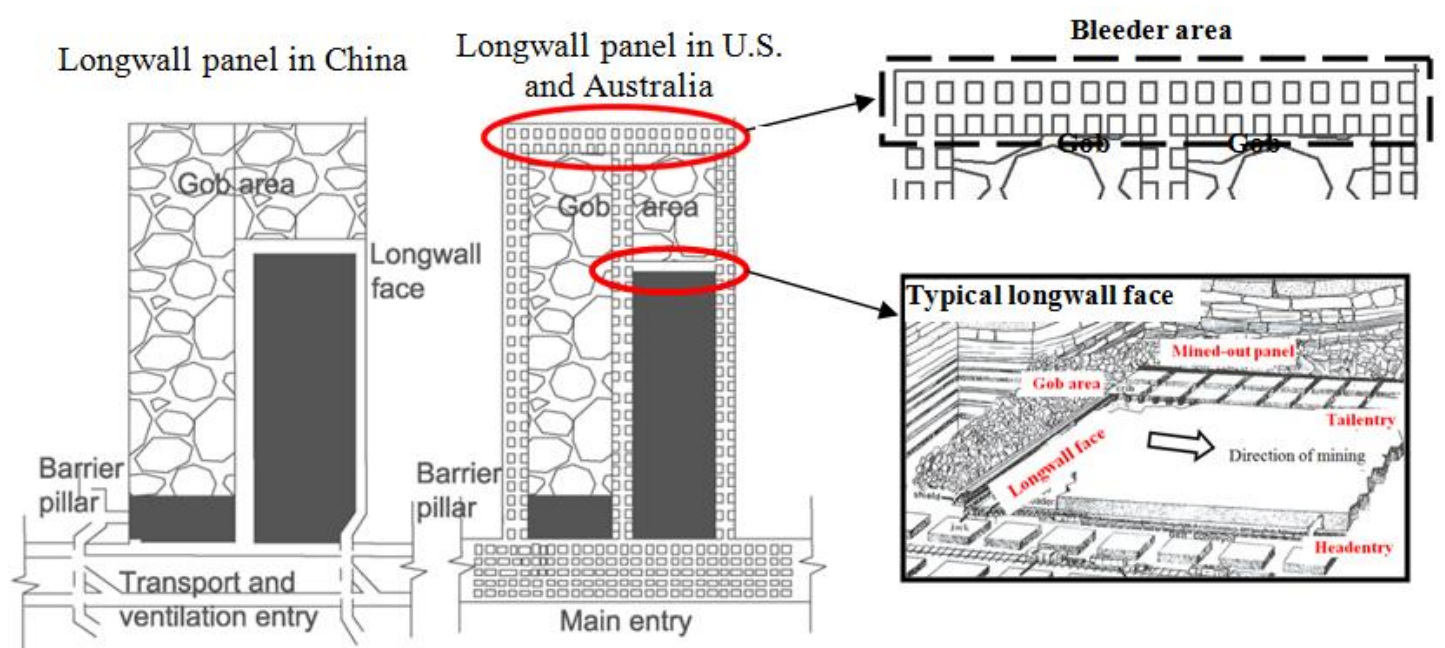

Figure 2-1 Two typical longwall mining layouts

By their mechanism, coal pillars can be divided into two types: stiff pillars and yield pillars (Peng, 2008). Stiff pillars are designed to support the expected load that the pillars 
will experience through their lives, while yield pillars are designed to yield at the proper time and rate, and transfer a proper amount of load to adjacent support blocks of coal. Because of the long servicing time of pillars in bleeders, these pillars should be designed as stiff pillars. Yield pillars are exclusively used in deep mines to avert pillar bump or floor heave. In other words, the main purpose of yield pillars is to relieve the highly concentrated stress by yielding to prevent sudden and violent pillar failure.

By the working time of pillars, coal pillars can also be classified into two other types: the long- time stability pillar and short-time stability pillar. Generally, the long-time pillar usually serves the coalmine for the life of the mine; these include pillars in main and submain entries and bleeder entries. The short-time pillar usually serves for the recovery of panels, including pillars in tailgates and headgates.

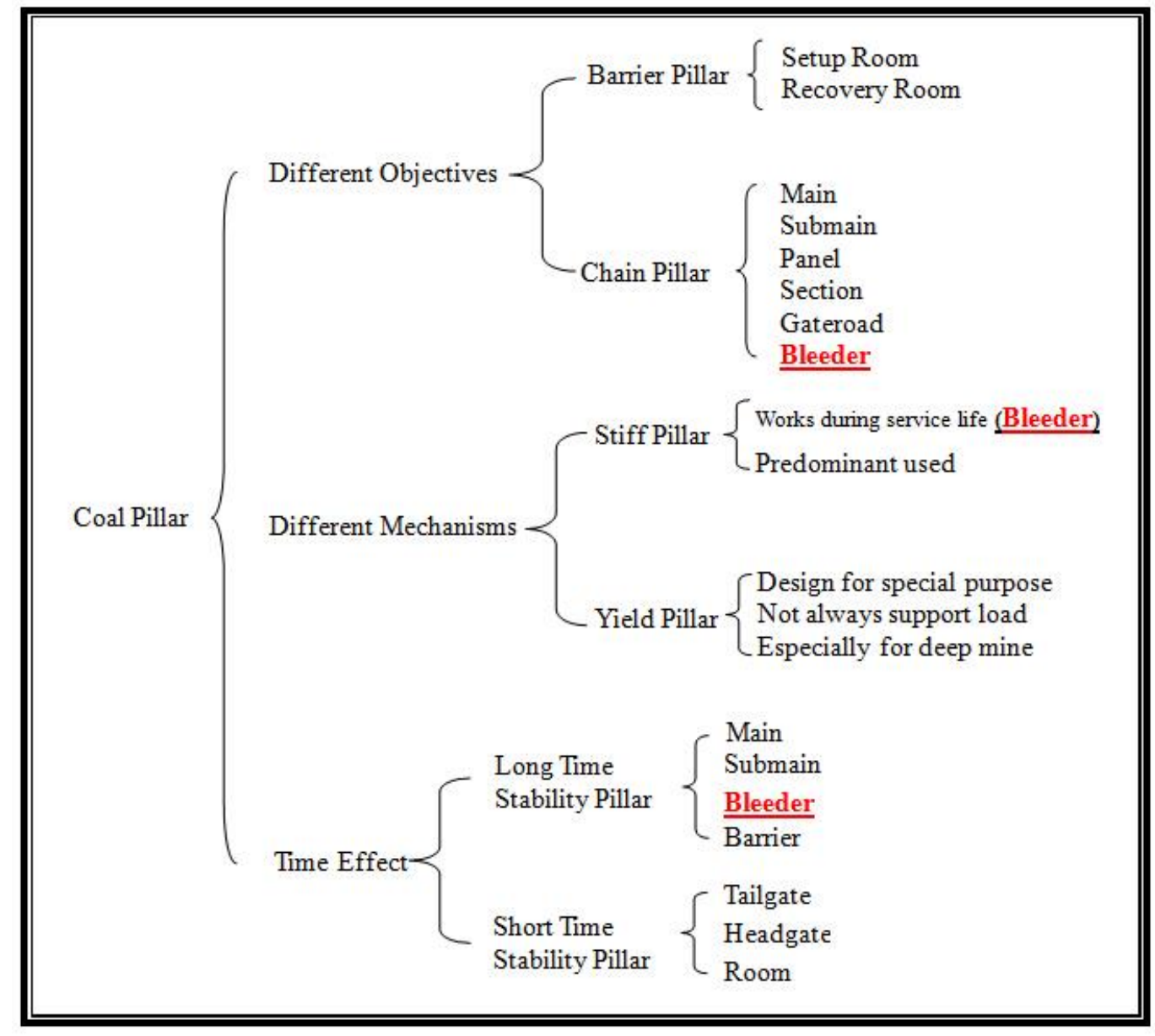

Figure 2-2 Coal pillar classification in underground coal mines 


\subsubsection{Bleeder pillar design}

The bleeder system is an important part of the underground mine ventilation system providing ventilation to areas of retreat mining. It plays a significant role in reducing methane accumulation and eliminating containments from the mine environment. Once the bleeder system is determined to implement for underground mining, design of the bleeder system is very critical. The bleeder is normally a three-entry system (Peng, 2008) and bleeder pillars are usually of same size in U.S. coal mines(Figure 2-3).

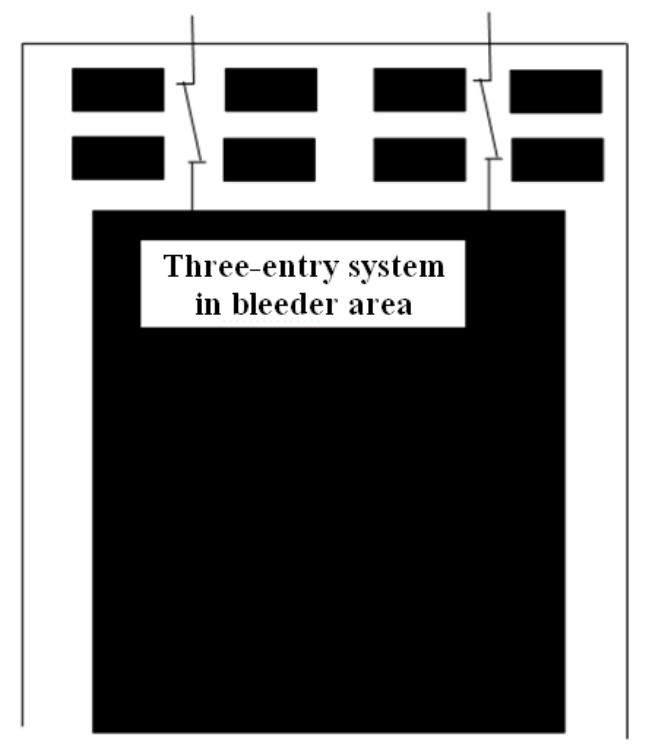

Figure 2-3 Three-entry system in bleeder area

For chain pillar design, three questions are critical (Peng and Chiang, 1984), and these questions are of equal importance for the design of bleeder pillars:

1) Should an equal-size or unequal-size pillar system be adopted?

2) What are the optimum arrangements of the unequal-size pillars if they are used in a three- or four-entry system?

3) What is the optimum size of chain pillars?

However, it is not enough to answer these questions; the ventilation capacity of the bleeder system cannot be neglected in the bleeder design stage. The minimum number of entries and minimum width of bleeder entries should be determined by the amount of fresh air needed to reach the last open crosscut of the farthest section to be mined. In the U.S., entry height is equal to seam thickness, and the lower seam usually requires more or 
wider entries. The optimum size of bleeder pillars depends on geological condition, ground control, and operational experience. Critical things to deliberate include how to make bleeder pillars undergo less damage during their service life, minimizing the cost of maintenance, while maintaining the planed intake air quantity. In addition, it is important to consider the design and arrangement of barrier pillars, which also affect the stability of bleeder pillars.

\subsubsection{Roof support in bleeder entries}

In bleeder design, pillar and roof supports often determine a bleeder system's efficiency during its life of service in the underground mining environment. Roof supports in bleeders are generally long-term supports ( 5 years or more), which means the support should be able to control the time-dependent deformation of the immediate roof (Barczak, 2008). In addition, a careful design and plan for bleeder pillars and entries will surely reduce the cost of maintenance for bleeders.

Supports in bleeder entries are mainly roof bolts, which are now widely used in underground coal mines all over the world. Introduced in 1940's, roof bolts have been the predominant support in mines, which includes coal and non-coal operations. Significant research in the past has tremendously improved the performance of the roof bolts. After years of development, there are various types of roof bolts on the market, which can be used for different roof and geological conditions (Table 2-1).

The secondary support in bleeder entries is evolving along with the advance of roof support technology. There are more than fifty standing-support products for the longwall tailgate and bleeder application (Barczak, 2008). All these products can be classified into two types, active support and passive support (Hoek, 2000), shown in Figure 2-4. The passive supports are external to the roof rock and respond to the downward movement of the rock stratum in the roof. Each support system usually has a unique installation procedure that varies from the traditional wood post to crib installations. 
Table 2-1 Type of roof bolts in the U.S. coal mines (Peng, 2008)

\begin{tabular}{|c|c|c|c|c|c|c|}
\hline \multirow{2}{*}{\multicolumn{2}{|c|}{ Type of bolts }} & \multirow{3}{*}{$\begin{array}{c}\begin{array}{c}\text { Diameter, } \\
\text { in. }(\mathrm{mm})\end{array} \\
5 / 8(15.9) \\
3 / 4(19.1)\end{array}$} & \multirow{3}{*}{$\begin{array}{c}\text { Grade } \\
\text { (strength), } \\
\text { ksi (MPa) }\end{array}$} & \multicolumn{2}{|c|}{ Length, $\mathrm{ft}(\mathrm{m})$} & \multirow{2}{*}{$\begin{array}{l}\text { Bolthole } \\
\text { diameter } \\
\text { in. }(\mathrm{mm})\end{array}$} \\
\hline & & & & Maximum & Average & \\
\hline \multirow{5}{*}{ Tensioned } & Mechanical & & & $8(2.4)$ & $5(1.5)$ & $\begin{array}{l}1.0 \quad(25.4) \\
1-3 / 8(34.9)\end{array}$ \\
\hline & Combination & $\begin{array}{c}3 / 4(19.1) \\
7 / 8(22.2) \\
1(25.4) \\
\mathrm{SRD}^{1} \\
\mathrm{~J}^{\text {bar }^{2}}\end{array}$ & $\begin{array}{l}60(413.7) \\
75(517.1) \\
90(620.5) \\
100(689.5)\end{array}$ & $24(7.3)$ & $8(2.4)$ & $\begin{array}{l}1-3 / 8(34.9) \\
1-1 / 2(38.1)\end{array}$ \\
\hline & $\begin{array}{l}\text { Tensioned rebar, } \\
\text { partially grouted }\end{array}$ & $\begin{array}{c}5 / 8(15.9) \\
3 / 4(19.1) \\
7 / 8(22.2) \\
1.0(25.4) \\
\text { SRD }^{1} \\
\mathrm{~J} \mathrm{bar}^{2}\end{array}$ & $\begin{array}{l}40(275.8) \\
60(413.7) \\
75(517.1) \\
90(620.5) \\
100(689.5)\end{array}$ & $8(2.4)$ & $7(2.1)$ & $\begin{array}{c}1 \cdot(25.4) \\
1-3 / 8(34.9)\end{array}$ \\
\hline & $\begin{array}{l}\text { Mechanically- } \\
\text { anchored, } \\
\text { resin - assisted }\end{array}$ & $\begin{array}{c}5 / 8(15.9) \\
3 / 4(19.1) \\
7 / 8(22.2) \\
1.0(25.4) \\
\mathrm{J} \mathrm{bar}^{2}\end{array}$ & $\begin{array}{ll}40 & (275.8) \\
55 & (379.2) \\
60 & (413.7) \\
75 & (517.1) \\
90 & (620.5) \\
100 & (689.5) \\
\end{array}$ & $16(4.9)$ & $6(1.8)$ & $\begin{array}{lr}1 & (25.4) \\
1-3 / 8 & (34.9) \\
1.5 & (38.1)\end{array}$ \\
\hline & $\begin{array}{l}\text { Cable, partially } \\
\text { grouted }\end{array}$ & $\begin{array}{l}0.6(15.2) \\
0.7(17.8) \\
0.9(22.9)\end{array}$ & $270(1861.5)$ & $35(10.7)$ & $12(3.7)$ & $\begin{array}{c}1 \quad(25.4) \\
1-3 / 8(34.9)\end{array}$ \\
\hline \multirow[t]{2}{*}{$\begin{array}{l}\text { Non- } \\
\text { tensioned }\end{array}$} & $\begin{array}{l}\text { Fully-grouted } \\
\text { resin }\end{array}$ & $\begin{array}{l}5 / 8(15.9) \\
3 / 4(19.1) \\
7 / 8(22.2) \\
1.0(25.4)\end{array}$ & $\begin{array}{l}40(275.8) \\
55(379.2) \\
60(413.7) \\
75(517.1) \\
90(620.5)\end{array}$ & $10(3.0)$ & $5(1.5)$ & $\begin{array}{lr}1 & (25.4) \\
1-3 / 8 & (34.9) \\
1.5 \quad(38.1)\end{array}$ \\
\hline & Cable & $\begin{array}{l}0.7(17.8) \\
0.9(22.9)\end{array}$ & $270(1861.5)$ & $20(6.1)$ & $12(3.7)$ & $\begin{array}{lr}1 & (25.4) \\
1-3 / 8 & (38.1)\end{array}$ \\
\hline $\begin{array}{l}\text { Fully- } \\
\text { grouted, } \\
\text { tensioned }\end{array}$ & $\begin{array}{l}\text { Tensioned rebar, } \\
\text { fully-grouted, } \\
\text { point-anchored }\end{array}$ & $\begin{array}{l}5 / 8(15.9) \\
3 / 4(19.1) \\
7 / 8(22.2) \\
1.0(25.4)\end{array}$ & $\begin{array}{ll}40 & (275.8) \\
60 & (413.7) \\
75 & (517.1) \\
90(620.5) \\
100(689.5)\end{array}$ & $8(2.4)$ & $\begin{array}{l}6(1.8) \\
7(2.1)\end{array}$ & $\begin{array}{lr}1 & (25.4) \\
1-3 / 8 & (34.9) \\
1.5 & (38.1)\end{array}$ \\
\hline \multirow[t]{3}{*}{ Truss } & Cable & $\begin{array}{l}0.5(12.7) \\
0.6(15.2) \\
0.7(17.8) \\
0.8(20.3)\end{array}$ & $270(1861.5)$ & $20(6.1)$ & $16(4.9)$ & $\begin{array}{lr}1 & (25.4) \\
1-3 / 8 & (34.9)\end{array}$ \\
\hline & Rigid & $\begin{array}{l}3 / 4(19.1) \\
7 / 8(22.2)\end{array}$ & $\begin{array}{l}40(275.8) \\
60(413.7)\end{array}$ & $20(6.1)$ & $16(4.9)$ & $1-3 / 8(34.9)$ \\
\hline & Sling & $3 / 4(19.1)$ & $60(413.7)$ & $20(6.1)$ & $16(4.9)$ & $1-3 / 8(34.9)$ \\
\hline
\end{tabular}

${ }^{1} \mathrm{SRD}$ (special rolled dimension) $0.804 \mathrm{in}$. (20.4 mm) or 0.914 in. $(23.2 \mathrm{~mm}$ ) in diameter

${ }^{2} \mathrm{~J}$ Bar 0.810 in. $(20.57 \mathrm{~mm})$ in diameter

${ }^{3} 5 / 8,6 / 8,7 / 8$, and $1 \mathrm{in}$. steel bars are commonly referred to as \#5, \#6, \#7, and \#8 bars 


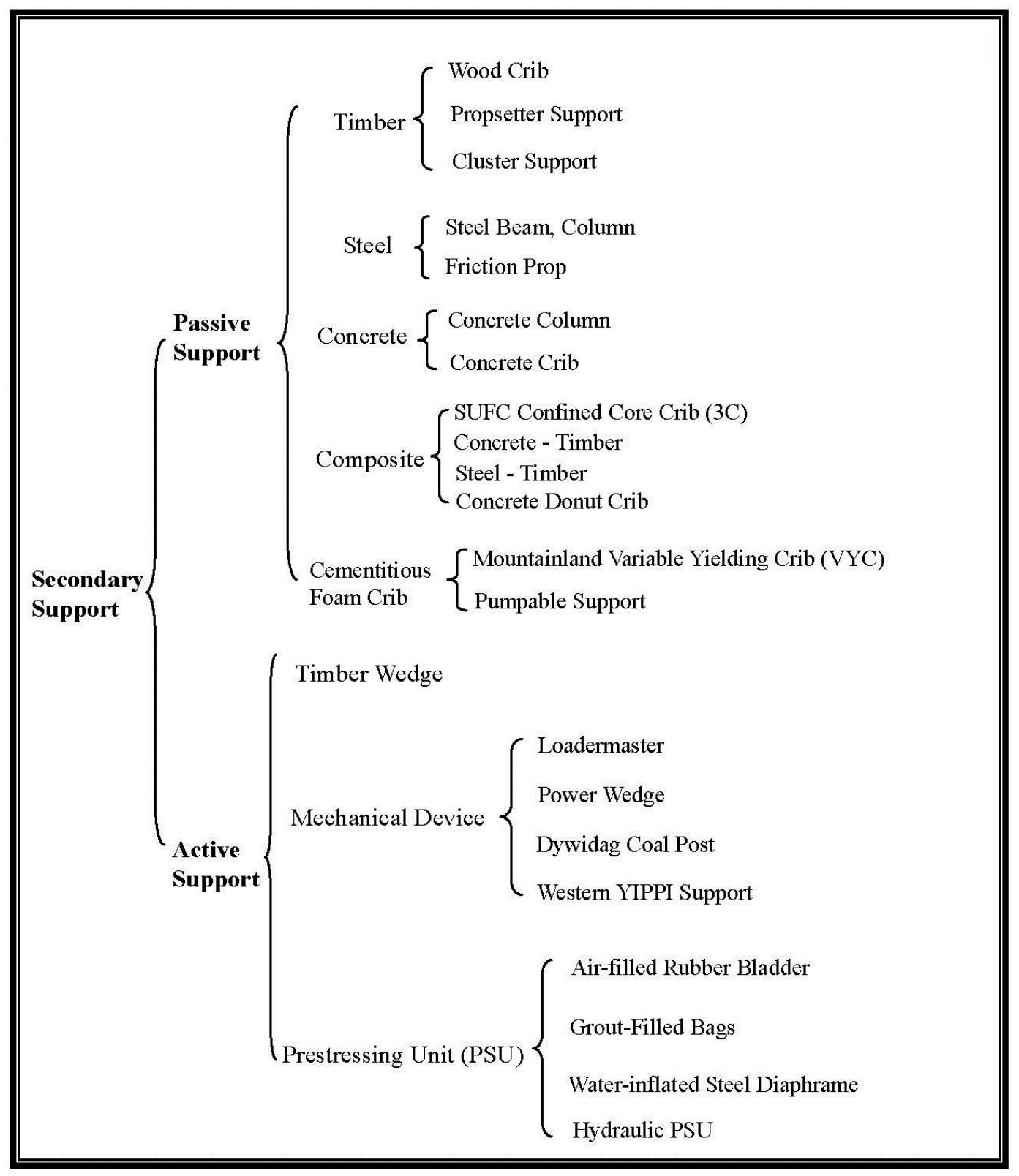

Figure 2-4 Secondary support in bleeder area

Historically, timber cribs and posts were the dominant forms of secondary support (Barczak, 2006). Timber support was always used in the first three decades in underground coal mines, until being substituted with roof bolts in the late 1940s (Mark, 2002). Even though roof bolting has become the dominant roof support technology in the field of ground control since the 1950s, timber cribs and posts remain a supplemental support technology in tailgate and bleeder applications, and are also still essential in mining extrication operations (Barczak, 1995). Timber cribs, which depend on the ratio 
of width to height, involve multiple piece of standard timber being laid on the slide and crossed, which spreads the load well and transfers it to many surfaces with lateral stability (Leach, 2012). To take full advantage of timber support, two alternative supports, Propsetter supports and Cluster props, were also introduced (Barczak, 2006). Propsetter props combine the stiffness of a prop with a built-in yield zone for mining heights of up to 10 feet and can be yielded up to 16-18 inches in a controlled manner. Comparing with timber cribs, Propsetter props use up to $72 \%$ less material and can reduce ventilation resistance by 76\% (Propsetter, 2014). Cluster props are based on the Propsetter support, which is bound together with three strong, pre-tensioned metal straps at the top, middle, and bottom section of the props (Cluster prop, 2014). This makes three props provide a unified and stable, yielding support system.

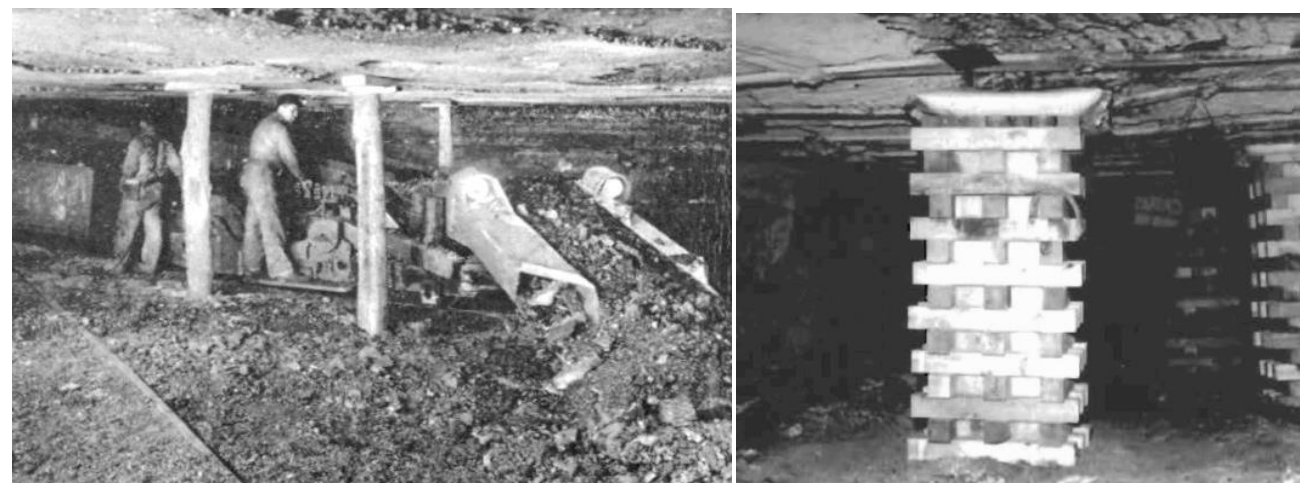

Figure 2-5 Wood cribs in bleeder area (C. Mark, 2002)

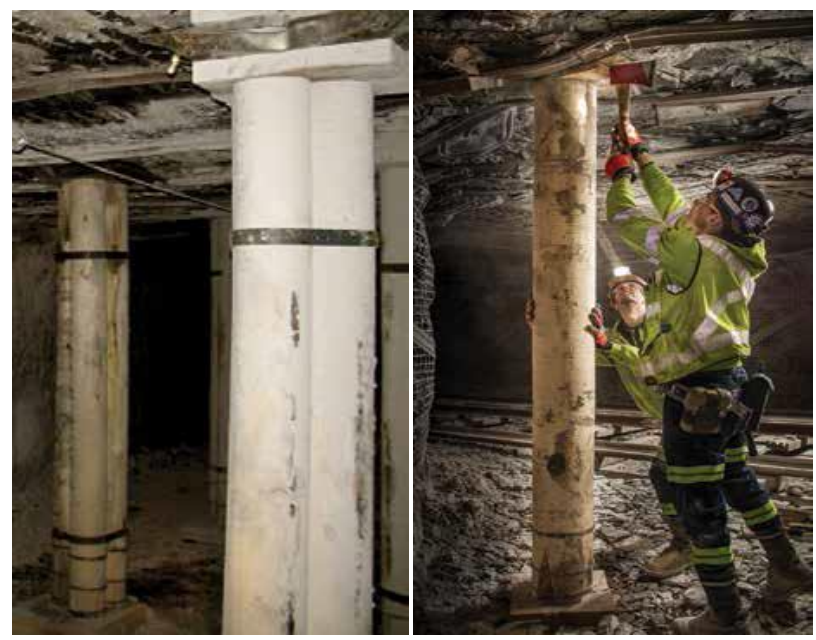

Figure 2-6 Prosetter and Cluster support in underground mine (Strata web, 2014)

Due to ground reaction and special ground control features in western U.S. mines and the 
increasing cost of mine timber, the Can support, one alternative method of support, was developed to meet market demand (Barczak, 2006). Because of its high stability and yield performance, the Can support is now the most widely used standing support system in the U.S. for longwall tailgate application. The significant drawback for this support is that it has to be topped off by wood crib blocks to establish roof contact or that you have to buy a machine to install Cans. The stiffness of the Can-wood system is greatly reduced compared to single Can support. The NIOSH Support Technology Optimization Program (STOP) software developed a new module to estimate the yield capacity of the wood structure compared to the Can (Barczak, 2000).
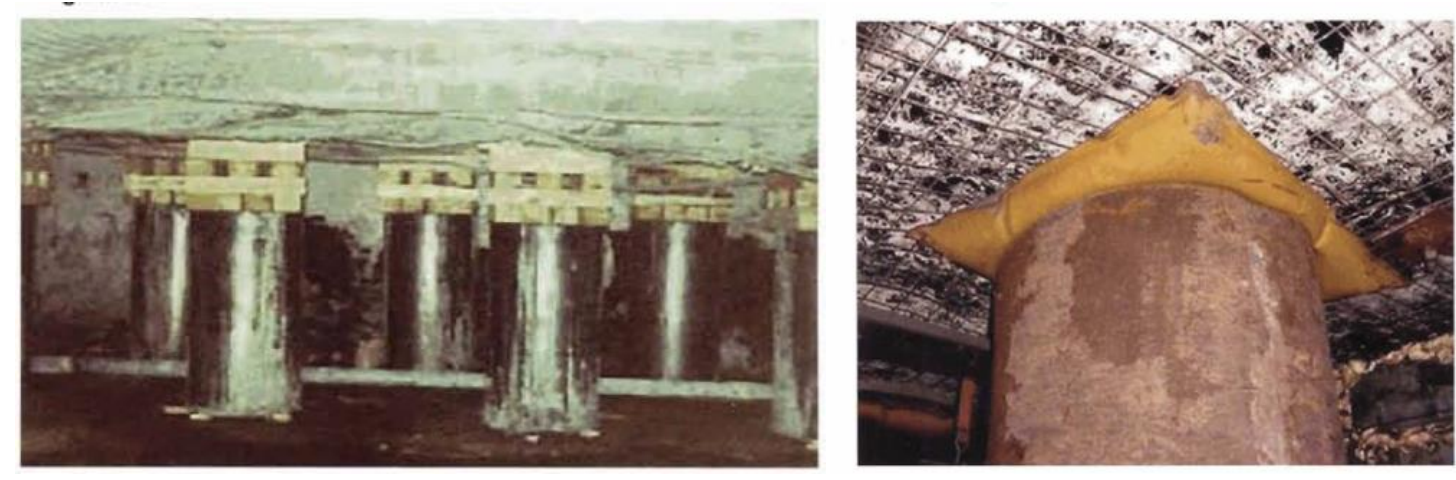

Figure 2-7 Can support and the Prestressing Units (T.M. Barczak, 2006)

Recently, a new prestressing technology was introduced and the prestressing unit (PSU) was developed to strengthen roof support power (Barczak, 2004). This new product can eliminate the stiffness reduction of wood cribs and allow the full capacity of the Can when installing it to the mine roof and floor. Further, the PSU can also be designed in different shapes and sizes to accommodate different sized Can supports.

In 1993, the first modern pumpable roof support was installed in the U.S. in the Southern Ohio Coal Company's Meigs No.2 mine; this was mainly used for the support of bleeder entries. This technology takes full advantage of pumpable supports being installed in inaccessible areas. This is very helpful for support in the bleeder because the bleeder is generally restricted due to power constraints, unpredictable ventilation problems, and other ground control problems. Despite the success of this application, the high material cost limits the use of this technology (Barczak, 2005 \& 2008). 

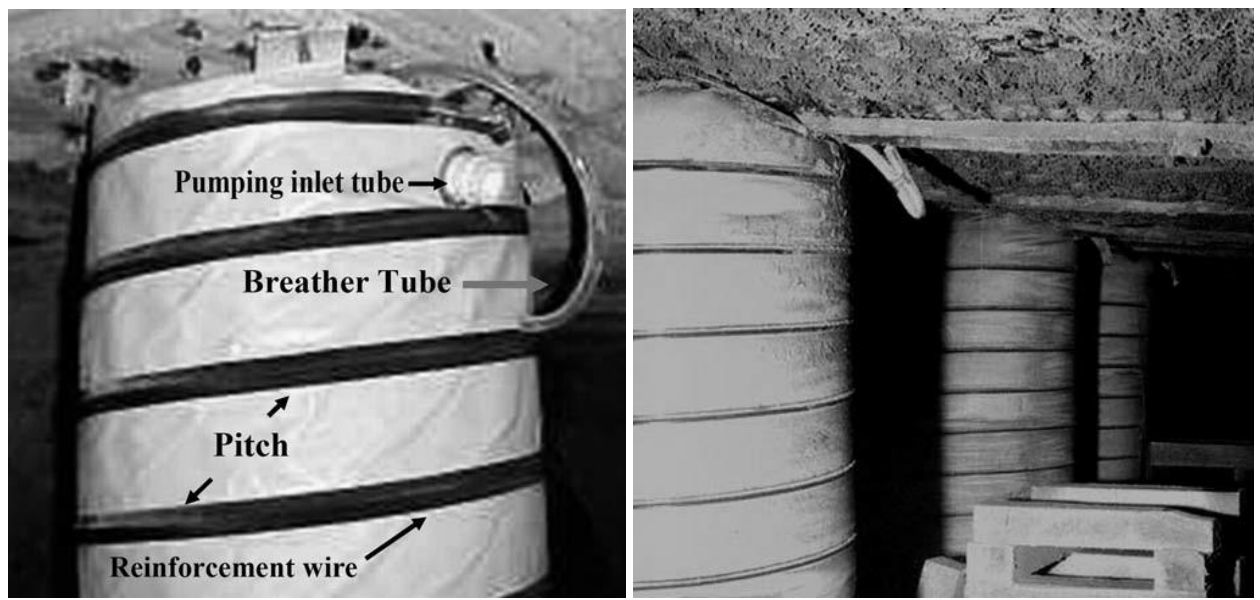

Figure 2-8 Pumpable support in longwall tailgate (T. M. Barczak, 2008)

Due to mining disturbances in bleeders, secondary support in bleeders is necessary and critical. However, secondary support has the potential to increase air resistance for ventilation, which is adverse for ventilation in bleeders (Grossbach, 2011). Thus, choosing reasonable secondary support is one of the critical factors for maintaining bleeders.

\subsection{Introduction of LaModel and FLAC}

\subsubsection{Numerical modeling in mining}

Stresses occurring in underground structures are due to the disturbance caused by mining. Knowing underground stress states is one of the fundamentally important for underground structure design (Rocscience, 2014). Recently numerical methods have gained widespread popularity as a tool for stress analysis (Jing, 2002 \& 2003; Starfield, 1998). This predictive capability comes from a variety of modeling methods, and the most commonly applied methods for rock mechanics is as follows as shown in Figure 2-9. In mathematics, the FDM (Finite difference method) is the simplest and one of the oldest methods of solving differential equations. It is a direct approximation of the governing PDEs (Partial Differential Equations) by replacing partial derivatives with differences at regular or irregular grids imposed over problem domains, thus transferring the original PDEs into a system of algebraic equations in terms of unknowns at grid points. The solution of the system can be obtained by the necessary initial and boundary conditions (Jing, 2003). The FEM is also a numerical technique to find approximate solutions to 
boundary value problems. The FEM, instead of solving the problems for the entire body in one operation, encompasses all the methods for connecting many simple element equations over many small sub-domains (elements) to approximate a more complex equation over a larger domain (Dhatt, 2012). After imposing the properly defined initial and boundary conditions, the global system of algebraic equations will be solved producing the required information for the larger domain (Zienkiewicz, 1977). The FEM is now the most widely applied numerical method in engineering. The disadvantage of the FDM/FEM is its interior discretization, and thus it cannot simulate infinitely large domains (Jing, 2003). As for large tabular deposits in mining activity, it would be time consuming and decrease computing efficiency.

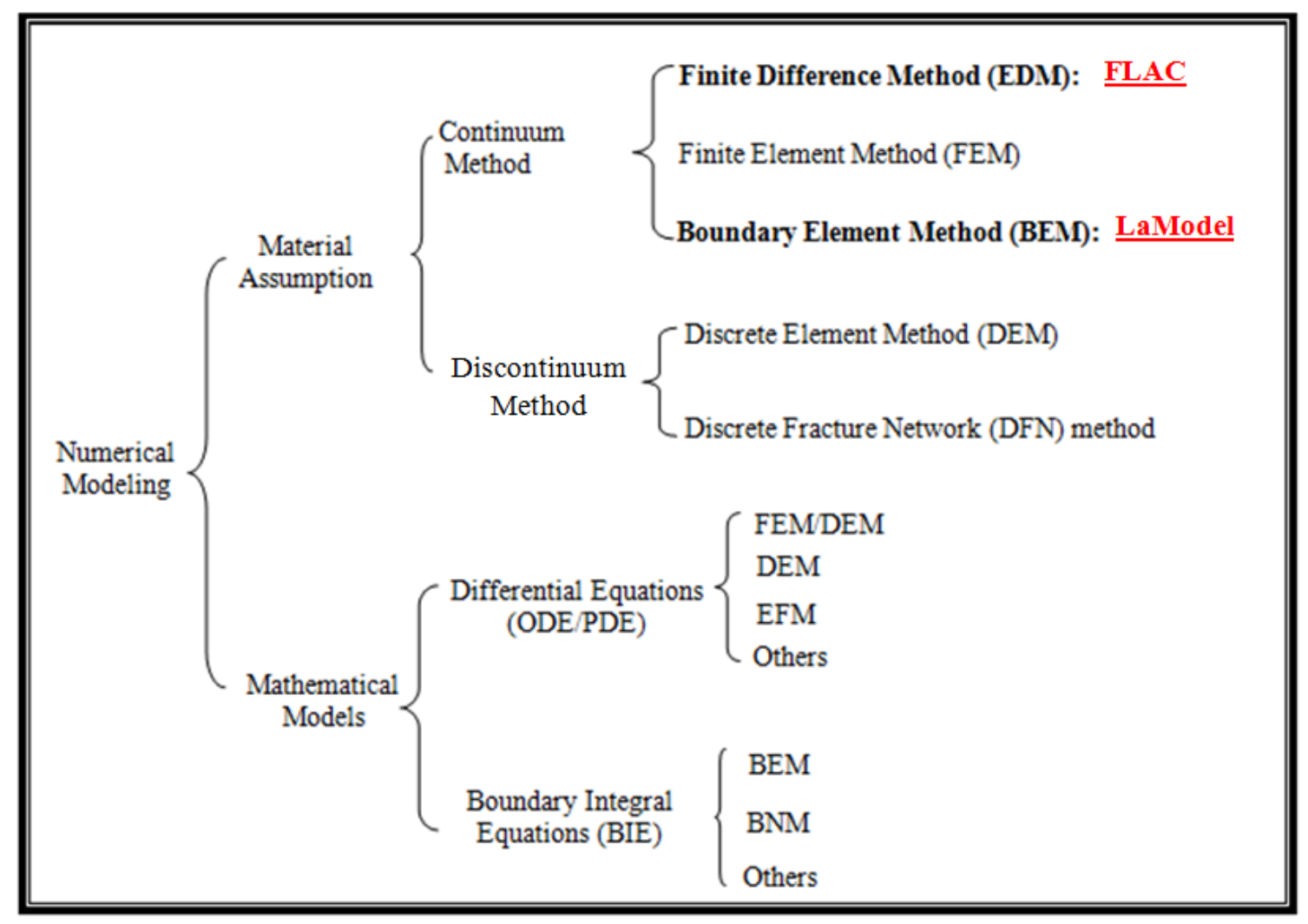

Figure 2-9 Numerical method for modeling

On the other hand, the boundary integral equations are classical tools for the analysis of boundary value problems for PDEs (Mukherjee, 2013). By using the BEM, the approximation of the boundary value problem is an exact solution of the differential equation in the domain and is parametrized by a finite set of parameters living on the 
boundary (Jing, 2003). So it enjoys greater accuracy over the EDM and FEM at the same level of discretization. It is also well suited for stress concentration and infinite domain problem, for only the boundary of the domain needs to be discretized. Compared to $\mathrm{FEM} / \mathrm{FDM}$, the BEM modeling is more efficient due to the reduction of dimensions.

The DEM is used to deal with large displacements caused by rigid body motion of individual blocks, including block rotation, fracture opening, and complete detachments; this is impossible with FDM, FEM or BEM (Jing, 2003). The DFN method is often used to simulate fluid flow in fractured rocks and is widely used in ground water flow in civil engineering reservoir simulation in coalbed methane and petroleum engineering (Jing, 2003; Dershowitz, 1995; Cacas, 1990).

\subsubsection{Development of displacement-discontinuity LaModel code}

As for the extraction of large tabular deposits including coal, potash, and other thin veintype deposits, the displacement-discontinuity (DD) method of the boundary element is a better choice due to its shorter data preparation time in calculation, high resolution of stress, and easy applicability to incompressible materials (A.A. Becker, 1992). Based on the homogeneous, elastic overburden model in the DD method of the boundary element, the MULSIM was initially created by Sinha (Sinha, 1979), and then the U.S. Bureau of Mines developed and optimized this program (Beckett and Madrid, 1988). After years of application, Dr. Heasley, in his doctoral thesis, pointed out several limitations of this program due to its inborn limitation (Heasley, 1998):

- It cannot accurately describe states of the gob area as observed in practice;

- The stress abutments obtained at the edge of these areas are much more extensive than field measurements or empirically tested formulas;

- The magnitude of the stress and displacement interaction in multi-seam is universally less than field test value.

Because of the successful applications of the frictionless laminated model of the overburden in predicting surface subsidence, the same model was implemented in a fullfeatured DD program in order to overcome above program and accurately calculate the stress and displacements at the seam (along with surface subsidence) (Heasley,1998 \& 
2008). The initial LaModel was written in DOS-based C in 1994 (Heasley, 2014). In 1999, the LaModel was implemented in Visual C++. In 2000, the coal and gob wizard was added to LaModel and the $400 \times 400$ grid was created at the same time. In 2001, the automatic mine grid generation and topographic grid generation was added. In 2002, the history and fishnet plots were added and units also being carried by the calculation. In 2003, the LaModel 2D was developed to analyze multi-seam interaction more easily. In 2004, the grid generation was coded directly into AutoCAD and the $1000 \times 1000$ grid was created. Further, the pillar safety factor calculation and intro-seam subsidence was added. In 2006, the stability mapping program was created, incorporating LaModel with geology and structural features into a comprehensive stability mapping system. In 2007, LaModel 2D was coded into the AMSS program and LaModel 2D was used to add a multiple seam capability to ALPS and ARMPS (Akinkugbe, 2004). In 2013, the LaModel program for the shallow cover multiple-seam mines was calibrated (Sears, 2013). In 2014, a computer code (ARMPS-LAM) was developed to effectively integrate the LaModel and ARMPS programs (Zhang, 2014), which allows an ARMPS-type LaModel analysis to be developed and run in just a few minutes. Now LaModel 3.0 is being developed, and new wizards are being developed and these will be improved in the coming years, with the goal of making the program function more effectively.

\subsubsection{Introduction of finite-difference FLAC program}

FLAC Version 7.0 (Fast Lagrangian Analysis of Continua) is a two-dimensional explicit finite-difference program for modeling geotechnical problems in the fields of mining, underground engineering, and rock mechanics (Itasca, 2011). In FLAC, the user can fit the shape of the object by grid, which is formed by elements or zones. These elements or zones also represent the materials of the object. These elements behave according to defined stress-strain laws in response to applied boundary conditions. FLAC also contains the powerful built-in programming language FISH, which can be used to extend FLAC's usefulness, implement your own constitutive models, and tailor analyses for specific needs. In addition, FLAC can also be operated in two modes: menu-driven and command-driven. All these features make FLAC an indispensable analysis-and-design tool in a variety of fields in civil, mining, and mechanical engineering. 
The general solution procedure represents the sequence of processes in FLAC (Figure 210). In FLAC, the explicit time-marching method is used to solve the algebraic equations and the solution is reached after a series of computational steps. Thus the number of steps required to reach a solution can be controlled automatically by code or manually by the user. The user ultimately must determine whether the number of steps is sufficient to reach the solved state.

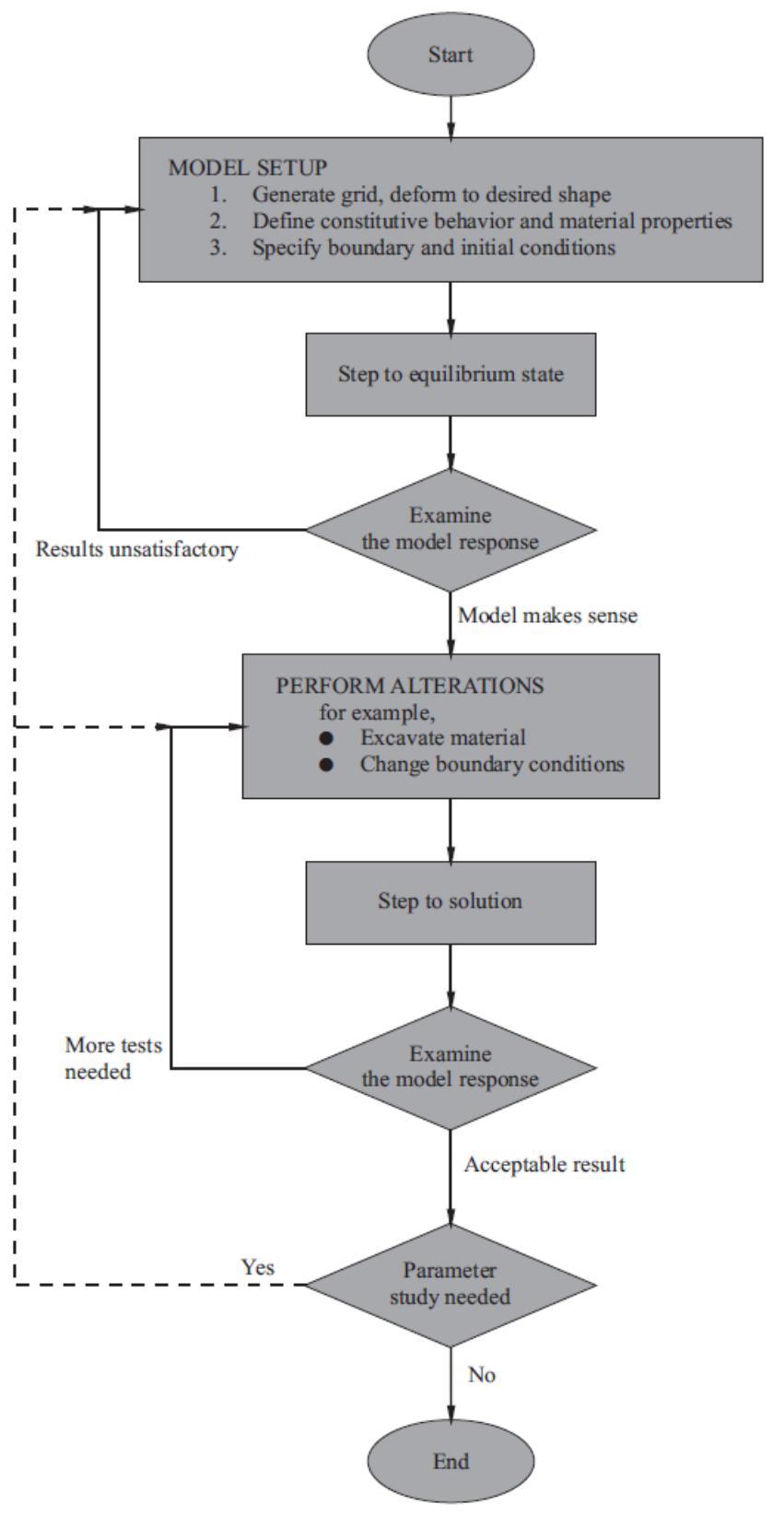

Figure 2-10 General solution procedure of FLAC (Itasca, 2011) 


\section{Chapter 3 Stability analysis of bleeder pillars by LaModel}

\subsection{Effects of overburden thickness and adjacent longwall faces}

This chapter aims to investigate the development of vertical stress and safety factor (SF) in bleeder pillars by LaModel during the retreat mining process. A hypothetical longwall panel was developed in LaModel followed by the retreat mining process. Two types of modeling were conducted. The first one is to investigate how the vertical stress and safety factor (SF) in bleeder pillars retreat during retreat mining process in a single panel. The effect of varying topography has also been taken into consideration. The second is to investigate whether the vertical stress and SF in bleeder pillars will be affected by the adjacent active longwall face during second mining.

\subsubsection{The displacement-discontinuity program-LaModel}

Combining the analytical approach and the empirical field data, the LaModel program is perhaps the most realistic approach for stability analysis of pillars in underground coalmines, especially in the United States (Mark, 1999 \& 2001). This displacementdiscontinuity program simulates the geological overburden as a stack of frictionless interface layers (Figure 3-1). It takes the overburden as a stack of homogeneous isotropic layers with frictionless interfaces, and each layer has the identical elastic modulus, Poisson's ratio, and thickness. This assumption does not require specific input material parameters for each layer, but it could provide reasonable strata response for modeling with the empirical theory obtained from previous research (Heasley, 1996, 1998 \& 2012). For example, when the laminated thickness is $157 \mathrm{ft}$, the modeling results fit the empirical abutment stress very well, as shown in Figure 3-2. The empirical abutment stress distribution shows the extension and magnitude of abutment stress around the panel based on extensive field measurements of abutment load in underground mining practice (Mark, 1990). Details of the field studies can be found in Reference (Mark, 1990). This means that the fundamental behavior of the laminated model for the abutment stress distribution agrees with the empirical abutment stress, which will be provided by a variation lamination thickness of the model. 
The mine geometry is either created or input into a grid generator, which converts the map into number of cells or elements. The CAD files of the mine map can be directly implemented into the grid generator. Additionally, surface topography can also be easily accounted for in the numerical model. Material properties are then assigned to each element and regions in the pillar and mine areas. The model is then run in different stages, simulating retreat-mining states before and after mining. Additional steps can be added to simulate the complete recovery of the pillars. Numerical simulation of any rock structure is a difficult task that is further aggravated with rock mass input properties. To meet this challenge, LaModel was especially tailored to calibrate the results with a database of successful and unsuccessful mine case histories that were tabulated from various coal producing states in the U.S. (Heasley, 2012).

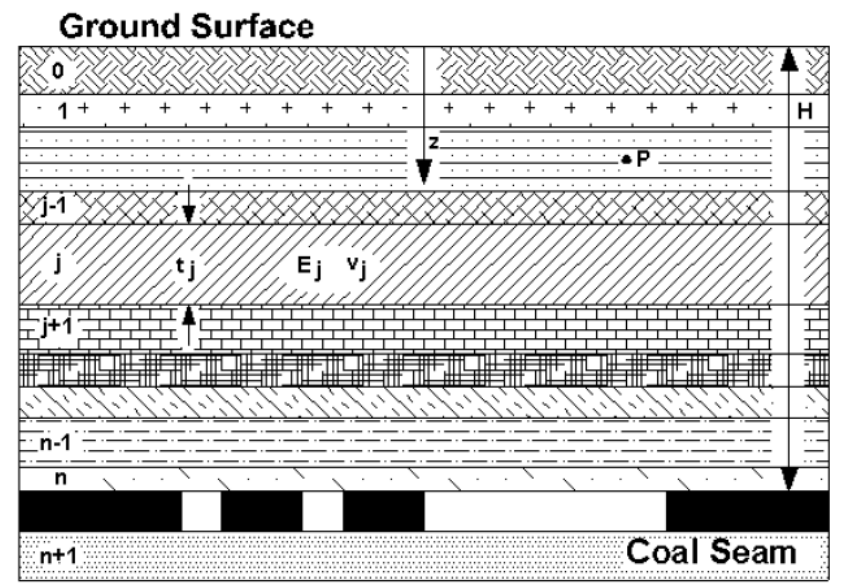

Figure 3-1 Schematic of laminated overburden (Heasley, 1998)

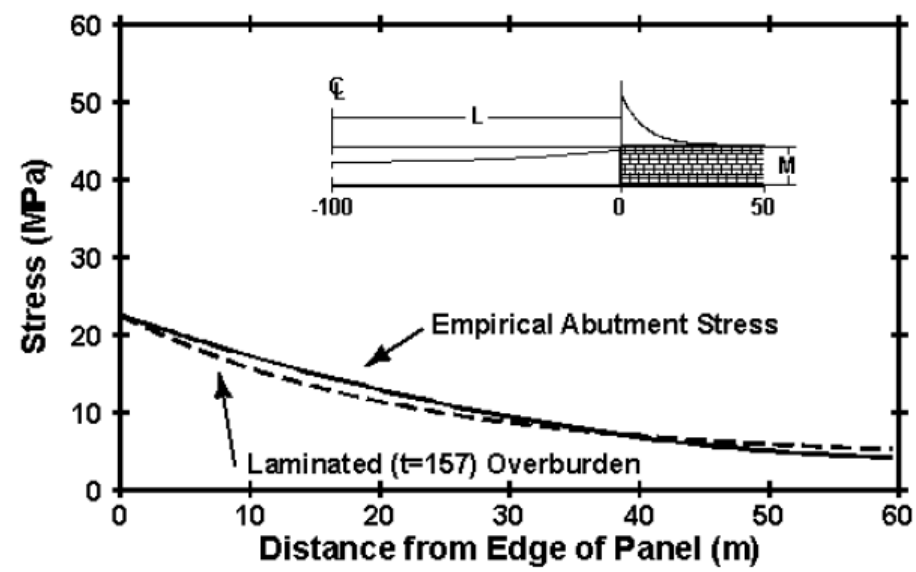

Figure 3-2 The laminated abutment stress fitted the empirical formula (Heasley, 1998) 
The SF (Safety Factor) for each element of the coal pillar is calculated as the ratio between the predefined peak stress and the applied vertical stress. Then the SF of the coal pillar is obtained by totaling and averaging each element for the entire area of the coal pillar (Hardy and Heasley, 2006).

$$
S F=\frac{\sigma_{p}}{\sigma_{a p p}}
$$

where $\mathrm{SF}$ is the stress safety factor for each element of pillar, $\sigma_{p}$ is the predefined peak stress, and $\sigma_{a p p}$ is the applied vertical stress. In LaModel, the predefined peak stress for coal is $900 \mathrm{psi}$, which is strongly recommended and has been tested as the valid coal strength value in U.S. coal fields (Mark, 1999). A safety factor of 1.4 is recommended as a design objective in LaModel, which means there would be only an $8.5 \%$ (4 out of 47) chance of misclassifying a potential pillar failure as a successful design when the SF is 1.4 (Heasley, 2012).

For numerical modeling in mining, reasonable parameters will provide accurate modeling results, which will be consistent with field measurement. The key input parameters of LaModel are rock mass stiffness, gob stiffness, and coal strength, which determine the accuracy of the LaModel analysis (Heasley, 2008).

Rock mass stiffness. The rock mass stiffness largely determines the abutment load distribution of the overburden. For a stiffer overburden, the extent of abutment pressure will increase and the convergence over the gob areas will decrease. Rock mass stiffness mainly depends on two parameters: rock mass modulus (E) and rock mass lamination thickness ( $t$ ); increasing one of the two parameters independently can increase rock mass stiffness. Both the two parameters have a major influence on the stress and displacement distribution at the seam and throughout the overburden. According to years of LaModel usage experience, the most practical and effective way to calibrate rock mass stiffness is to set the rock mass modulus first and then solely adjust the lamination thickness to obtain a reasonable abutment stress distribution. The rock mass modulus can be calculated (Heasley, 1998 \& 2008), 


$$
t=\frac{8.38 E_{s} \sqrt{12\left(1-v^{2}\right)}}{E h} \cdot(5 \sqrt{H}-d)^{2}
$$

where $\mathrm{t}$ is the lamination thickness in the rock mass, Es is the elastic modulus of the seam, $\mathrm{E}$ is the elastic modulus of the rock mass, $\mathrm{v}$ is the Poisson's ratio of the rock mass, $\mathrm{h}$ is the seam thickness, $\mathrm{H}$ is the seam depth, and $\mathrm{d}$ is the width of the yield zone.

Gob stiffness. In LaModel, the interaction between overburden stiffness and gob stiffness determines the distribution of the overburden load above the gob areas from the gob to the adjacent pillar. Through calibrating the overburden rock mass stiffness, a reasonable extent of abutment stress will be obtained. The gob modulus then becomes the main parameter used to determine the overburden load distribution above the gob. For a specific gob material, five parameters are needed to define the material: the initial modulus (100 psi), the final modulus (3002281psi), the ultimate vertical stress (4003psi), the gob height factor, and the gob Poisson's ratio (0.25). Gob height factor is the ratio of gob thickness to seam thickness, accounting for the difference in height between the gob and the coal seam; gob height factor is one in LaModel, as the gob and coal seam thickness are identical in mining practice. It is also preferable to modify the final modulus to adjust the functional stiffness of the gob material while keep all other four parameters as the above defaults (Heasley, 2008). Based on historical field experience, gob stiffness is calibrated in LaModel by adjusting the final modulus to match the empirical gob load derived from the abutment angle $\left(21^{\circ}\right)$ concept (Figure 7 ) in the two ALPS (Analysis of Longwall Pillar Stability) and ARMPS (Analysis of Retreat Mining Pillar Stability), two empirical-based software programs that are widely used in the U.S. (Mark, 1992 \& 1997). The abutment angle determines how much load is carried by the gob area, which is calibrated from the measurement of longwall abutment stress. These stress measurements indicated that an abutment angle of $21^{\circ}$ is appropriate for normal caving conditions in U.S. underground coal mines (Mark, 1997). It should be noted that the abutment angle should not be considered a physical reality, but an approximation defining the magnitude of the side abutment loading (Mark, 1987).

Coal strength. In-situ coal strength should be obtained for each specific coal field. However, it is difficult to obtain a representative in-situ coal strength value based on 
laboratory test of coal specimens. In LaModel, the default coal strength is $6.0 \mathrm{MPa}$ (900psi), which is strongly recommended and has been tested as the valid coal strength value in U.S. coal fields (Mark, 1999). Coal pillar strength is based on the MarkBieniawski pillar strength formula,

$$
s_{p}=s_{0}\left(0.64+0.54 w / h-0.18\left(w^{2} / l h\right)\right)
$$

where $s_{p}$ is pillar strength, $s_{0}$ is in-situ coal strength $\left(s_{0}=900 p s i\right), w$ is pillar width, $h$ is pillar height, and 1 is pillar length.

\subsubsection{Model Development}

As with any numerical simulation, the geometry of the object is created in the numerical model. For the LaModel program, mine geometry can be directly imported into the program from a map created in AutoCAD. Additionally, surface topography can be easily accounted for in the numerical model. In the present study, the mine geometry for a longwall panel was created using the grid editor, the tool in LaModel creating the mining model layout. Two mine layouts were prepared for the current study; one layout represents a single longwall panel (Figure 3-3(a)), and the other layout represents multiple panels (Figure 3-3(b)). In each of the layouts the named bleeder pillars represent pillars of interest; in mining scenario 1 (Figure 3-3 (a)), the selected pillars for the current study are $4 \mathrm{a}$ and $4 \mathrm{~b}$, and in mining scenario 2 (Figure 3-3 (b)), the selected pillars are 1a, $1 \mathrm{~b}, 1 \mathrm{c}, 1 \mathrm{~d}, 2 \mathrm{a}, 2 \mathrm{~b}, 2 \mathrm{c}$, and $2 \mathrm{~d}$. The overburden over these layouts is $500 \mathrm{ft}, 1,000 \mathrm{ft}, 1500$ $\mathrm{ft}$ and $2000 \mathrm{ft}$ for each mining scenario, respectively. A typical cross section for the $500 \mathrm{ft}$ overburden is provided in Figure 3-3 (c).

In addition to the above geometric conditions, the numerical model also includes the following details: The thickness of coal seam is 5 feet (Figure 3-3 (c)). The plan of the panel is $800 \times 640$ feet. The barrier pillar is $640 \times 100$ feet. The tailgate and headgate have three entries, each 20 feet wide, and includes $60 \times 40$ feet pillars. The bleeders are a threeentry system, and each entry is 20 feet wide, including $60 \times 40$ feet pillars. In mining scenario 2 , there are three neighboring panels, which include two mined panels and one panel in the development stage. The geometry of bleeder pillar, bleeder entry, panel width, and length for each panel is the same in mining scenario 1 . The general input 
parameters are the default and recommended values of LaModel program. The simulations are performed in ten steps in LaModel and in each step the longwall face is advanced by the following distances: 50, 50, 50, 100, 100, 100, 100, and 200 feet, respectively. The step here means the mining sequence of the longwall panel; the first step means the longwall faces start moving from the setup room, where the retreat mining of longwall panel starts.
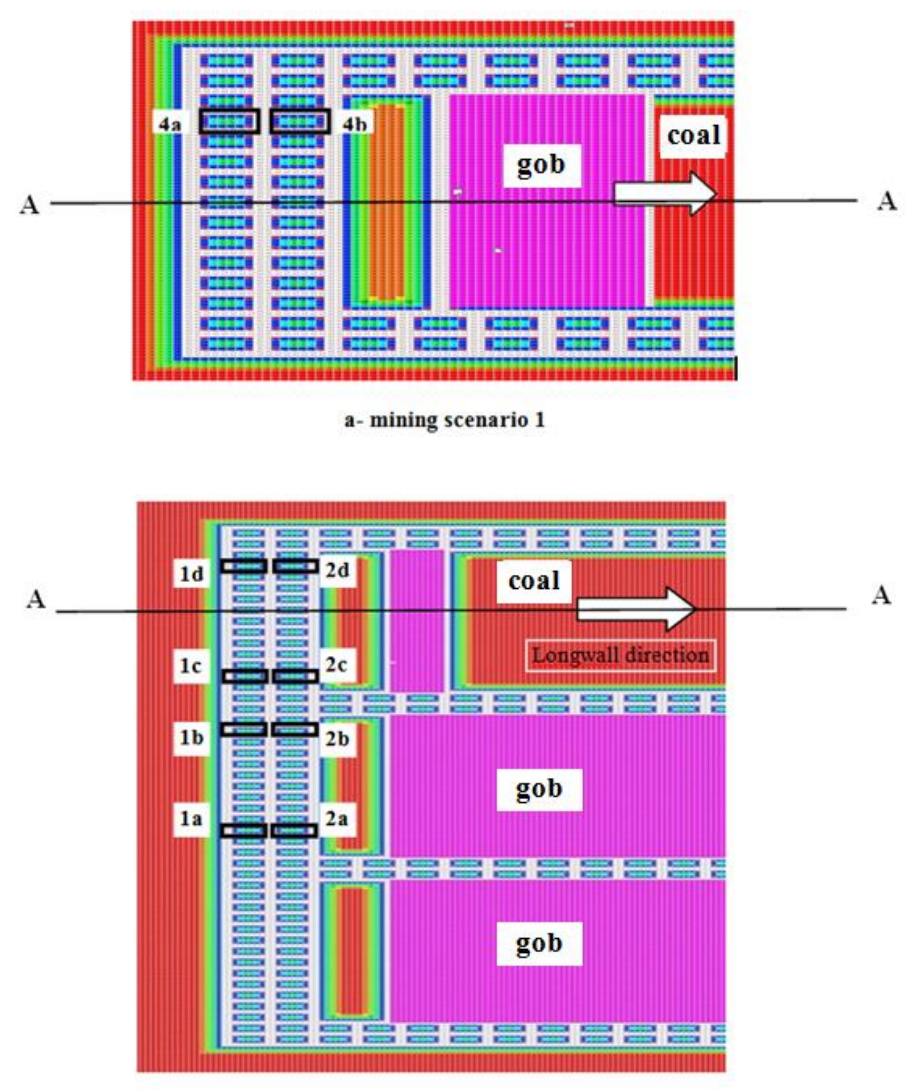

b- mining scenario 2

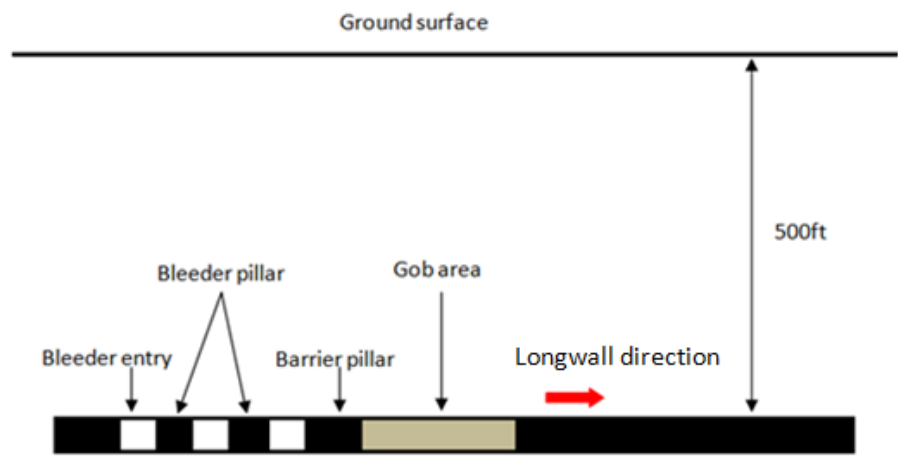

c-cross-section of A-A in mining scenario 1 and 2

Figure 3-3 Two modeling layouts by LaModel 
Table 3-1 Input material properties in the LaModel program

\begin{tabular}{|c|c|c|}
\hline \multirow{4}{*}{$\begin{array}{c}\text { Grid generation } \\
\text { parameters }\end{array}$} & Element width (ft) & 10 \\
\cline { 2 - 3 } & Seam boundary & Symmetric \\
\cline { 2 - 3 } & Seam thickness (ft) & 5 \\
\cline { 2 - 3 } & Mining steps & 10 \\
\cline { 2 - 3 } & Elastic modulus (psi) & $3,000,000$ \\
\cline { 2 - 3 } $\begin{array}{c}\text { Rock mass stiffness } \\
\text { parameter }\end{array}$ & Poisson's ratio & 0.25 \\
\cline { 2 - 3 } & Coal modulus (psi) & $3,000,000$ \\
\cline { 2 - 3 } & Width of gob (ft) & 800 \\
\cline { 2 - 3 } & Initial gob modulus (psi) & 100 \\
\cline { 2 - 3 } & Gob height factor & 1 \\
\cline { 2 - 3 } & Upper limit stress for gob (psi) & 9,000 \\
\hline In-situ coal strength & Coal strength & 900 \\
\hline
\end{tabular}

Table 3-2 Input values for rock mass properties produced by LaModel Wizards Results

\begin{tabular}{|c|c|c|}
\hline \multicolumn{3}{|c|}{ Input parameters for mining scenario 1 and 2 } \\
\hline Overburden cover (ft) & Lamination thickness (ft) & Final modulus for gob (psi) \\
\hline 500 & 261 & $2,777,942$ \\
\hline 1000 & 536.3 & 841,891 \\
\hline 1500 & 759.6 & 508,131 \\
\hline 2000 & 983.2 & 391,072 \\
\hline
\end{tabular}

Simulation results are presented in the following sections. The analysis investigates the stability of the bleeder pillars during a longwall retreat operation that includes single and multiple panels. Additionally, the effect of stress development on bleeder pillar stability caused by the moving longwall face was also analyzed.

\subsubsection{Stress development and safety factors for bleeder pillars in mining scenario 1}

The creation of an excavation disturbs the original state of stress equilibrium in the earth material. Due to this change, stresses are concentrated around the entry and induce 
deformation in the rock. In underground coal mines, coal pillars are left behind as natural support, and additional supports are provided in the entry to prevent a roof fall. It is imperative that pillars are designed to withstand the weight of the overburden as well as the stress regime imposed due to the opening of the entry. The development of vertical stress in bleeder pillars under 500 feet depth of cover is discussed. The vertical stresses on bleeder pillar $4 \mathrm{a}$ and $4 \mathrm{~b}$ after each mining step are presented in Figure 3-5. The vertical stresses in bleeder pillars $4 \mathrm{a}$ and $4 \mathrm{~b}$ are over 950 psi, which is much higher than the in-situ stress (566 psi). The vertical stress in both pillars increases when the longwall face advances by 300 feet from the setup room, and then stress remains constant for the rest of the longwall advancement. The vertical stress in bleeder pillar $4 \mathrm{~b}$ is higher than pillar 4a at each mining step (Figure 3-5). Additionally, it is seen that as the longwall face moves forward, the SF of bleeder pillar also changes. From Figure 3-5, the SF is above 3.4, which means the bleeder pillar will have greater than a $91.5 \%$ (when the SF is 1.4 ) chance of being stable during mining process, which satisfies the requirements of underground coal mining application. The SF of bleeder pillars decreases as the longwall face moves forward, and then remains constant during the retreat mining process.

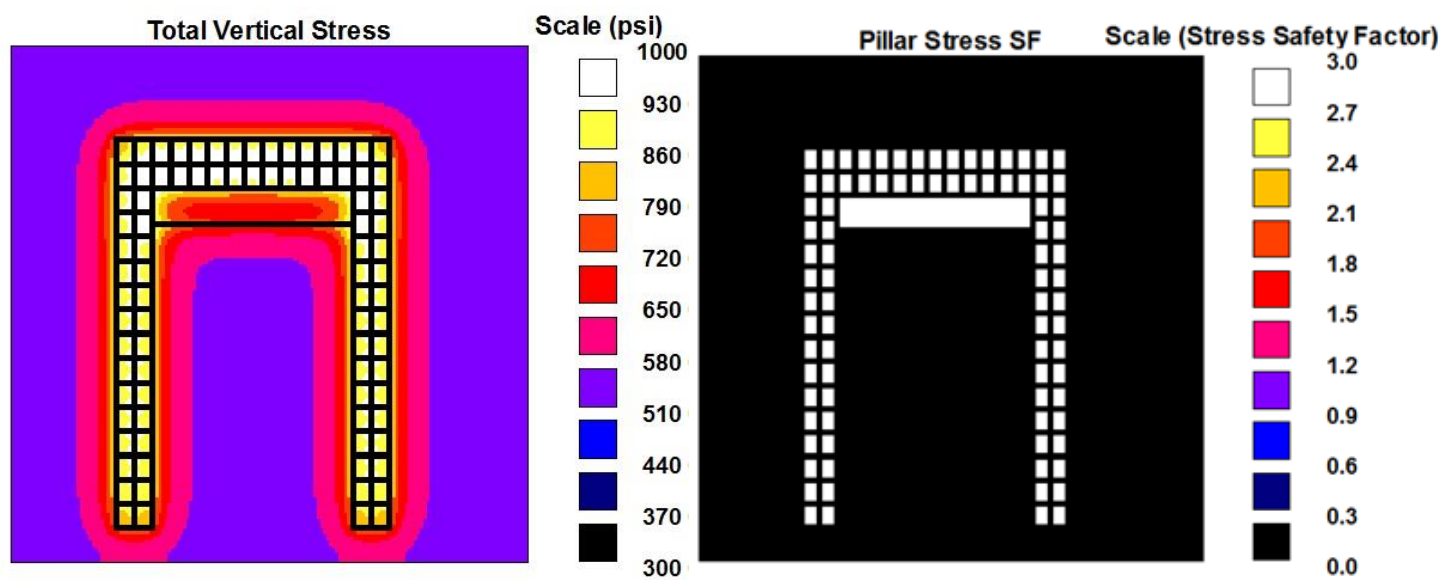

(a) The $1^{\text {st }}$ mining step 


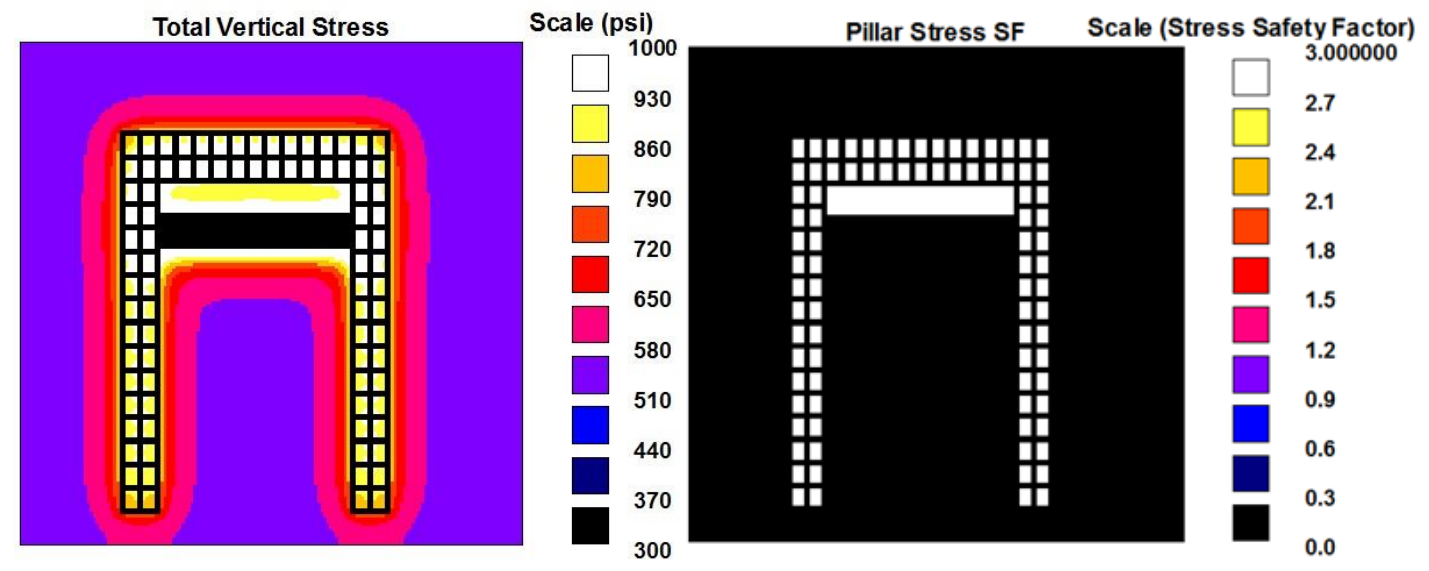

(b) The $3^{\text {rd }}$ mining step

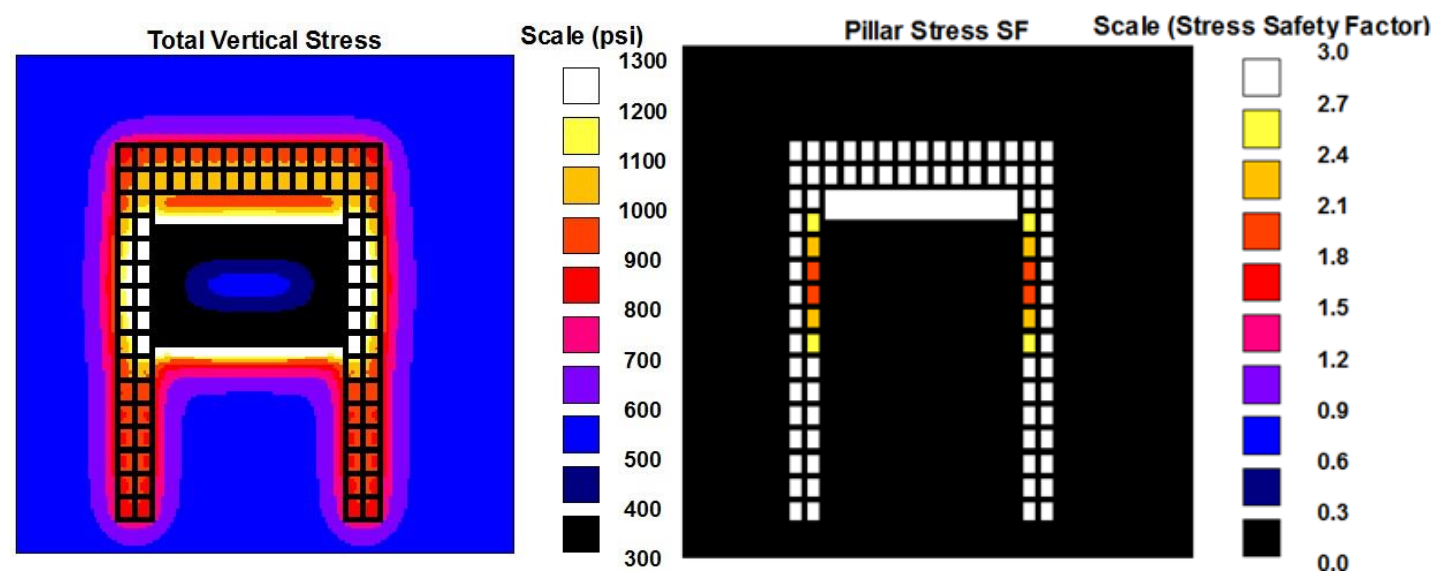

(c) The $7^{\text {th }}$ mining step

Figure 3-4 The vertical stress $(1,3,7$ steps) and pillar stress $\mathrm{SF}(1,3,7$ steps $)$ in bleeder pillars under 500ft overburden during retreat mining process

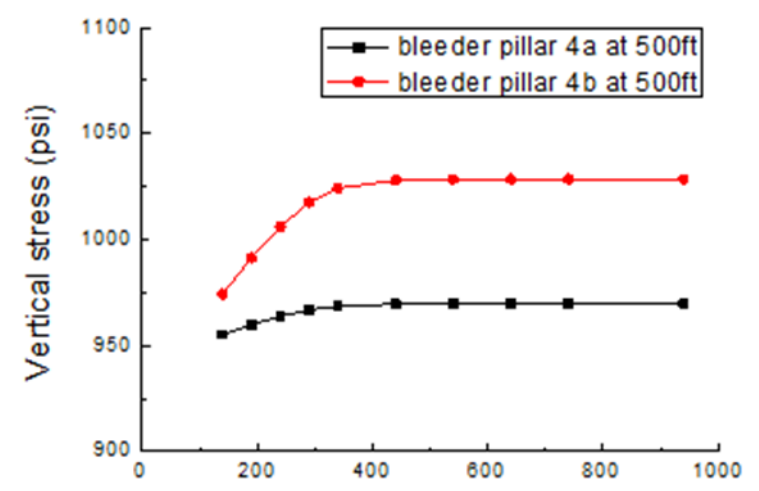

Distance from bleeder pillar to longwall face moves after each mining step (ft) 


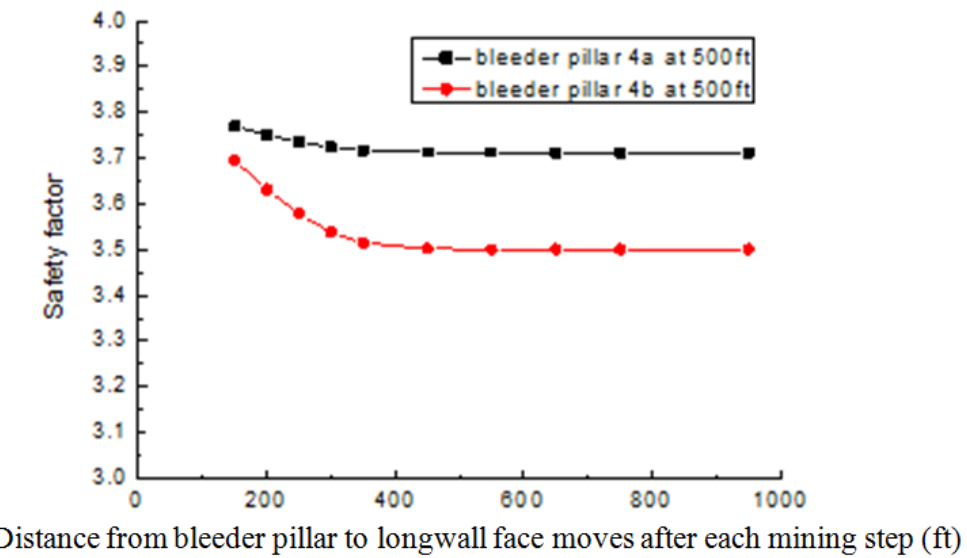

Figure 3-5 Development of the vertical stress and SF with advancing longwall face

\subsubsection{Stress development and safety factors for bleeder pillars in mining scenario 2}

In the second mining scenario, multiple mining panels are analyzed, and it is found that the bleeder pillars are still stable when stresses are overlapping due to the multiple panels. Figure 3-6 shows the total vertical stress acting on the bleeder pillars in multiple panels at 1 st, $3^{\text {rd }}$, and 7 th steps under 500 feet depth of cover. The vertical stress development and SF on the bleeder pillars 1a, 1b, 1c, 1d, 2a, 2b, 2c, and 2d at each mining step are presented in Figure 3-7; the SF in bleeder pillar 1c, ld, 2c, and 2d remain constant while $\mathrm{SF}$ in pillar $1 \mathrm{a}, 1 \mathrm{~b}, 2 \mathrm{a}$, and $2 \mathrm{~d}$ are similar to the results with single panel in mining scenario 1.

The vertical stress in pillar $1 \mathrm{c}$ and $1 \mathrm{~d}$, and $2 \mathrm{c}$ and $2 \mathrm{~d}$ shows the same pattern as discussed in mining scenario 1. Further, vertical stress in the bleeder pillars behind the mined-out panel (1a, 1b, 2a, and 2b) are higher than that in bleeder pillars at the same location behind the active mining panel $(1 \mathrm{c}, 1 \mathrm{~d}, 2 \mathrm{c}$, and $2 \mathrm{~d})$ during the initial retreat mining process. After the compacted gob area was formed in panel 3, vertical stress in pillars 2a and $2 \mathrm{c}, 2 \mathrm{~b}$ and $2 \mathrm{~d}, 1 \mathrm{a}$ and $1 \mathrm{c}$, and $1 \mathrm{~d}$ and $1 \mathrm{c}$ are in same state. These results indicate that the longwall face rarely influences the adjacent panel in bleeders. 

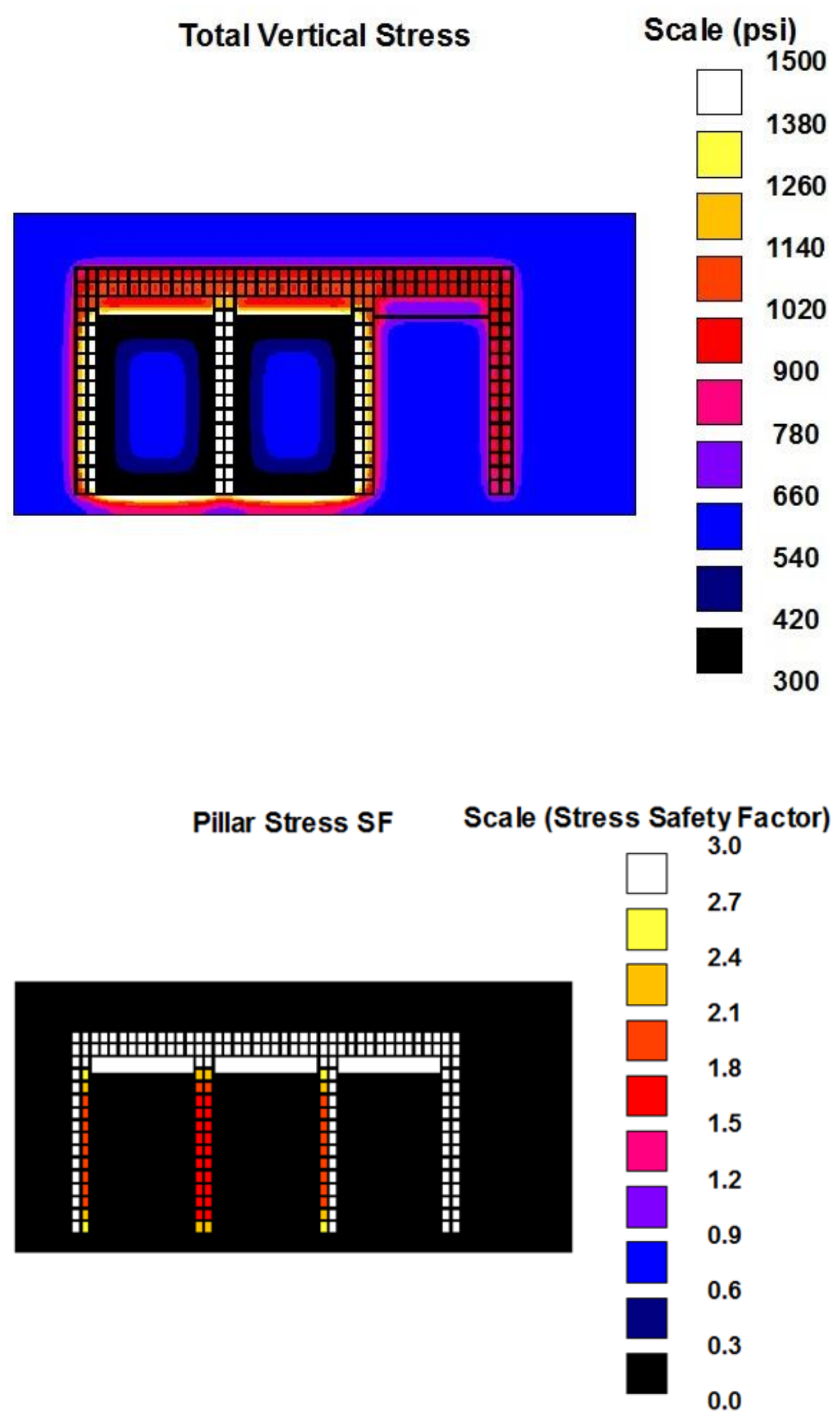

(a) The $1^{\text {st }}$ mining step 

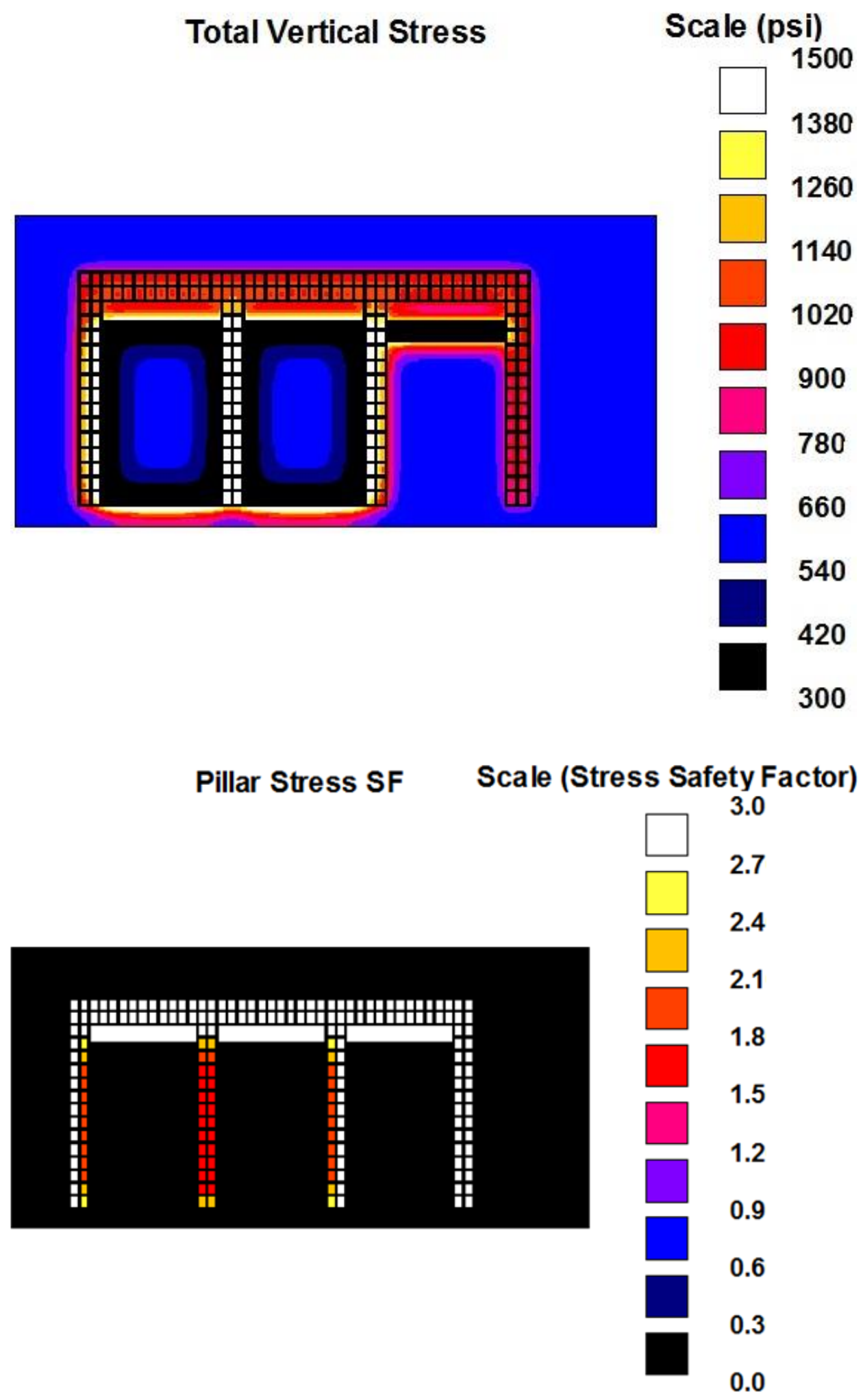

(b) The $3^{\text {rd }}$ mining step 

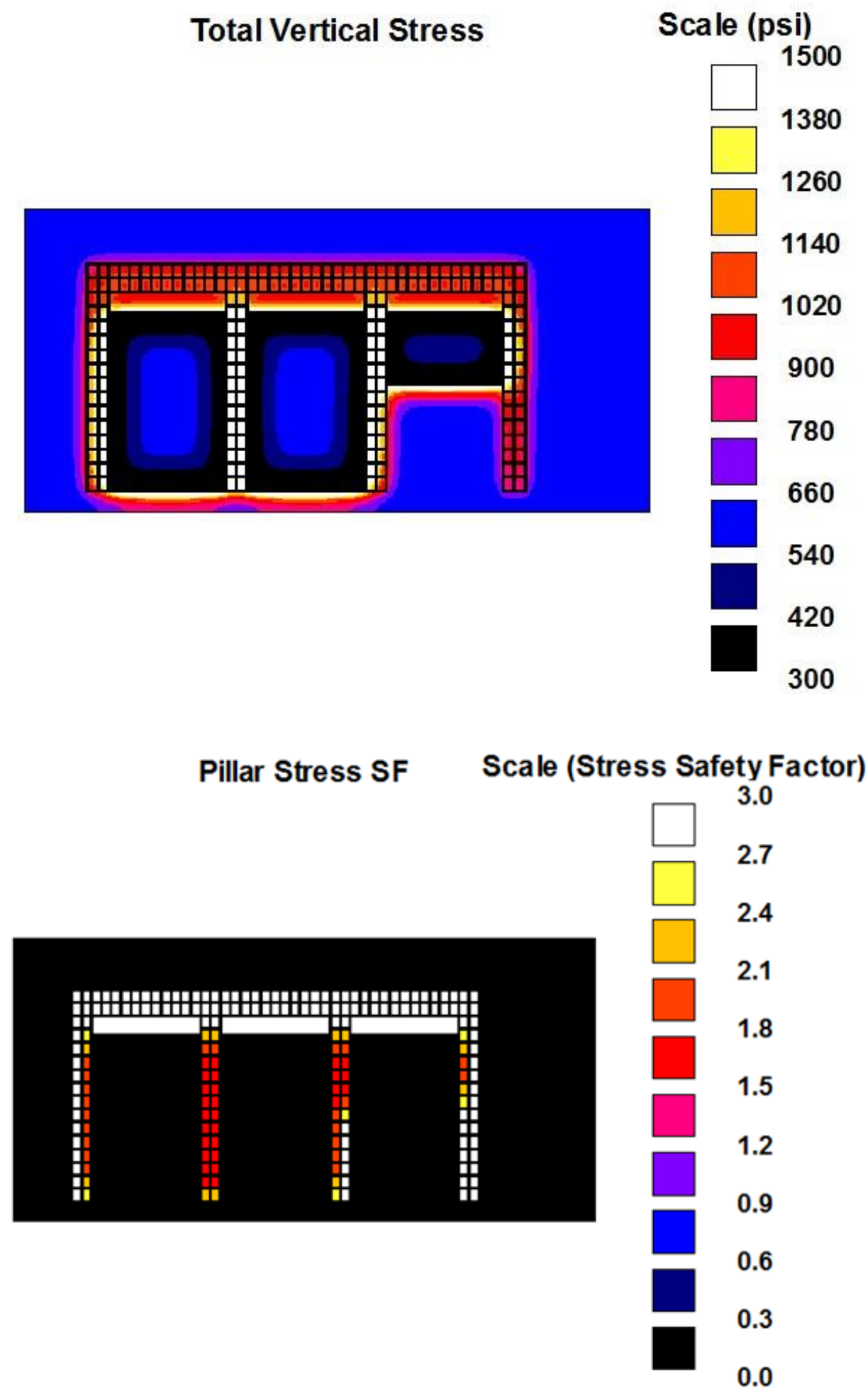

(c) The $7^{\text {th }}$ mining step

Figure 3-6 The vertical stress $(1,3,7$ steps) and pillar stress $S F(1,3,7$ steps) on bleeder area for multiple panels under $152.5 \mathrm{~m}$ overburden during retreat mining process 


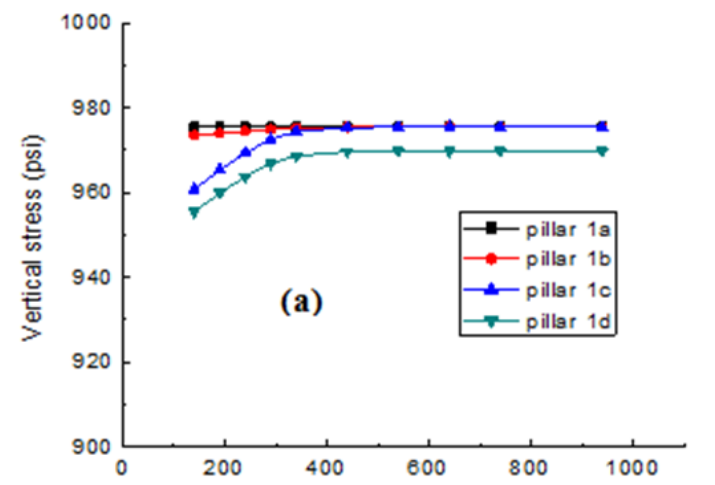

Distance the longwall face moves after each mining step (ft)

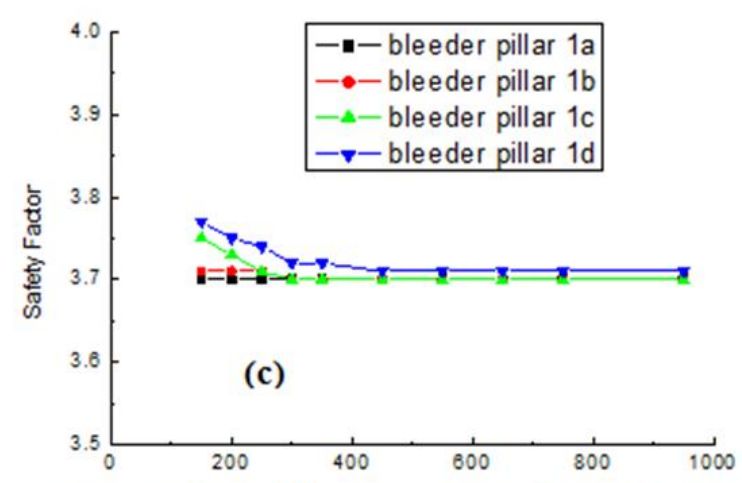

Distance the longwall face moves after each mining step (ft)
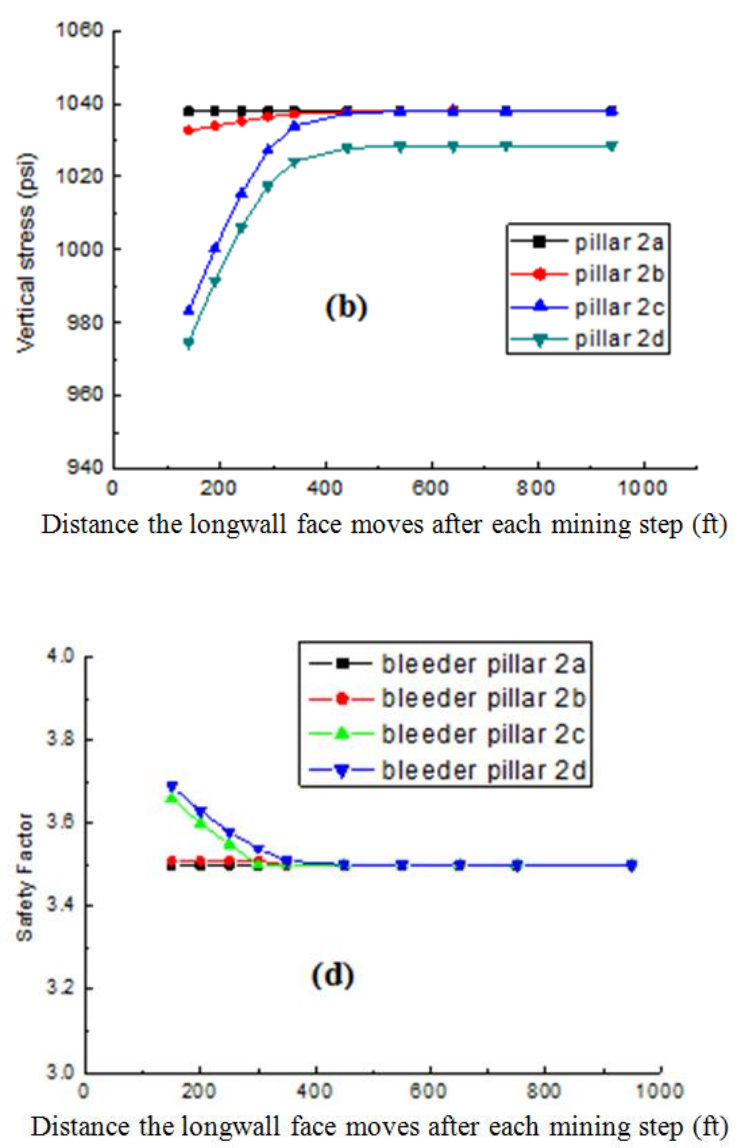

Figure 3-7 Vertical stress and SF plots in bleeder pillars of multiple panels with advancing longwall face

\subsubsection{Discussion}

Numerical analysis of the pillars in bleeders due to longwall movement has yielded some interesting results. To help understand the loading process on the bleeder pillar, see Figure 3-8, which shows the caving of the strata from the seam to the surface. The maximum stress applied on bleeder pillars is due to abutment loading. Loading is applied to the pillars when the longwall face advances in the first periodic weighting stage. In this stage, the entire stratum behaves as a beam that, due to its weight, moves toward the empty space. In this process, pillars adjacent to the setup room experience the most stress, followed by the bleeder pillars. 


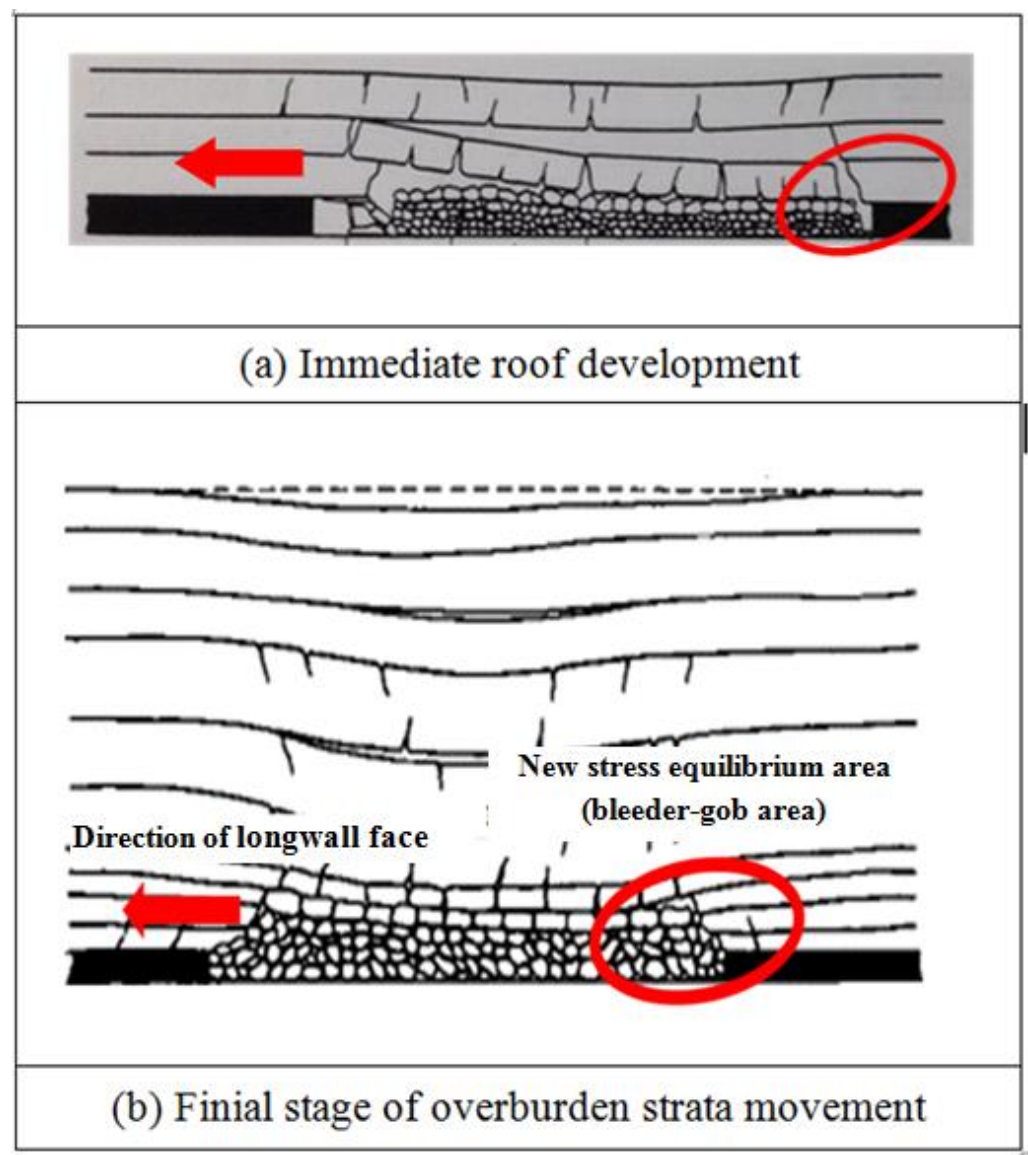

Figure 3-8 Abutment loading development process during retreat mining (modified after

Peng, 2008)

Once the longwall advances beyond the first periodic weighting stage, the stratum fails under its own weight and fills up the empty space. The first weighting phase refers to the distance from the setup room entry to the final stage of an interval with a large-area caving of the immediate roof, until the complete breakage of the upper strata in the main roof (Peng, 1984). After the first phase, periodic weighting will follow with cyclical breakage of the immediate roof or the main roof, or both; periodic weighting distance is the distance between two consecutive roof weightings. The immediate roof (Figure 3-8(a)) will fall on the mine floor and be broken into irregular but platy shapes of various sizes, also called caving zone. At this time, the gob area is composed of caved-in and loose rock fragments; these will continue to be consolidated under the load of the stratum. During this sequence of gob compaction, excessive stress produced due to beam effect will be transferred onto the gob. Once the gob is completely compacted, it is able to take the load 
of the overburden. The gob pressure decreases from the compacted center of the gob area to the gob boundary once the center of gob area is compacted enough to provide support for the overburden weight (Figure 3-9). This also means the bleeder loading will be supported by the compacted gob area and the bleeder pillars simultaneously, once the compacted gob is formed. Therefore, it is seen that once the face advances a certain distance, the stresses in bleeder pillars remain constant and do not change.

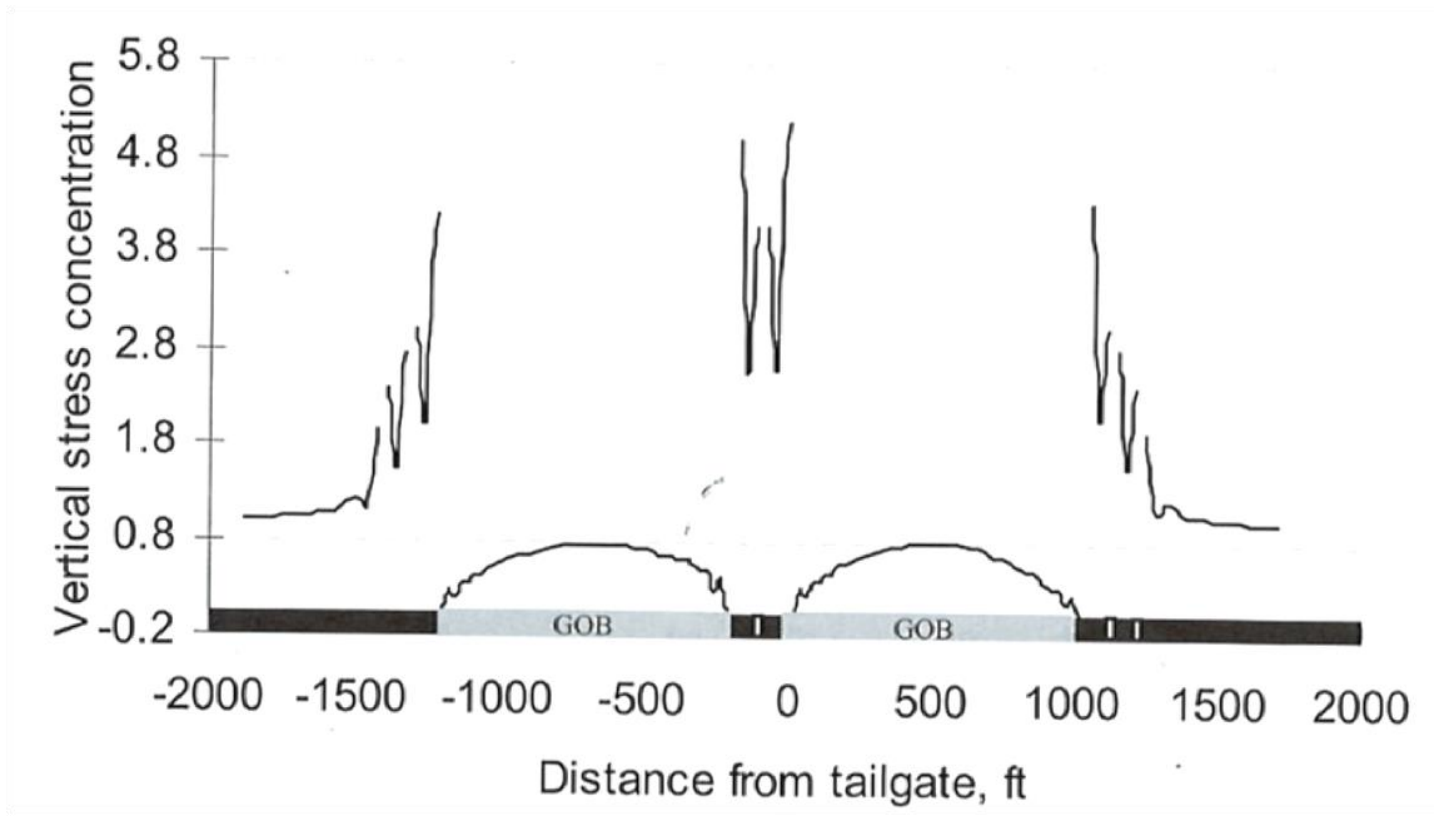

Figure 3-9 Vertical stress concentration in gob area (Peng 2007)

The vertical stresses in bleeder pillars $4 \mathrm{a}$ and $4 \mathrm{~b}$ under different overburden covers (500 $\mathrm{ft}, 1000 \mathrm{ft}, 1500 \mathrm{ft}$, and $2000 \mathrm{ft}$ ) after each mining step are presented in Figures 3-10. The increase in vertical stress on bleeder pillars under deep cover is greater than that under shallow cover, primarily due to overburden stress. Although the change in overburden contributes to the development of vertical stress in bleeder pillars $4 \mathrm{a}$ and $4 \mathrm{~b}$, the pattern of increase in stress is similar to the patterns described earlier for shallow cover (500 ft).

Coal mines have reached new depths, and it is imperative that the pillar design methods be reevaluated. This study focuses on bleeder pillar stability under various depths of cover and multiple panels in the same seam. Bleeder pillars usually serve for the entire life of a coal mine and therefore, the effect of long-term stability of the pillars also needs to be assessed. 


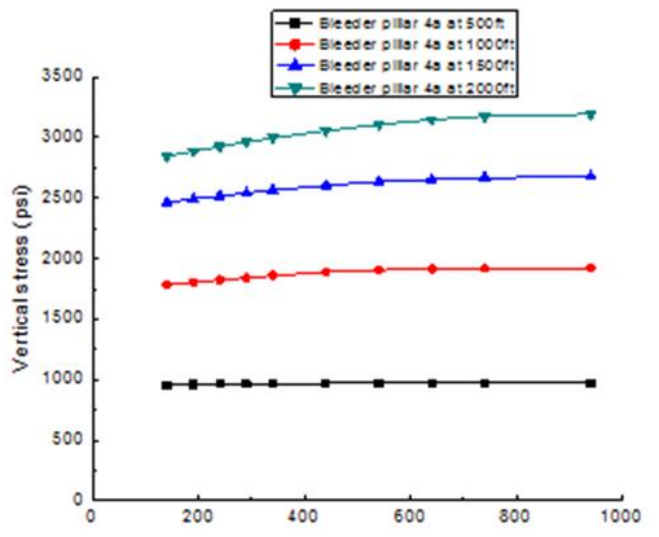

Distance the longwall face moves after each mining step (ft)

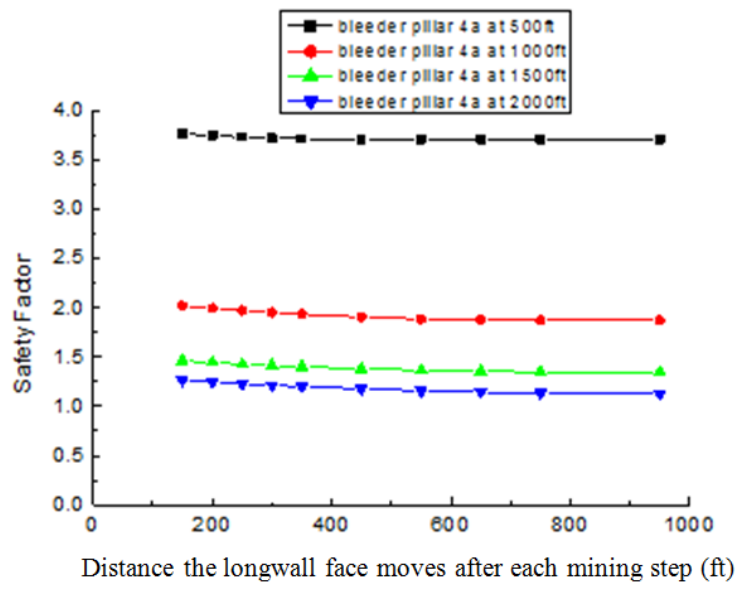

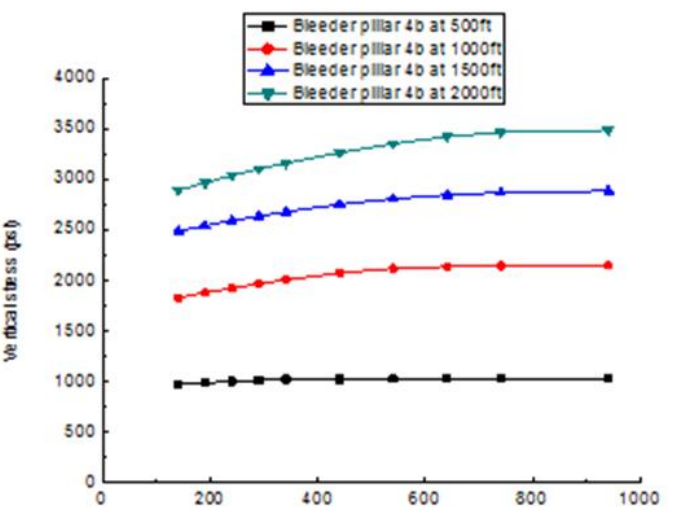

Distance the longwall face moves after each mining step (ft)

Figure 3-10 Vertical stress and SF plots in bleeder pillars under different overburden with advancing longwall face

\subsubsection{Conclusion}

Two models were developed for the purpose of examining vertical stress development in bleeder pillars as well as analyzing their safety factors during retreat longwall mining. For this purpose, the displacement-discontinuity LaModel program was used to simulate mining conditions.

In the first model, a single panel under different overburden covers was studied. The simulations show that vertical stress acting on bleeder pillars increases with the advance of the longwall face and then attains a constant stress state. The three stages of abutment development in the bleeders were shown to explain the development of vertical stress in bleeder pillars. The reason for the vertical stress behavior is due to the stress regime in 
the panel being affected by the creation of an empty space to the compacted gob, resulting in the vertical stresses increasing and then attaining a constant state. The safety factors for this mining scenario show that the pillars will be stable under different depths of cover.

In the second model, three panels were considered; panel 1 and 2 represented mined panels and panel 3 was an active panel. From the simulations, it was found that the bleeder pillars behind the mined-out panels are subjected to higher vertical stress than the pillars in the active mining panel. However, it was also found that the advancing longwall face did not influence vertical stress development in bleeder pillars of the adjacent panel. Additionally, through safety factor, it was found that the bleeder pillars will remain stable for the current geometry and mining conditions. 


\subsection{The size effect of bleeder pillars}

This section aims to investigate the size effect on bleeder pillars during the retreat mining process in a single coal seam. Two types of models were developed for this section. The first model is aimed at investigating the arrangement effect of pillars in bleeders. For rectangular pillars, if the length of the pillar is parallel (or perpendicular) to the longwall face, we say that the pillar is parallel (or perpendicular) to the longwall face. The arrangement effect refers to the stress (SF) variation in pillars resulting from different arrangements of rectangular pillars (Figure 3-11). The second model is aimed at investigating the development of vertical stress and SF in bleeder pillars when the same bleeder loading is supported by difference sizes of bleeder pillars (Figure 3-12). In this scenario, the same bleeder loading means the area of bleeder and its overburden is the same.

\subsubsection{Model Development}

The arrangement effect of bleeder pillar on the development of vertical stress and SF in bleeder pillars will be discussed relative to varying pillar sizes and pillar arrangements during retreat mining period in the single coal seam under $500 \mathrm{ft}$ cover. The two mining scenarios are created as follows: For mining scenario 1, the bleeder areas are supported by $60 \times 40 \mathrm{ft}$ and $90 \times 60 \mathrm{ft}$ bleeder pillars in different arrangements, respectively. For mining scenario 2, the same bleeder loading is supported by different sizes of bleeder pillars, $100 \times 60 \mathrm{ft}, 60 \times 60 \mathrm{ft}, 60 \times 40 \mathrm{ft}$, and $60 \times 30 \mathrm{ft}$.
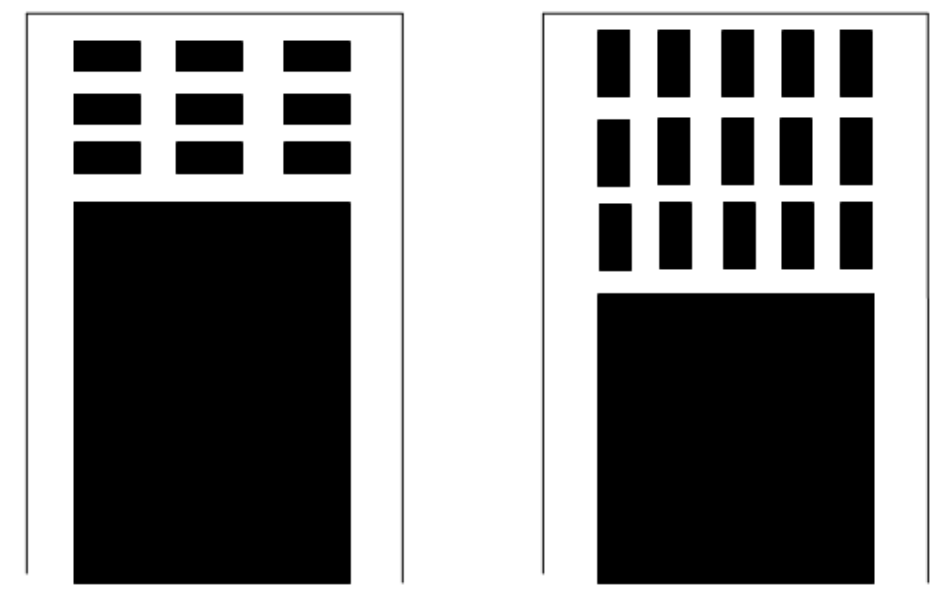

Figure 3-11 Layouts of bleeder pillars in mining scenario 1 


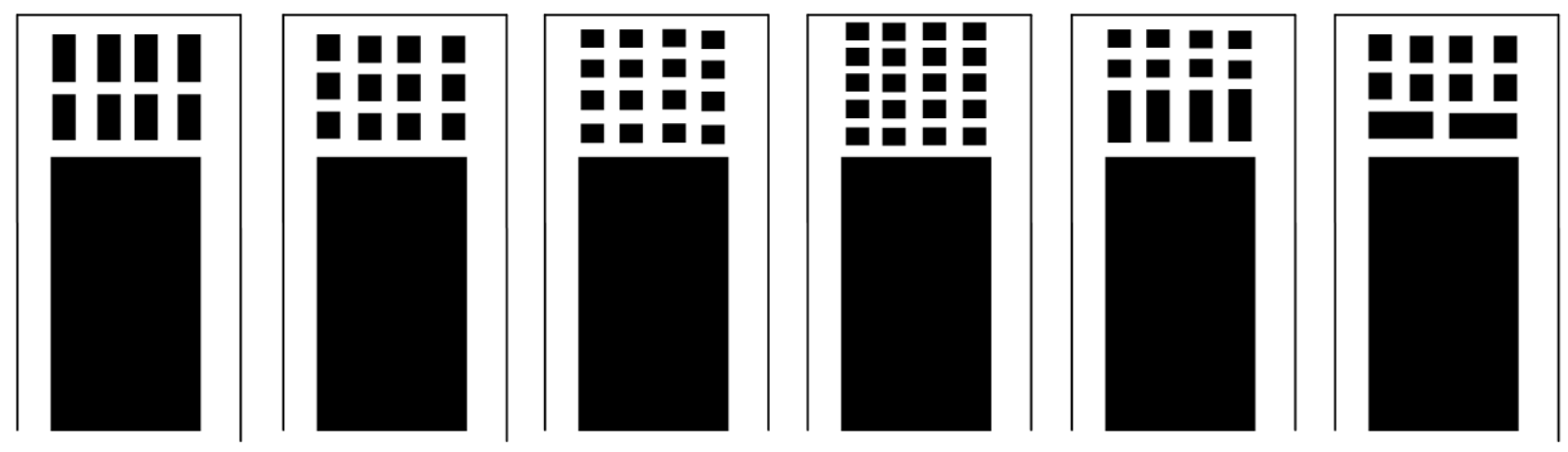

Figure 3-12 Layouts of bleeder pillars in mining scenario 2

The overburden cover is $500 \mathrm{ft}$, and the thickness of the coal seam is $5 \mathrm{ft}$. The panel is $800 \times 780 \mathrm{ft}$, and no barrier pillars are left for bleeder pillars. The tailgate and headgate have three entries, each $20 \mathrm{ft}$ wide with $60 \times 40 \mathrm{ft}$ pillars. The bleeder has entries, each 20 $\mathrm{ft}$ wide with different sizes of bleeder pillars. For mining scenario 1, the same size of bleeder pillars $(60 \times 40 \mathrm{ft}$ or $90 \times 60 \mathrm{ft})$ are used to support the bleeder area, but the arrangement of pillars is different; the longer cross-section is parallel or vertical to the longwall face. Compared with scenario 1, mining scenario 2 only has two differences: the pillar size and the arrangement of bleeder pillars.

Table 3-3 Input material properties in the LaModel program

\begin{tabular}{|c|c|c|}
\hline \multirow{4}{*}{$\begin{array}{c}\text { Grid generation } \\
\text { parameters }\end{array}$} & Element width (ft) & 10 \\
\cline { 2 - 3 } & Seam boundary & Symmetric \\
\cline { 2 - 3 } & Seam thickness (ft) & 5 \\
\hline \multirow{4}{*}{$\begin{array}{c}\text { Rock mass stiffness } \\
\text { parameter }\end{array}$} & Mining steps & 10 \\
\cline { 2 - 3 } & Elastic modulus (psi) & $3,000,000$ \\
\cline { 2 - 3 } & Poisson's ratio & 0.25 \\
\cline { 2 - 3 } & Coal modulus (psi) & $3,000,000$ \\
\cline { 2 - 3 } & Width of gob (ft) & 800 \\
\cline { 2 - 3 } & Initial gob modulus (psi) & 100 \\
\cline { 2 - 3 } & Gob height factor & 1 \\
\hline In-situ coal strength & Upper limit stress for gob (psi) & 4,000 \\
\hline
\end{tabular}


The general input parameters are the default values of LaModel program. The input values and panel layout are typed in by LamPre, which is the pre-processing section of LaModel. In this process, all retreat-mining processes are finished within 10 mining steps. The step here means the mining sequence of the longwall panel; the first step means the longwall faces start moving from the setup room, where the retreat mining process of the longwall panel starts. The distance of longwall face in each step is $0 \mathrm{ft}, 50 \mathrm{ft}, 50 \mathrm{ft}, 50 \mathrm{ft}$, $50 \mathrm{ft}, 50 \mathrm{ft}, 50 \mathrm{ft}, 50 \mathrm{ft}, 100 \mathrm{ft}$, and $100 \mathrm{ft}$, respectively. After each step, induced vertical stresses and safety factor (SF) in bleeder pillars are obtained by running LaModel.

\subsubsection{Stress distribution and safety factor in bleeder pillars in mining scenario 1}

The size of the pillar plays an important role in maintaining the stability of bleeder entries, and is also one of the key factors for pillar design. From Section 3.1.2 we know the vertical stress in bleeder pillars will first increase and then remain constant when the longwall face moves forward. In this section, the size effect of bleeder pillars caused by pillar arrangement was discussed. Two arrangements of rectangular pillars were studied; the length side of rectangular pillar was parallel or perpendicular to the longwall face.

Two different sizes of pillar, $90 \times 60 \mathrm{ft}(\mathrm{A}$ and a) and $60 \times 40 \mathrm{ft}(\mathrm{B}$ and b) bleeder pillars under different arrangements will be discussed. Two sizes of pillars are used to confirm whether the arrangement of pillars is independent of pillar size. For pillar arrangement, pillar A (B) is vertical to the longwall face while the pillar a (b) is parallel to the longwall face (Figure 3-13, 14). The first left column of bleeder pillars will be used as an example to discuss the modeling results (Figure 3-13, 14). 

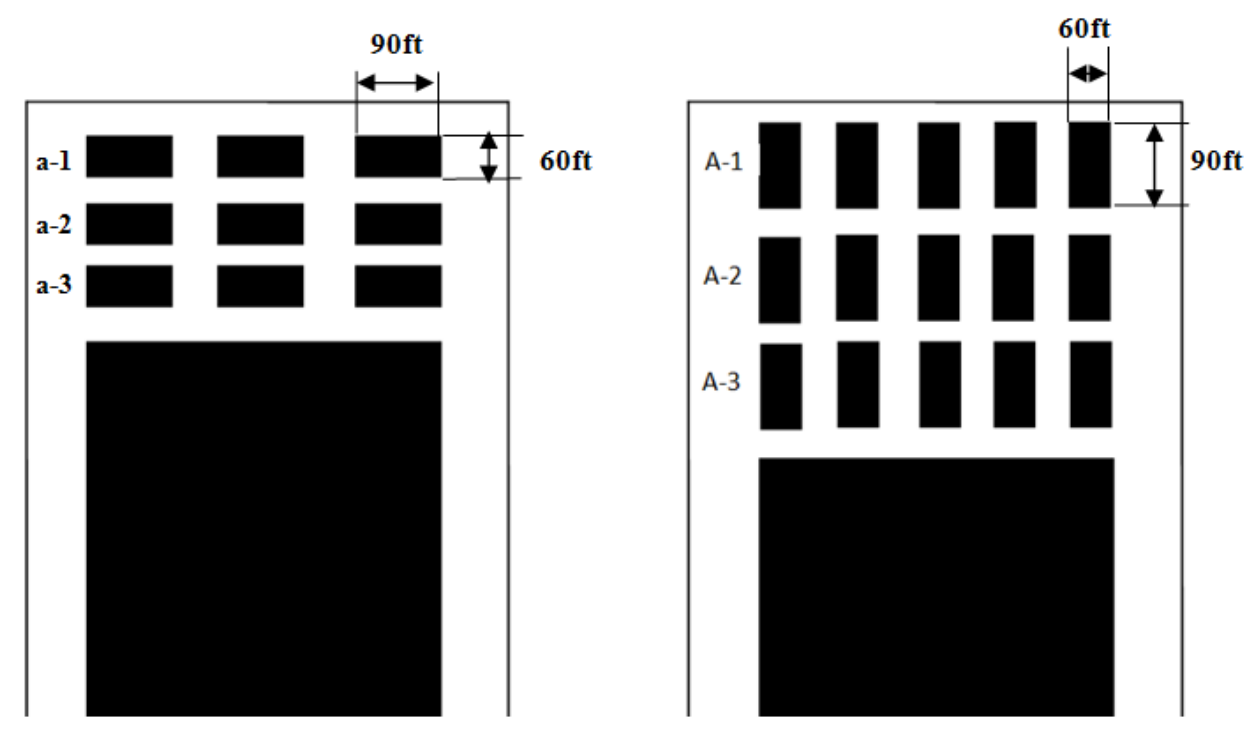

Figure 3-13 Layout of bleeder area with $60 \times 90 \mathrm{ft}$ pillars
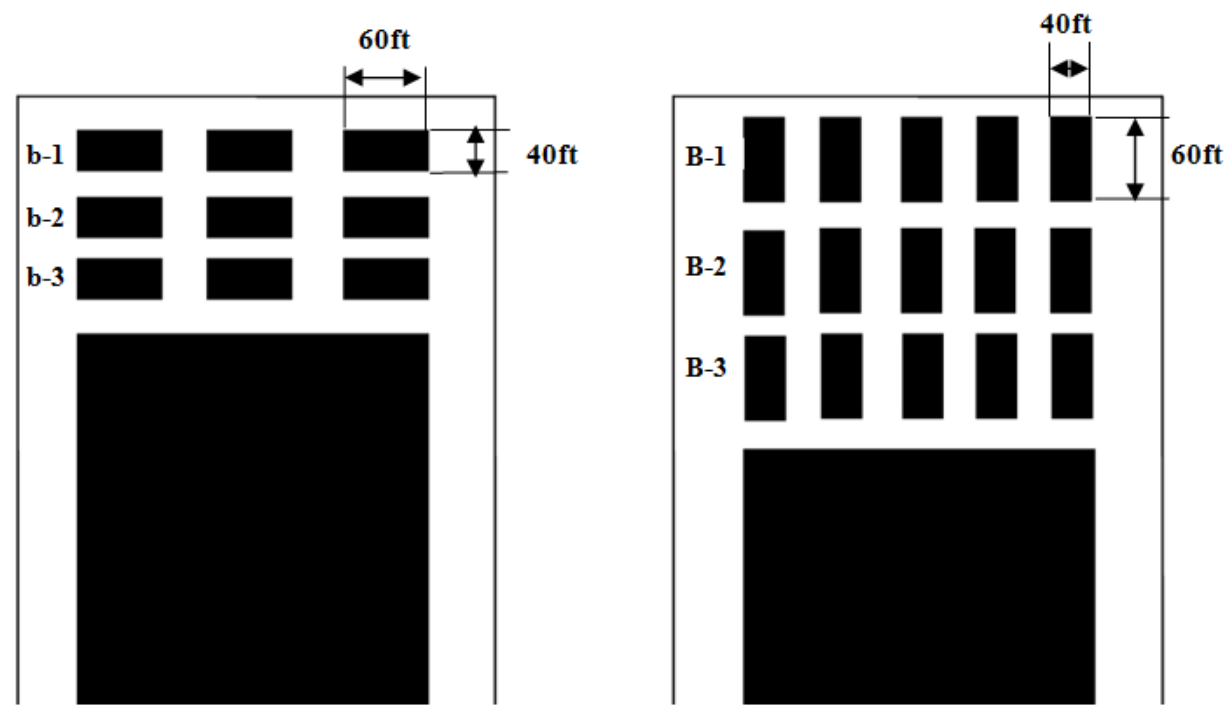

Figure 3-14 Layout of bleeder area with $60 \times 40 \mathrm{ft}$ pillars

Modeling results show that bleeder pillars nearer to the longwall face (a-3, A-3) are subject to higher induced vertical stress (above 1300psi), while other bleeder pillars (a-1, $\mathrm{a}-2, \mathrm{~A}-1, \mathrm{~A}-2)$ remain around $900 \mathrm{psi}$, which is still higher than the in-situ stress $(562.5$ psi). The vertical stress on pillars a-1, a-2, and a-3, is higher than on the corresponding pillar A-1, A-2, A-3 (Figure 3-15); the vertical tress in pillar a-3 is much higher than that in pillar A-3. The difference of a-3 and A-3 are more striking than that of a-1 and A-1. From the previous discussion, it can be concluded that the arrangement of bleeder pillars 
does cause different induced vertical stress in the bleeder pillar during the retreat mining process. Induced vertical stress in bleeder pillars perpendicular to the longwall face is usually higher than that in bleeder pillars parallel to the longwall face. Furthermore, the arrangement effect of bleeder pillars will expand when the pillar is close to the gob area or the pillar is under higher vertical stress.

The safety factor in pillar A-1, A-2, and A-3 is higher than in the pillar a-1, a-2, and a-3, respectively; the safety factor (SF) in bleeder pillars first decreases with increasing mining distance and then remains unchanged later (Figure 3-16), which is similar to the development of vertical stress on bleeder pillars. The safety factors of bleeder pillars are all above 3.5 during the retreat mining process, which means these pillars will be stable during their lifetime. The development of SF in bleeder pillars shows a similar pattern as that of induced stress in bleeder pillars.

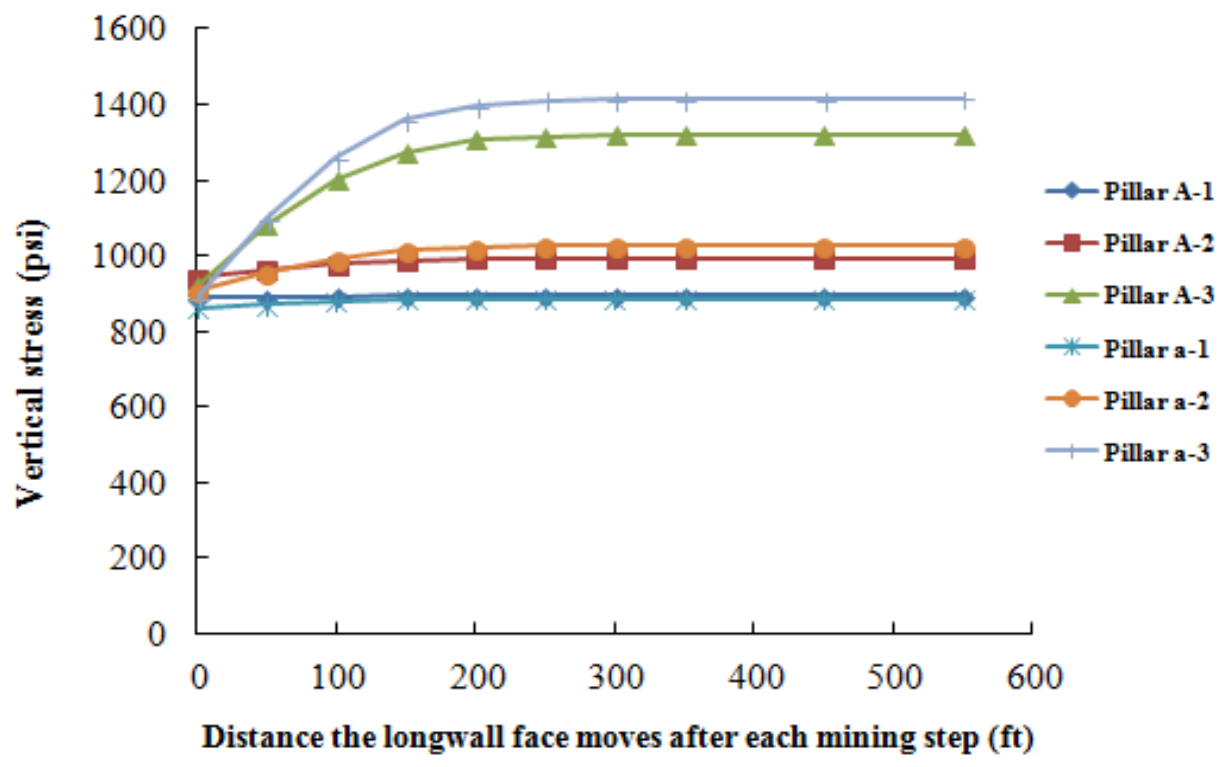

Figure 3-15 Development of vertical stress in bleeder pillars (a-1 to a-3 and A-1 to A-3) during retreat mining process 


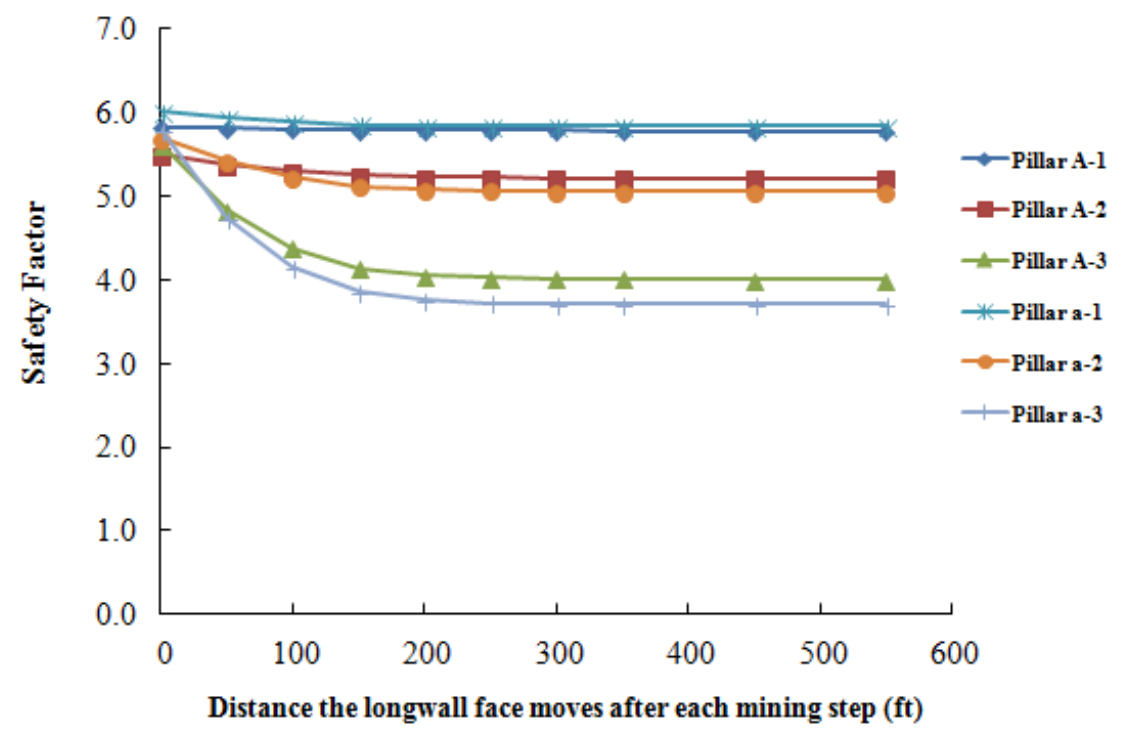

Figure 3-16 Development of SF in bleeder pillars (a-1 to a-3 and A-1 to A-3) during retreat mining process
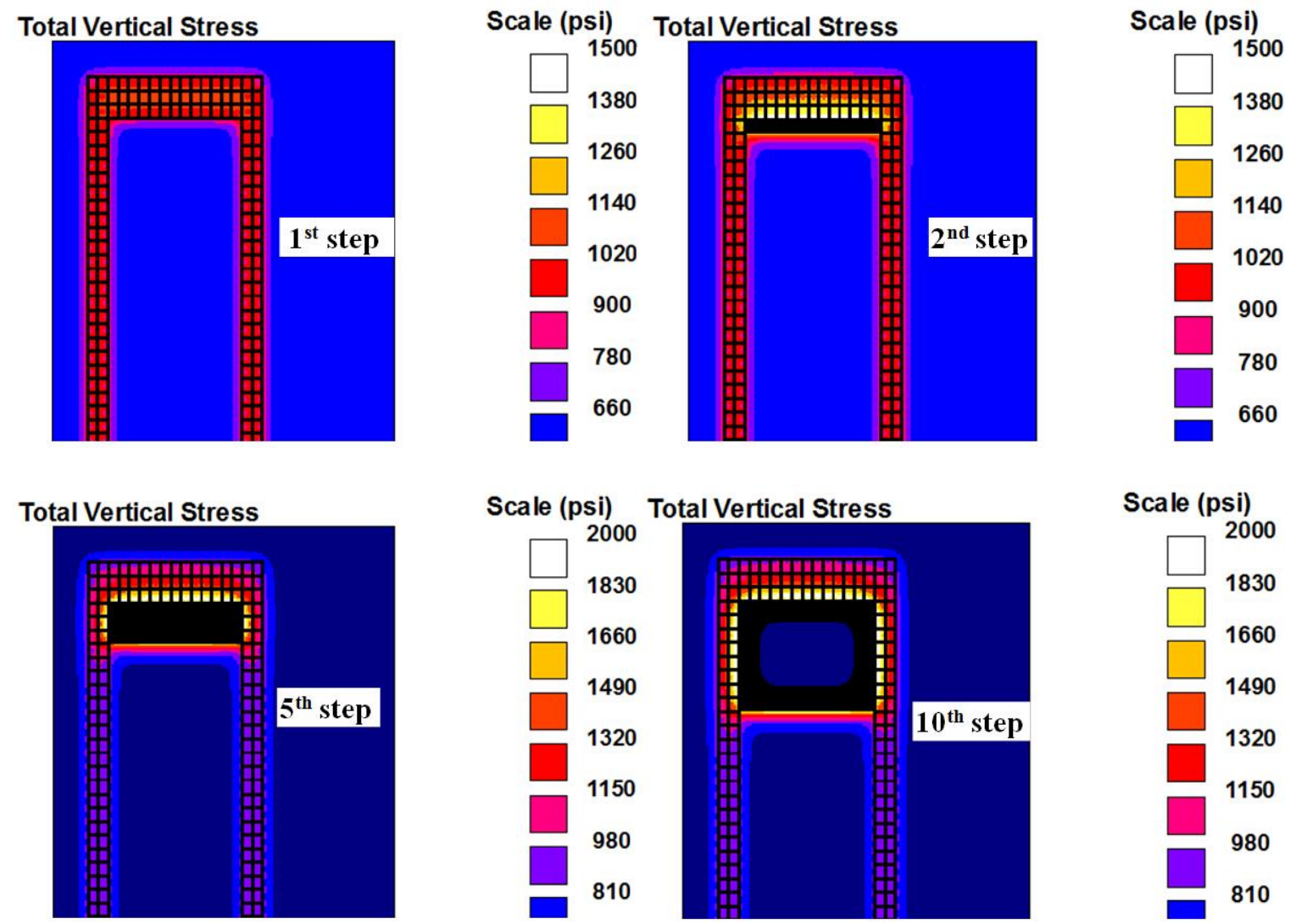

Figure 3-17 The development of total vertical stress in bleeder pillars (A-1, A-2, A-3) at 1, $2,5,10$ steps during retreat mining process 

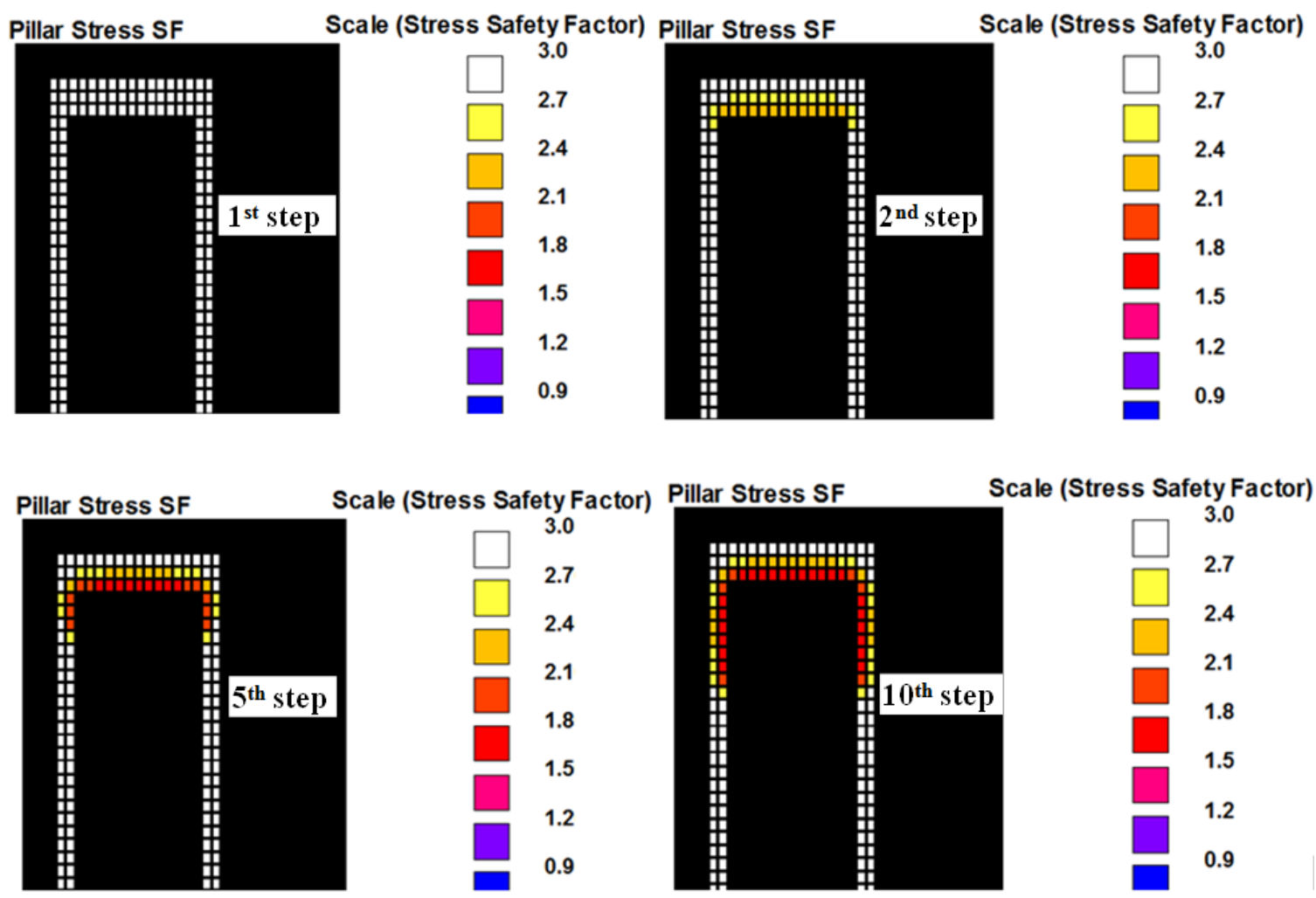

Figure 3-18 The development of stress SF in bleeder pillars (A-1, A-2, A-3) at 1, 2, 5, 10 steps during retreat mining process

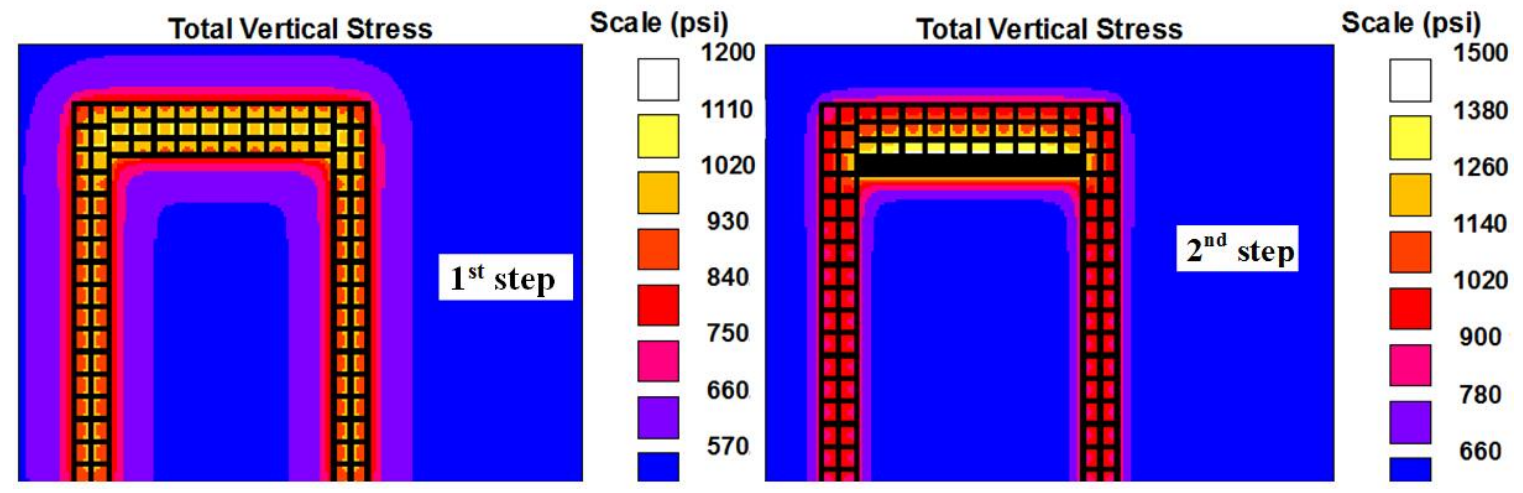



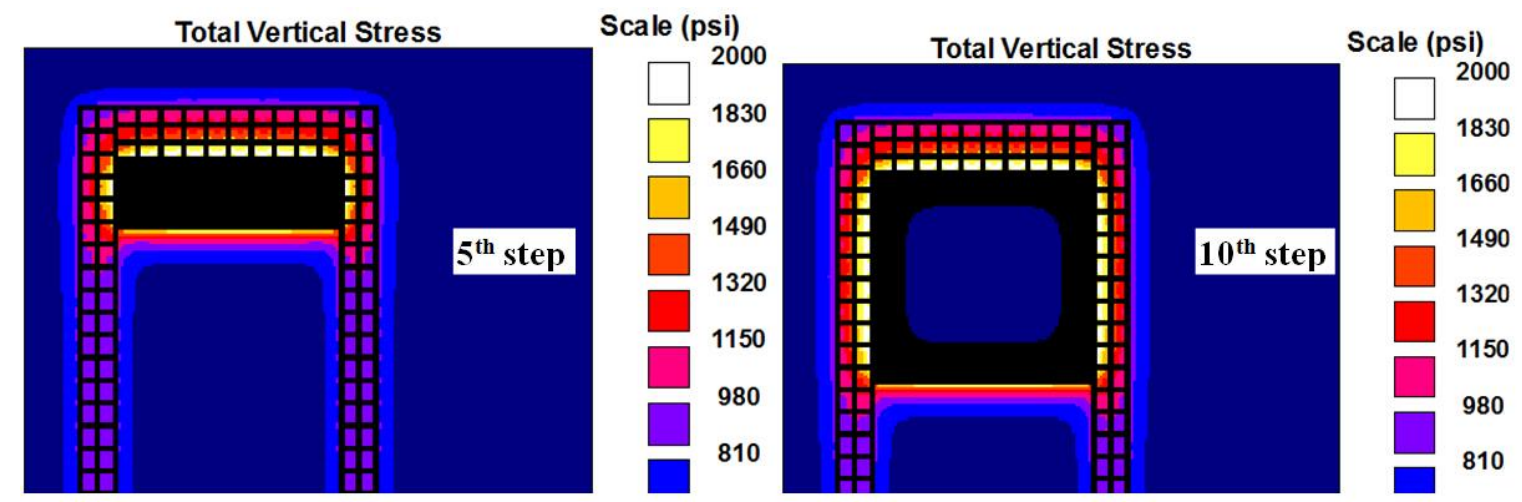

Figure 3-19 The development of total vertical stress in bleeder pillars (a-1, a-2, a-3) at 1, 2,5,10 steps during retreat mining process
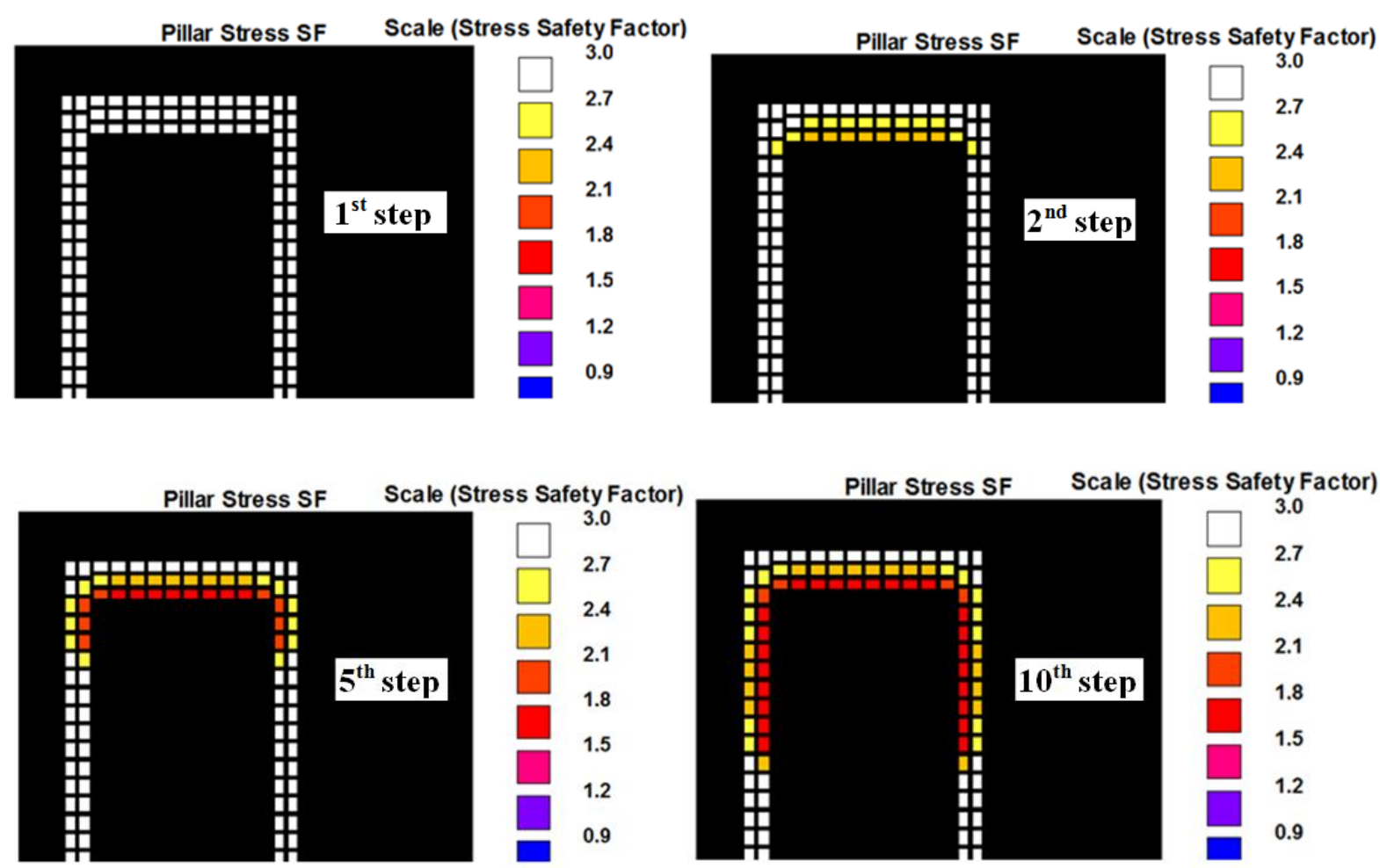

Figure 3-20 The development of stress SF in bleeder pillars (a-1, a-2, a-3) at 1, 2, 5, 10 steps during retreat mining process

Different arrangements of pillars influence vertical stress in bleeder pillars, which is confirmed by the modeling results. The vertical stress in pillar B and b shows the similar pattern with pillar A and a (Figure 3-21, 22). However, there are small deviations for the SF in pillar B and b even though pillar size is the same: SF in bleeder pillar b (b-1, b-2, and b-3) is much lower than corresponding pillar B (B-1, B-2, and B-3). This means the 
bleeder pillar in panel B (B-1, B-2, and B-3) is more stable than that in panel b (b-1, b-2, and $b-3)$.

It is clear that the stress and SF development in bleeder pillars B (B-1, B-2, and B-3) and $\mathrm{b}(\mathrm{b}-1, \mathrm{~b}-2$, and $\mathrm{b}-3)$ are similar to that in bleeder pillar A (A-1, A-2, and A-3) and a (a-1, a-2, and a-3). This also indicates that the arrangement effect on stress and SF in bleeder pillar is independent of pillar size.

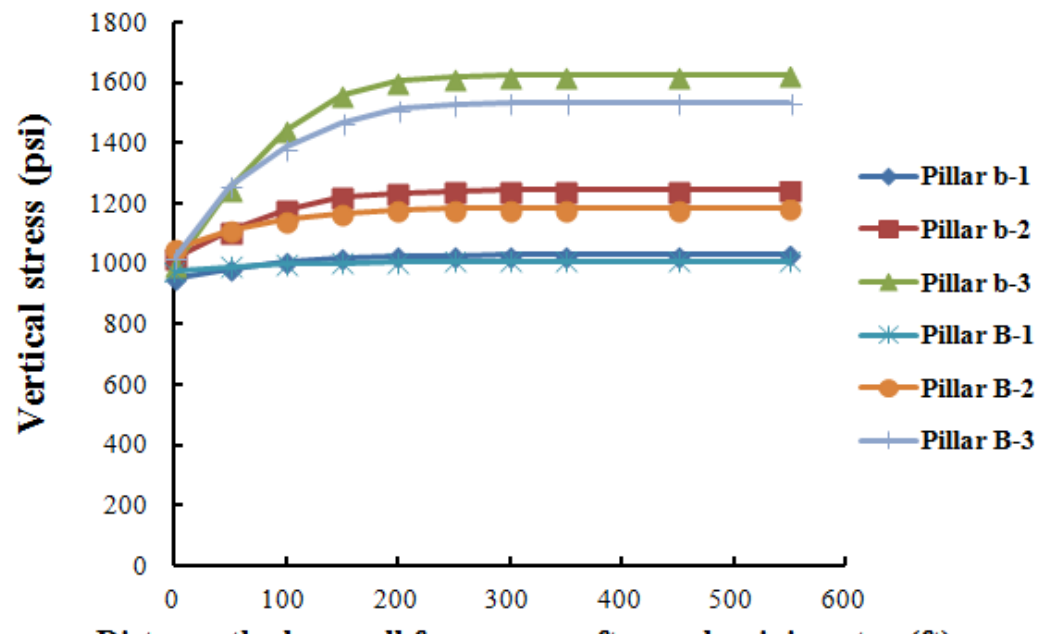

Distance the longwall face moves after each mining step (ft)

Figure 3-21 Development of vertical stress in bleeder pillar (b-s and B-s) during retreat mining process

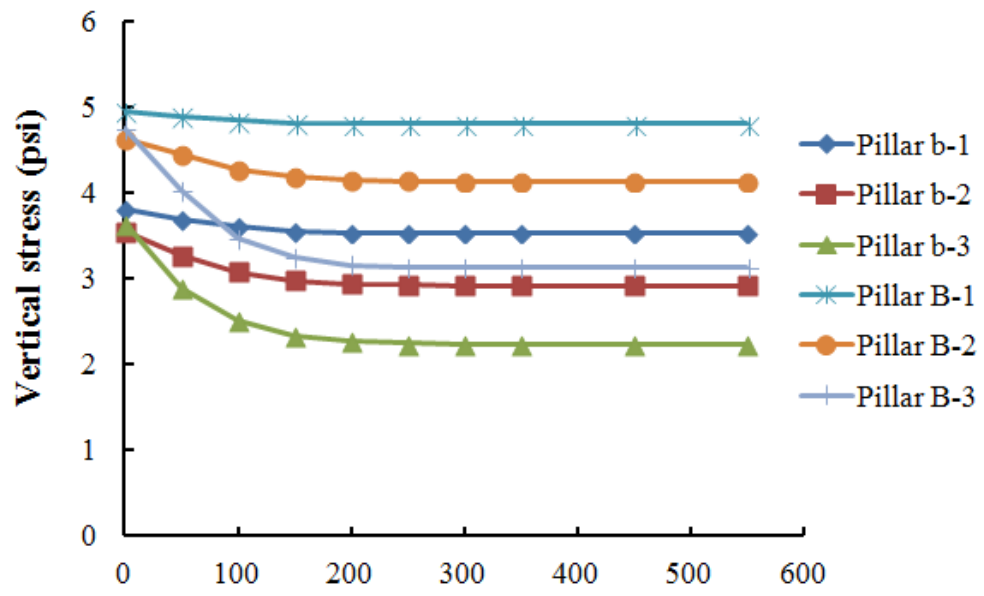

Distance the longwall face moves after each mining step (ft)

Figure 3-22 Development of vertical stress in bleeder pillar (b-s and B-s) during retreat mining process 


\subsubsection{Stress distribution and safety factor in bleeder pillars in mining scenario 2}

In this section, different sizes of bleeder pillar will be employed to support the same bleeder area. In other words, the bleeder loading in the bleeders is the same for different panel (C, B, E, F, and G, H), while the size of bleeder pillar is different (Figure 3-23). Panel C, D, E, F have bleeder pillars in $100 \times 60 \mathrm{ft}, 60 \times 60 \mathrm{ft}, 60 \times 40 \mathrm{ft}, 60 \times 30 \mathrm{ft}$, respectively. The pillar G1 is $100 \times 60 \mathrm{ft}$, and pillar G2 and G3 are $60 \times 40 \mathrm{ft}$ in panel G. The pillar H1 is $60 \times 90 \mathrm{ft}$, and pillar $\mathrm{H} 2$ and $\mathrm{H} 3$ are $60 \times 60 \mathrm{ft}$ in panel $\mathrm{H}$. The first left column of bleeder pillars will be used as an example to discuss the modeling results (Figure 3-23).

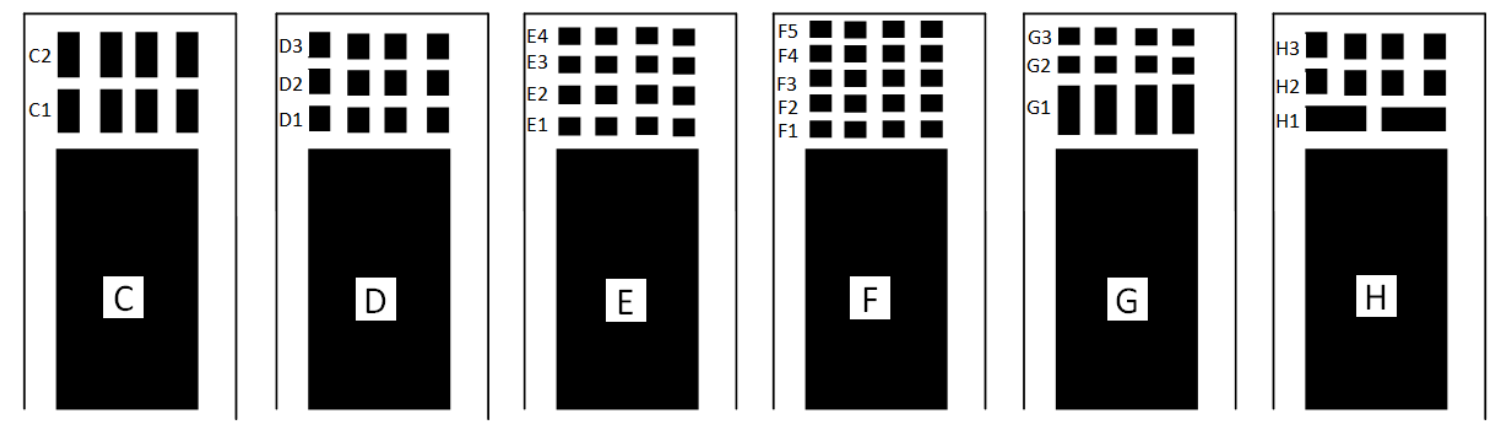

Figure 3-23 Bleeder area supported by different sizes of bleeder pillars

Figure 3-24 shows that the vertical stress in pillars D-3 and D-2 in step 10 increased by $54 \%$ and $12 \%$ more than that in step 1 , and the vertical stress in pillars F-1, F-2, F-3, F-4, and F-5 in step 10 increased by $68 \%, 28 \%, 12 \%, 0.06 \%$ and $0.03 \%$, respectively. Figure 3-25 and 26 show the development of vertical stress in bleeder pillars (F-1, F-2, F-3, F-4, F-5) and (D-1, D-2, D-3) at 1, 2, 5, and 10 steps during retreat mining process. From both two cases, it is clear that the increase of vertical stress in bleeder pillars closest to the longwall face is the maximum among all the pillars. These pillars are also subject to the highest stress during the retreating mining process later. Bleeder pillars from panel $\mathrm{C}$ and E also show a similar pattern. Since these pillars, which are closest to the gob, are sbujected to high vertical stress and have the potential to fail first, we need to focus on the change of vertcial stress in these pillars. 

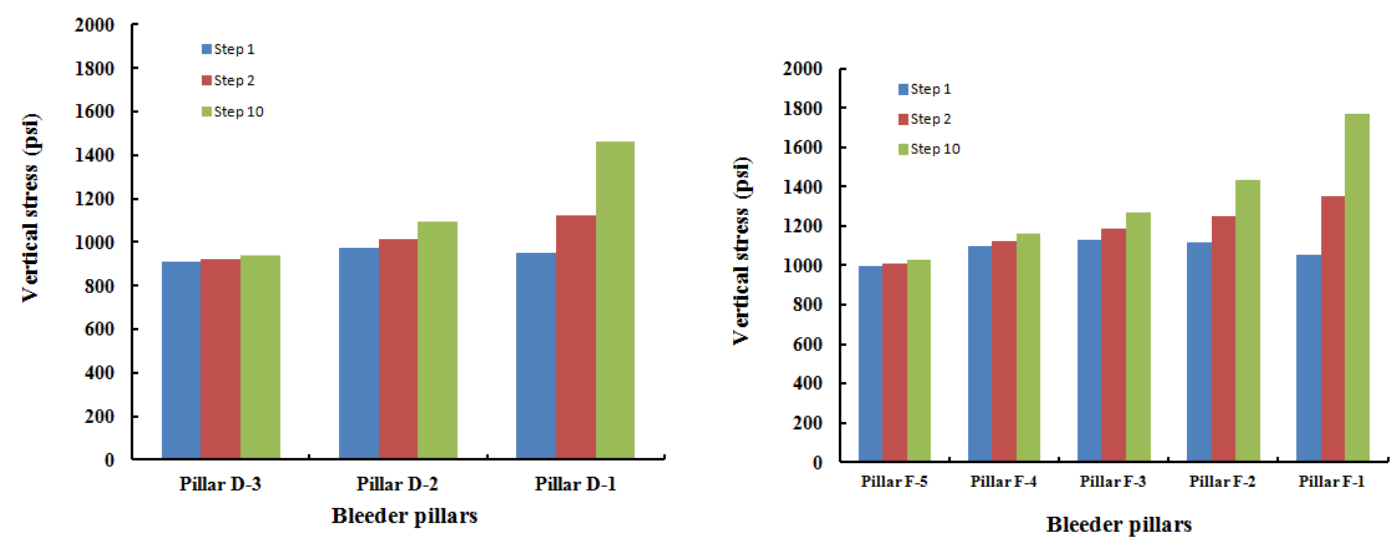

Figure 3-24 Development of vertical stress in bleeder pillar for 1, 2 and 10 steps
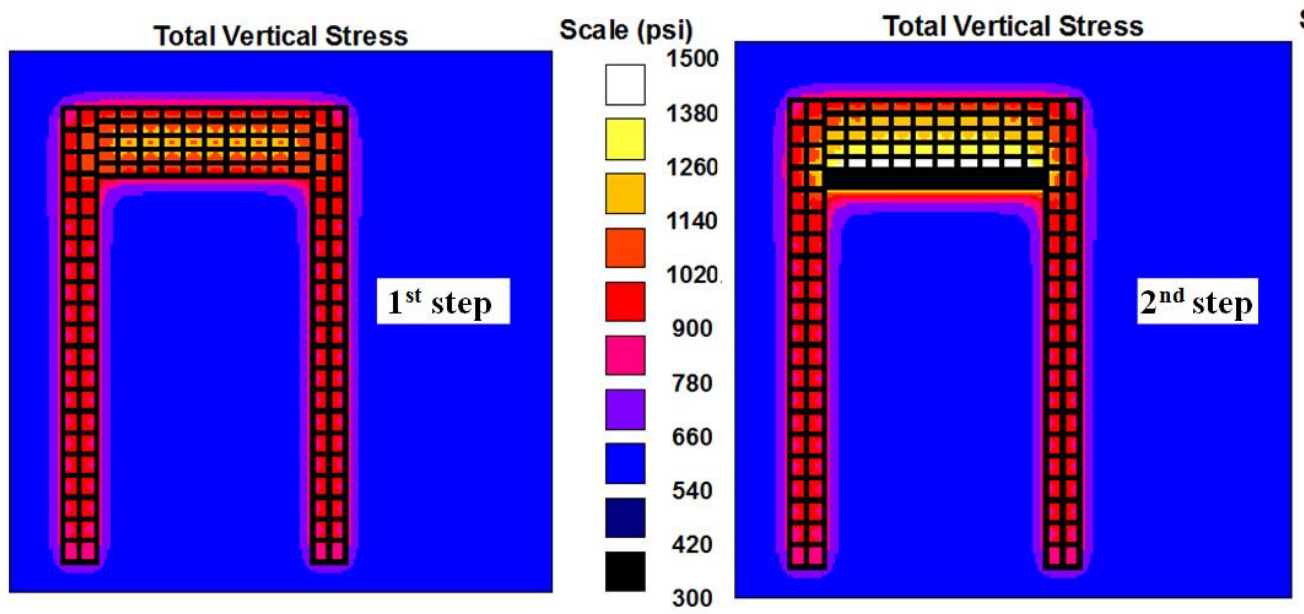
Scale (psi)

Total Vertical Stress

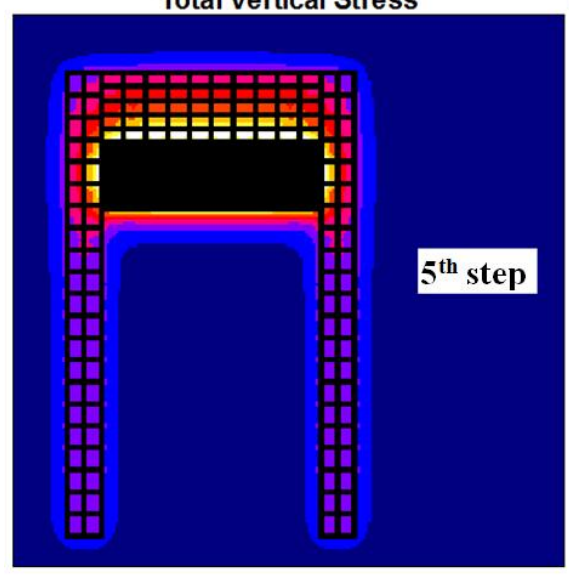

Scale (psi)

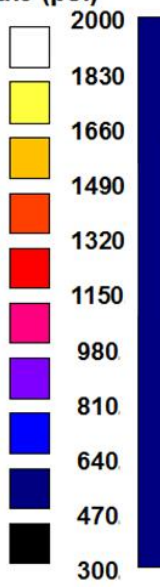

Total Vertical Stress

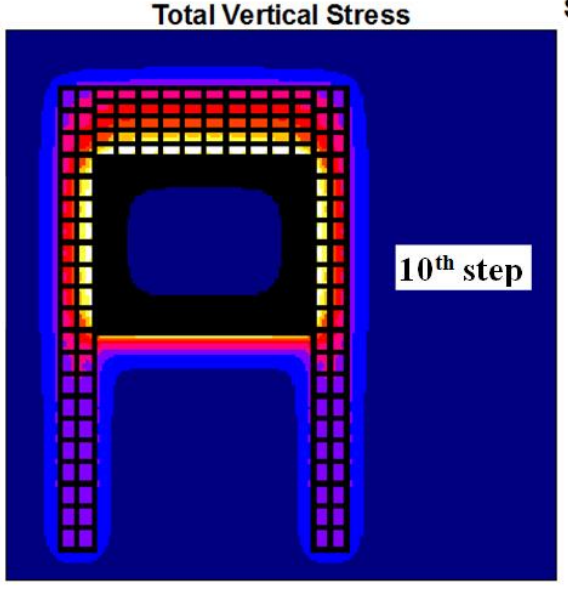

Scale (psi)

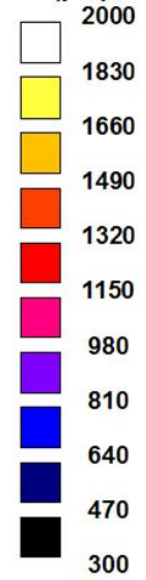

Figure 3-25 The development of vertical stress in bleeder pillars (F-1, F-2, F-3, F-4, F-5) at 1, 2,5,10 steps during retreat mining process 


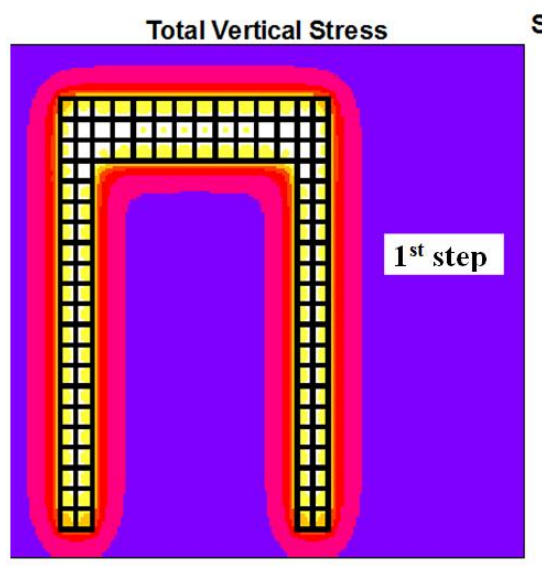

Scale (psi)
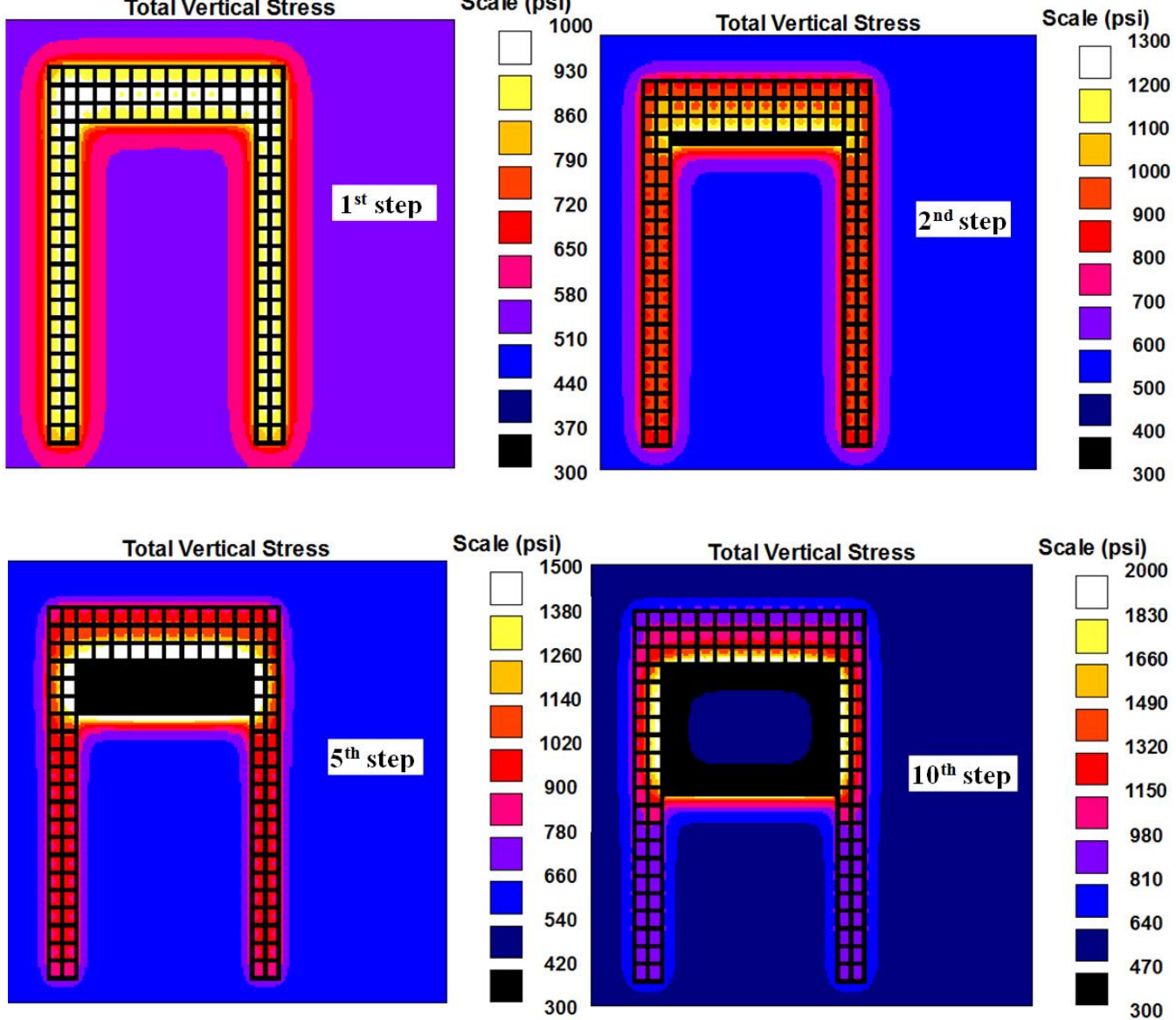

Figure 3-26 The development of vertical stress in bleeder pillars (D-1, D-2, D-3) at 1, 2,5,10 steps during retreat mining process

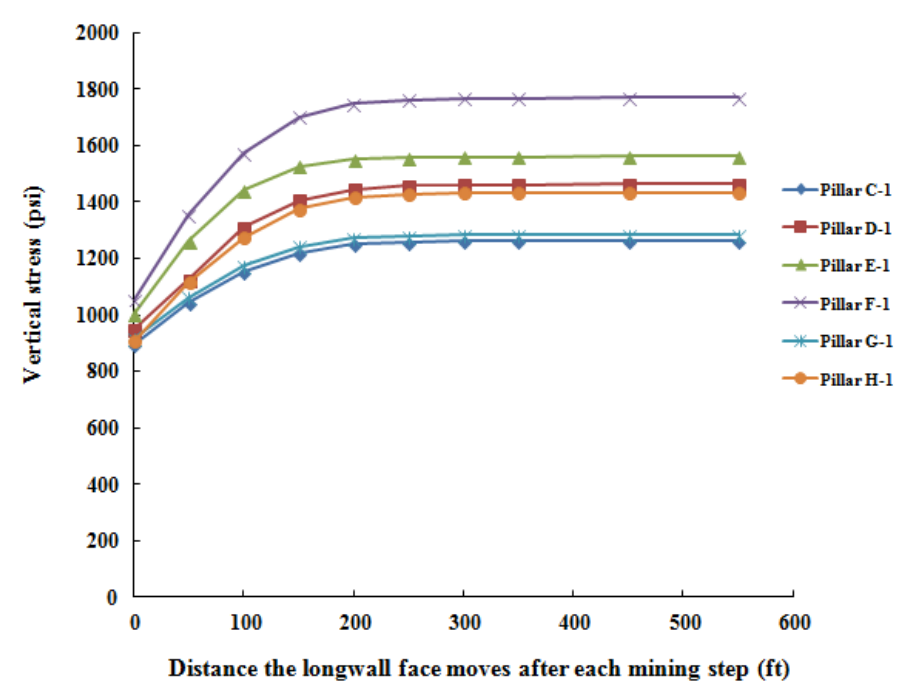

Figure 3-27 Development of vertical stress in bleeder pillars (C-1, D-1,E-1,F-1,G-1,H-1) during retreat mining process 
The vertcial stress in bleeder pillars F-1, E-1, D-1, H-1, G-1, and C-1 decreases in the following order: F-1, E-1, D-1, H-1, G-1, and C-1 in each step during the retreat mining process, obviously higher than in-situ stress (562.5psi) (Figure 3-27). The pillar sizes of F-1 $(60 \times 30 \mathrm{ft})$ and E-1 $(60 \times 40 \mathrm{ft})$ are smaller than the other four pillars, which results in higher vertical stress in bleeder pillars (F-1 and E-1). Panels D, H and G have four bleeder entries and the vertical stress in D-1 $(60 \times 60 \mathrm{ft})$ is higher than H-1 $(60 \times 120 \mathrm{ft})$ and G-1 $(120 \times 60 \mathrm{ft})$, which can also be attributed to the pillar size of bleeder pillars. The vertical stress in pillar $\mathrm{H}-1$ is higher than G-1 even though the pillar sizes are the same, which is caused by arrangment of bleeder pillars (already disscussed in Section 3.2.2). It is obvious that the vertical stress in $\mathrm{C}-1$ pillar is the lowest because of its greatest size among all the pillars.

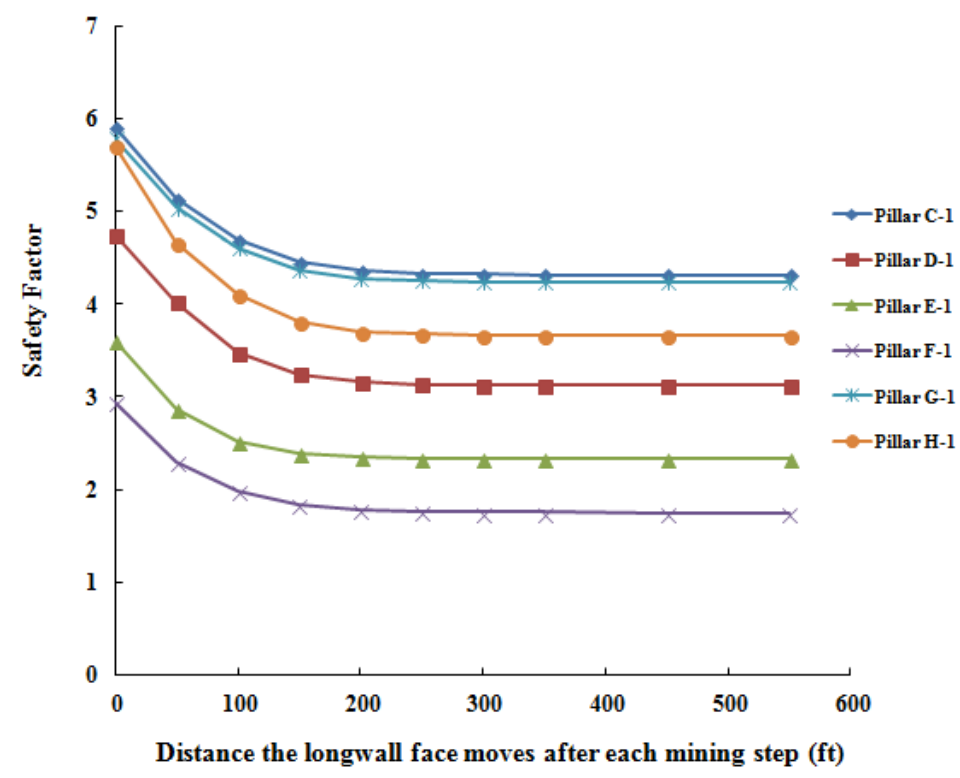

Figure 3-28 Development of stress SF in bleeder pillar (C-1, D-1, E-1, F-1, G-1, and H-1) during retreat mining process

As shown in Figure 3-28, the safety factor of bleeder pillars C-1, G-1, H-1, D-1, E-1, and F-1 decreases in the following order: C-1, G-1, H-1, D-1, E-1, and F-1. The change in safety factor follows the same pattern as vertical stress in these pillars. It should also be pointed out that vertical stress in bleeder pillars D-1 and H-1 are very close, but the safety factor is different,which was attributed to the size effect of bleeder pillar. 


\subsubsection{Discussion}

In mining practice, induced vertical stress decreases with distance from gob behind the longwall face (Figure 3-29). The distribution of vertical stress determines induced vertical stress in bleeder pillars, which finally results in stress variation in bleeder pillars of different arrangements. It should be noted that the extent of the abutment zone is $9.3 \sqrt{H}$ and $90 \%$ of abutment loads are within $5 \sqrt{H}$ in the abutment zone in the LaModel program (Heasley, 2008).

\section{Ground surface}

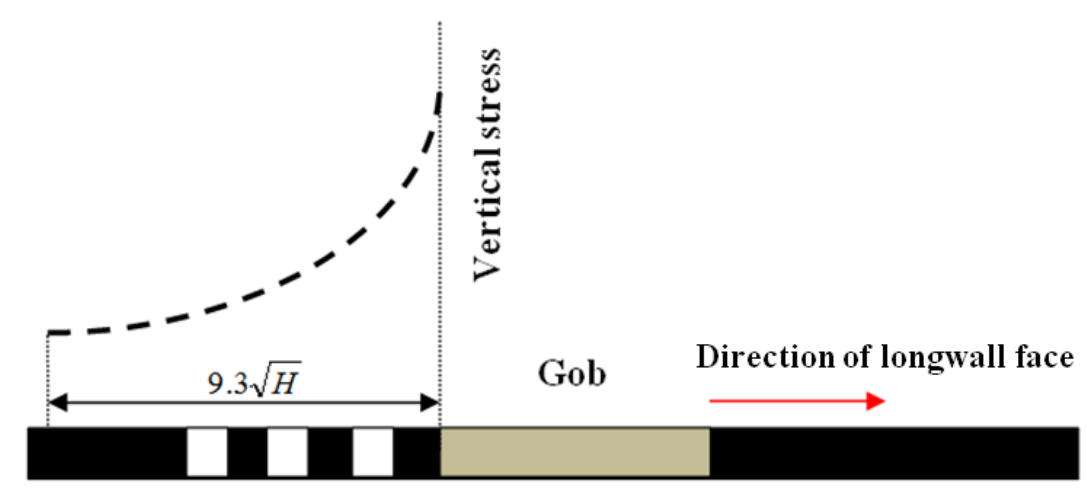

Figure 3-29 Distribution of induced vertical stress behind gob

In LaModel program the Mark-Bieniawaski formula (Mark, 1997) is employed by taking the shape of pillar into consideration (Eqution 3-3).

$$
s_{p}=s_{i}\left[0.64+0.54(w / h)-0.18\left(w^{2} / l h\right)\right]
$$

where $s_{p}$ is pillar strength, $s_{i}$ is in-situ coal strength, $w$ is pillar width, 1 is pillar length, and $\mathrm{h}$ is pillar height.

The safety factor, defined as the ratio of pillar strength to pillar loading (induced vertical stress), is the most important parameter to assess the stability of bleeder pillar. In LaModel, the safety factor accounts for both the extent of induced vertical stress (Figure 3-29) and the size and shape of bleeder pillar (Equation 3-3). The extent of induced vertical stress determines the stress state of bleeder pillar, while the size and shape of 
pillar dertermines whether the bleeder pillar can support the bleeder loading and remain stable during its service life.

\subsubsection{Conclusion}

Two types of models were developed to evaluate the size effect on bleeder pillars for the stability of bleeders during the retreat longwall mining process.

At first, the size effect caused by pillar arrangement was discussed. Bleeder pillars suffer different induced vertical stresses during the retreat mining process because of the arrangement of bleeder pillars; induced vertical stress in bleeder pillars perpendicular to the longwall face is usually higher than that in bleeder pillar parallel to the longwall face. The reason is that induced vertical stress decreases with distance from the gob area behind longwall face, and the extension of induced vertical stress in the bleeder area determines the stress state of bleeder pillar. The SF of pillars parallel to the longwall face is lower than the SF of pillars perpendicular to the longwall face for the same size of bleeder pillar.

Then the size effect of bleeder pillars was studied; different sizes of bleeder pillars are employed in the same bleeder area to support same bleeder loading. Bleeder pilllars nearest to the longwall face are the most prone to fail because of higher induced vertical stress. Small pillars suffer from higher induced vertical stress than do larger pillars. The safety factor of bleeder pillars is determined by both induced vertical stress and pillar size in LaModel; the development of SF for different sizes of bleeder pillar has deviation compared with that of vertical stress in bleeder pillars. 


\section{Chapter 4 Roof stability analysis of bleeder entries by FLAC}

\subsection{Model development in FLAC}

In this section, our attention is focused on roof deformation and stress distribution around bleeder entries during the retreat mining process. FLAC is used to evaluate roof stability in bleeder entries in one of the coal mines operated in the Upper Freeport coal seam area. The mechanics of FLAC is followed and the steps are:

(1) Simplification of the real problem,

(2) Geology and geometry of the problem,

(3) The constitutive behavior and material properties in the model,

(4) In-situ state or boundary condition of model, and

(5) Run the model and obtain results.

\subsubsection{Simplification of the real problem}

The following assumptions are made to simplify the real problem:

(a) The geo-materials are homogenous and isotropic. This assumption reduces the complexity of the problem. The calculated in-situ vertical stress was equal to,

$$
\delta_{z}=\gamma H=\rho g \mathrm{H}
$$

where $\rho$ is density of geo-material, $\mathrm{g}$ is gravity accelerate and $\mathrm{H}$ is overburden depth.

(b) Measured in-situ horizontal stress for each underground coalmine is different and may depend on the tectonic, folding, faulting or historical events. Although high horizontal stress are attributed to cause roof falls, there are also many cases where roof falls are not caused by horizontal stress (Peng 2006).

\subsubsection{Geology and geometry of the problem}

The stratigraphic column for the coal mine is shown in Table 4-1. The overburden cover of the Upper Freeport coal seam is $1046.32 \mathrm{ft}$. The thickness of coal seam is $6.56 \mathrm{ft}$. The bleeders are a three-entry system; the bleeder entry is $20 \mathrm{ft}$ and bleeder pillar is $60 \mathrm{ft}$ wide (Figure 4-1). 
Table 4-1 The simplified stratigraphic column of overburden strata

\begin{tabular}{|c|c|c|c|c|c|c|c|c|c|}
\hline \multirow{2}{*}{ Rock Strata } & \multirow{2}{*}{$\mathbf{T}(\mathbf{f t})$} & \multirow{2}{*}{ From $(f t)$} & \multirow{2}{*}{ To(ft) } & \multirow{2}{*}{$\begin{array}{c}\text { Density } \\
\left(\text { slug/ft }{ }^{3}\right) \\
\end{array}$} & \multirow{2}{*}{\begin{tabular}{|c|} 
K (Bulk M) \\
$\left(\mathbf{l b f} / \mathrm{ft}^{2}\right)$ \\
\end{tabular}} & \multirow{2}{*}{\begin{tabular}{|c|} 
G(shear M) \\
$\left(\mathrm{lbf} / \mathrm{ft}^{2}\right)$ \\
\end{tabular}} & \multirow{2}{*}{\begin{tabular}{|r|} 
Cohesion \\
$\left(\mathbf{l b f} / \mathrm{ft}^{2}\right)$ \\
\end{tabular}} & \multirow{2}{*}{\begin{tabular}{l|} 
Friction \\
(degree)
\end{tabular}} & \multirow{2}{*}{$\begin{array}{l}\text { Tension } \\
\left(\mathbf{l b f} / \mathrm{ft}^{2}\right)\end{array}$} \\
\hline & & & & & & & & & \\
\hline soil & 20 & 1140 & 1160 & 3.73 & $3.77 \mathrm{E}+07$ & $1.17 \mathrm{E}+07$ & $1.73 \mathrm{E}+04$ & 28 & $5.76 \mathrm{E}+03$ \\
\hline clay shale & 91 & 1050 & 1140 & 4.66 & $7.10 \mathrm{E}+07$ & $3.86 \mathrm{E}+07$ & $5.09 \mathrm{E}+04$ & 29 & $1.73 \mathrm{E}+04$ \\
\hline sandstone & 55 & 994 & 1050 & 5.19 & $2.02 \mathrm{E}+08$ & $1.85 \mathrm{E}+08$ & $1.22 \mathrm{E}+05$ & 35 & $4.68 \mathrm{E}+04$ \\
\hline clayshale & 39 & 955 & 994 & 4.66 & $7.10 \mathrm{E}+07$ & $3.86 \mathrm{E}+07$ & $5.09 \mathrm{E}+04$ & 29 & $1.73 \mathrm{E}+04$ \\
\hline siltshale & 32 & 923 & 955 & 4.97 & $2.38 \mathrm{E}+08$ & $1.79 \mathrm{E}+08$ & $7.53 \mathrm{E}+04$ & 33 & $2.77 \mathrm{E}+04$ \\
\hline clayshale & 20 & 904 & 923 & 4.66 & $7.10 \mathrm{E}+07$ & $3.86 \mathrm{E}+07$ & $5.09 \mathrm{E}+04$ & 29 & $1.73 \mathrm{E}+04$ \\
\hline limestone & 102 & 802 & 904 & 5.13 & $3.00 \mathrm{E}+08$ & $1.38 \mathrm{E}+08$ & $1.37 \mathrm{E}+05$ & 31 & $4.85 \mathrm{E}+04$ \\
\hline calcareous clay & 12 & 790 & 802 & 5.13 & $1.46 \mathrm{E}+08$ & $6.76 \mathrm{E}+07$ & $4.19 \mathrm{E}+04$ & 31 & $1.48 \mathrm{E}+04$ \\
\hline siltshale & 10 & 780 & 790 & 4.97 & $2.38 \mathrm{E}+08$ & $1.79 \mathrm{E}+08$ & $7.53 \mathrm{E}+04$ & 33 & $2.77 \mathrm{E}+04$ \\
\hline sandstone & 8 & 772 & 780 & 5.19 & $2.02 \mathrm{E}+08$ & $1.85 \mathrm{E}+08$ & $1.22 \mathrm{E}+05$ & 35 & $4.68 \mathrm{E}+04$ \\
\hline siltshale & 12 & 760 & 772 & 4.97 & $2.38 \mathrm{E}+08$ & $1.79 \mathrm{E}+08$ & $7.53 \mathrm{E}+04$ & 33 & $2.77 \mathrm{E}+04$ \\
\hline carbonaceous d & 2 & 758 & 760 & 4.66 & $7.10 \mathrm{E}+07$ & $3.86 \mathrm{E}+07$ & $5.09 \mathrm{E}+04$ & 29 & $1.73 \mathrm{E}+04$ \\
\hline Coal seam'C' & 6 & 752 & 758 & 2.74 & $5.40 \mathrm{E}+07$ & $1.93 \mathrm{E}+07$ & $3.89 \mathrm{E}+04$ & 28 & $1.30 \mathrm{E}+04$ \\
\hline calcareous clay & 4 & 748 & 752 & 4.66 & $1.46 \mathrm{E}+08$ & $6.76 \mathrm{E}+07$ & $4.19 \mathrm{E}+04$ & 31 & $1.48 \mathrm{E}+04$ \\
\hline limestone & 36 & 712 & 748 & 5.13 & $3.00 \mathrm{E}+08$ & $1.38 \mathrm{E}+08$ & $1.37 \mathrm{E}+05$ & 31 & $4.85 \mathrm{E}+04$ \\
\hline calcareous clay & 14 & 698 & 712 & 4.91 & $1.62 \mathrm{E}+08$ & $7.48 \mathrm{E}+07$ & $6.16 \mathrm{E}+04$ & 30 & $2.13 \mathrm{E}+04$ \\
\hline clay stone & 15 & 683 & 698 & 4.88 & $1.64 \mathrm{E}+08$ & $1.03 \mathrm{E}+08$ & $5.09 \mathrm{E}+04$ & 30 & $1.76 \mathrm{E}+04$ \\
\hline gray clay shale & 7 & 676 & 683 & 3.92 & $6.60 \mathrm{E}+07$ & $3.05 \mathrm{E}+07$ & $4.59 \mathrm{E}+04$ & 29 & $1.56 \mathrm{E}+04$ \\
\hline Coal seam'B' & 9 & 667 & 676 & 2.74 & $5.40 \mathrm{E}+07$ & $1.93 \mathrm{E}+07$ & \begin{tabular}{|l|}
$3.89 \mathrm{E}+04$ \\
\end{tabular} & 28 & $1.30 \mathrm{E}+04$ \\
\hline gray clayshale & 19 & 649 & 667 & 4.66 & $7.10 \mathrm{E}+07$ & $3.86 \mathrm{E}+07$ & $5.09 \mathrm{E}+04$ & 29 & $1.73 \mathrm{E}+04$ \\
\hline siltshale & 104 & 544 & 649 & 4.97 & $2.38 \mathrm{E}+08$ & $1.79 \mathrm{E}+08$ & $7.53 \mathrm{E}+04$ & 33 & $2.77 \mathrm{E}+04$ \\
\hline calcareous clay & 36 & 508 & 544 & 5.13 & $1.46 \mathrm{E}+08$ & $6.76 \mathrm{E}+07$ & $4.19 \mathrm{E}+04$ & 31 & $1.48 \mathrm{E}+04$ \\
\hline gray clayshale & 62 & 446 & 508 & 4.66 & $7.10 \mathrm{E}+07$ & $3.86 \mathrm{E}+07$ & $5.09 \mathrm{E}+04$ & 29 & $1.73 \mathrm{E}+04$ \\
\hline siltshale & 22 & 424 & 446 & 4.97 & $2.38 \mathrm{E}+08$ & $1.79 \mathrm{E}+08$ & $7.53 \mathrm{E}+04$ & 33 & $2.77 \mathrm{E}+04$ \\
\hline sandstone & 20 & 404 & 424 & 5.19 & $2.02 \mathrm{E}+08$ & $1.85 \mathrm{E}+08$ & $1.22 \mathrm{E}+05$ & 35 & $4.68 \mathrm{E}+04$ \\
\hline calcareous clay & 15 & 390 & 404 & 5.13 & $1.46 \mathrm{E}+08$ & $6.76 \mathrm{E}+07$ & $4.19 \mathrm{E}+04$ & 31 & $1.48 \mathrm{E}+04$ \\
\hline claystone & 49 & 340 & 390 & 4.82 & $8.35 \mathrm{E}+07$ & $4.54 \mathrm{E}+07$ & $2.80 \mathrm{E}+04$ & 28 & $9.32 \mathrm{E}+03$ \\
\hline siltshale & 20 & 321 & 340 & 4.97 & $2.38 \mathrm{E}+08$ & $1.79 \mathrm{E}+08$ & $7.53 \mathrm{E}+04$ & 33 & $2.77 \mathrm{E}+04$ \\
\hline sandstone & 12 & 309 & 321 & 5.19 & $2.02 \mathrm{E}+08$ & $1.85 \mathrm{E}+08$ & $1.22 \mathrm{E}+05$ & 35 & $4.68 \mathrm{E}+04$ \\
\hline gray clayshale & 65 & 244 & 309 & 4.66 & $7.10 \mathrm{E}+07$ & $3.86 \mathrm{E}+07$ & $5.09 \mathrm{E}+04$ & 29 & $1.73 \mathrm{E}+04$ \\
\hline sandstone & 51 & 193 & 244 & 5.19 & $2.02 \mathrm{E}+08$ & $1.85 \mathrm{E}+08$ & $1.22 \mathrm{E}+05$ & 35 & $4.68 \mathrm{E}+04$ \\
\hline gray clayshale & 12 & 181 & 193 & 4.66 & $7.10 \mathrm{E}+07$ & $3.86 \mathrm{E}+07$ & $5.09 \mathrm{E}+04$ & 29 & $1.73 \mathrm{E}+04$ \\
\hline siltshale & 5 & 176 & 181 & 4.97 & $2.38 \mathrm{E}+08$ & $1.79 \mathrm{E}+08$ & $7.53 \mathrm{E}+04$ & 33 & $2.77 \mathrm{E}+04$ \\
\hline sandstone & 51 & 125 & 176 & 5.19 & $2.02 \mathrm{E}+08$ & $1.85 \mathrm{E}+08$ & $1.22 \mathrm{E}+05$ & 35 & $4.68 \mathrm{E}+04$ \\
\hline siltshale & 8 & 117 & 125 & 5.29 & $1.62 \mathrm{E}+08$ & $1.21 \mathrm{E}+08$ & $1.16 \mathrm{E}+05$ & 33 & $4.29 \mathrm{E}+04$ \\
\hline gray clayshale & 2 & 115 & 117 & 5.16 & $2.06 \mathrm{E}+08$ & $1.12 \mathrm{E}+08$ & $1.04 \mathrm{E}+05$ & 29 & $3.52 \mathrm{E}+04$ \\
\hline Coal seam 'A' & 6 & 108 & 115 & 2.74 & $5.40 \mathrm{E}+07$ & $1.93 \mathrm{E}+07$ & $3.89 \mathrm{E}+04$ & 28 & $1.30 \mathrm{E}+04$ \\
\hline gray clayshale & 5 & 103 & 108 & 5.16 & $2.06 \mathrm{E}+08$ & $1.12 \mathrm{E}+08$ & $1.04 \mathrm{E}+05$ & 29 & $3.52 \mathrm{E}+04$ \\
\hline siltshale & 5 & 98 & 103 & 5.10 & $3.43 \mathrm{E}+08$ & $1.87 \mathrm{E}+08$ & \begin{tabular}{|l|}
$2.76 \mathrm{E}+05$ \\
\end{tabular} & 33 & $5.53 \mathrm{E}+04$ \\
\hline siltshale & 49 & 49 & 98 & 4.97 & $2.63 \mathrm{E}+08$ & $1.97 \mathrm{E}+08$ & $7.53 \mathrm{E}+04$ & 33 & $2.77 \mathrm{E}+04$ \\
\hline sandstone & 49 & 0 & 49 & 5.19 & $2.02 \mathrm{E}+08$ & $1.85 \mathrm{E}+08$ & $1.22 \mathrm{E}+05$ & 35 & $4.68 \mathrm{E}+04$ \\
\hline
\end{tabular}




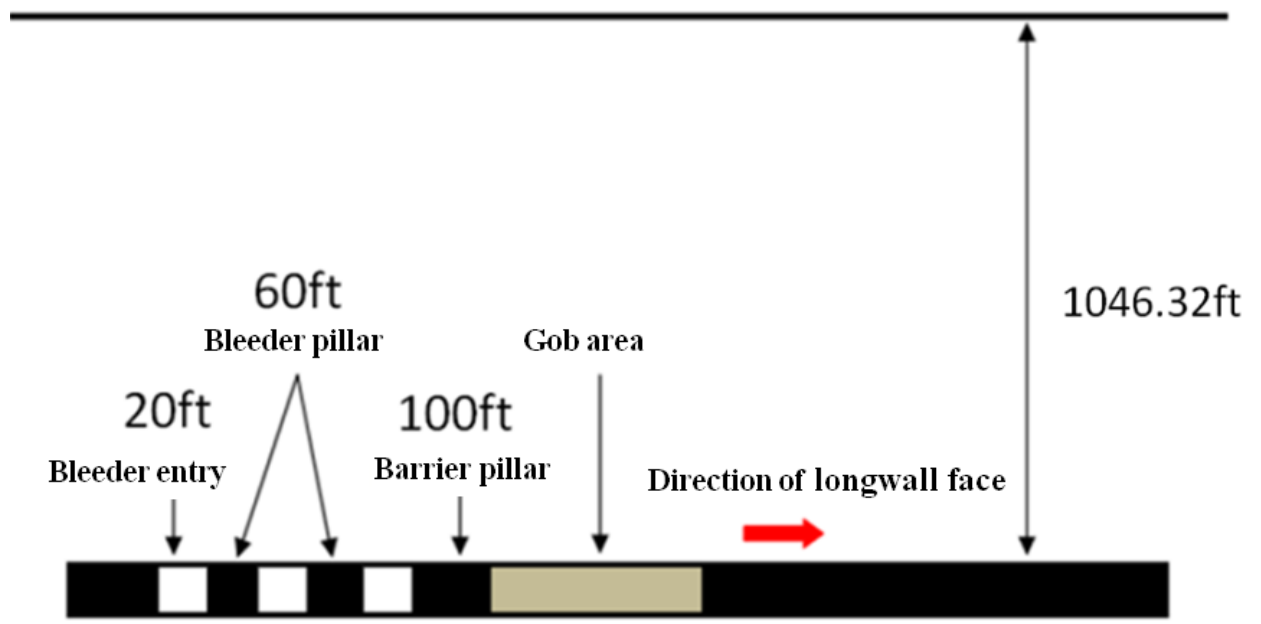

Figure 4-1 The geometry of longwall face

\subsubsection{Constitutive models}

There are 14 basic constitutive models provided in FLAC. Three plastic models are used and introduced in detail: Mohr-Coulomb model, strain-softening model, and double yielding model. These three models are used for different material properties in the model.

\section{(a) Mohr-Coulomb model}

The Mohr-Coulomb failure criterion is the best known and the most frequently used model in mining application for its simplicity. However, the shortcoming is that it does not consider the effect of intermediate principal stress. The required properties for the Mohr-Coulomb model are: density, bulk modulus, shear modulus, friction angle, cohesion, dilation angel, and tensile strength. The bulk modulus-K and shear modulus-G can be obtained by Young's modulus, E, and Poisson's ratio v,

$$
K=\frac{E}{3(1-2 v)}, G=\frac{E}{2(1+v)}
$$

In FLAC, the principle stresses $\sigma_{1}, \sigma_{2}, \sigma_{3}$, are used, and the out-of-plane stress, $\sigma_{\mathrm{zz}}$, are being used for one of these. The principal stresses and principal directions are evaluated from the stress tensor components, shown in following order (the compressive stresses are negative),

$$
\sigma_{1} \leq \sigma_{2} \leq \sigma_{3}
$$


The failure criterion for the M-C model is shown in the plane as illustrated in Figure 4-2. The failure envelope is defined from point A to point B by the Mohr-Coulomb yield function,

$$
f^{s}=\sigma_{1}-\sigma_{3} N_{\phi}+2 c \sqrt{N_{\phi}}
$$

From $\mathrm{B}$ to $\mathrm{C}$ by a tension yield function of the form,

$$
f^{t}=\sigma^{t}-\sigma_{3}
$$

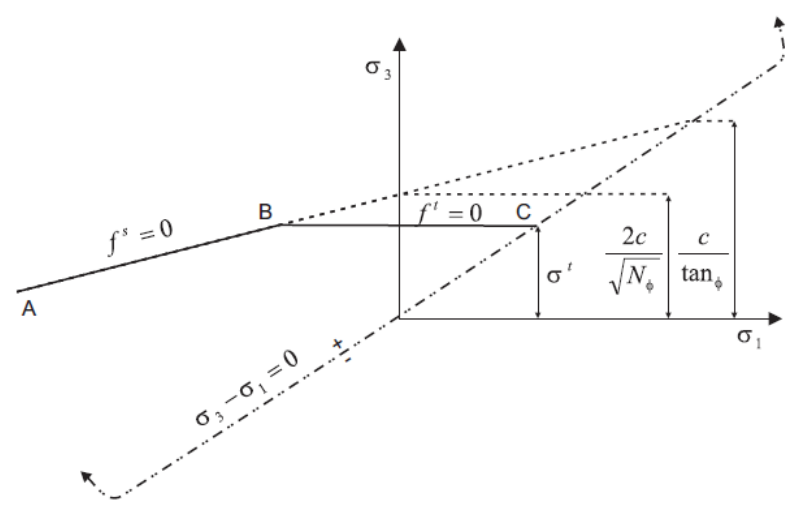

Figure 4-2 The Mohr-Coulomb failure criterion in FLAC (Itasca, 2011)

where $\Phi$ is friction angle, $\mathrm{c}$ is cohesion, $\sigma_{\mathrm{t}}$ is tensile strength, and

$$
N_{\phi}=\frac{1+\sin \phi}{1-\sin \phi}
$$

For a material with friction, $\Phi>0$ and the tensile strength of the material cannot exceed the value $\sigma_{\max }^{\mathrm{t}}$ given by

$$
\sigma_{\max }^{t}=\frac{c}{\tan \phi}
$$

\section{(b) The strain-softening model}

The strain-softening model represents the nonlinear softening behavior of material based on user defined relations, which prescribe the variations of the Mohr-Coulomb model properties (cohesion, friction angle, and dilation angle) as functions of the deviatoric plastic strain. 
Plastic shear strain is measured by the shear hardening parameter $\mathrm{e}^{\mathrm{ps}}$, and its incremental form is defined (Vermeer and deBorst, 1984),

$$
\Delta e^{p s}=\left\{\frac{1}{2}\left(\Delta e_{1}^{p s}-\Delta e_{m}^{p s}\right)^{2}+\frac{1}{2}\left(\Delta e_{m}^{p s}\right)^{2}+\frac{1}{2}\left(\Delta e_{3}^{p s}-\Delta e_{m}^{p s}\right)^{2}\right\}^{\frac{1}{2}}
$$

where $\Delta e_{m}^{p s}=\frac{1}{3}\left(\Delta e_{1}^{p s}+\Delta e_{3}^{p s}\right), \Delta e_{j}^{p s}, j=1,3$ are the principal plastic shear strain increments. Figure 4-3 shows a stress-strain curve for the strain-softening material indicating that the softening part is upon yield and the left residual strength. Before the peak strength, the curve is linear, only showing the elastic property of material. After yield, the total strain is composed of elastic and plastic part. In the softening/hardening model, the post-failure part behaves along with the proposed piecewise-linear relation of softening properties.

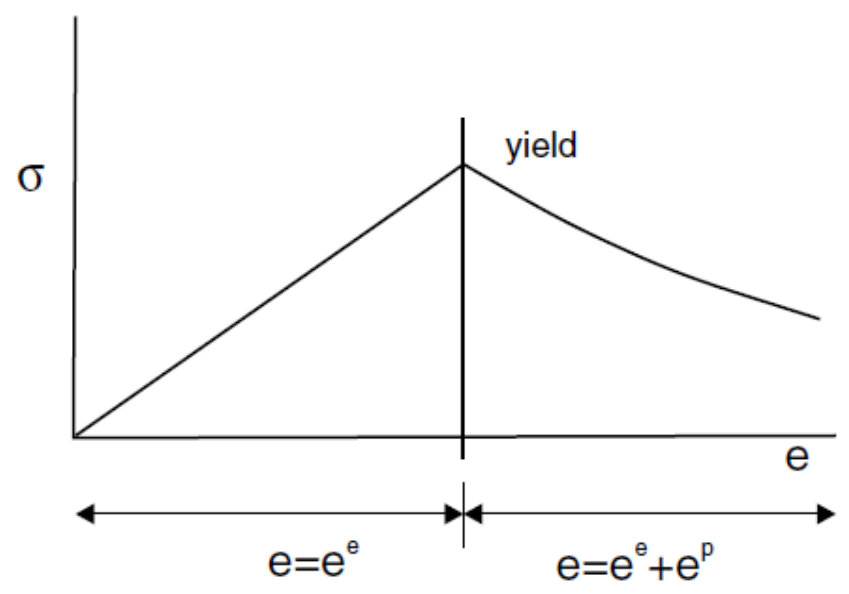

Figure 4-3 The stress-strain curve of strain-softening model in FLAC (Itasca, 2011)

\section{(c) Double-yield model}

The double-yield model represents material with the ability to be in high irreversible compacted state in addiction to shear yielding. The backfill material or cemented granular material is this kind of material. The gob material is strain hardening material, which means the modulus of the deformation increases with increasing compaction. This strainhardening property can be simulated by the double yielding model in FLAC (Pappas and Mark, 1993). 
The double yielding model takes the permanent volume changes due to isotropic pressure into consideration by "cap pressure," in addition to the shear and tensile failure envelopes in the strain-softening model. The hardening behavior of the double yielding model is activated by volumetric plastic strain following a piecewise-linear defined table. Any laboratory-determined hardening behavior may be modeled by the double yielding model.

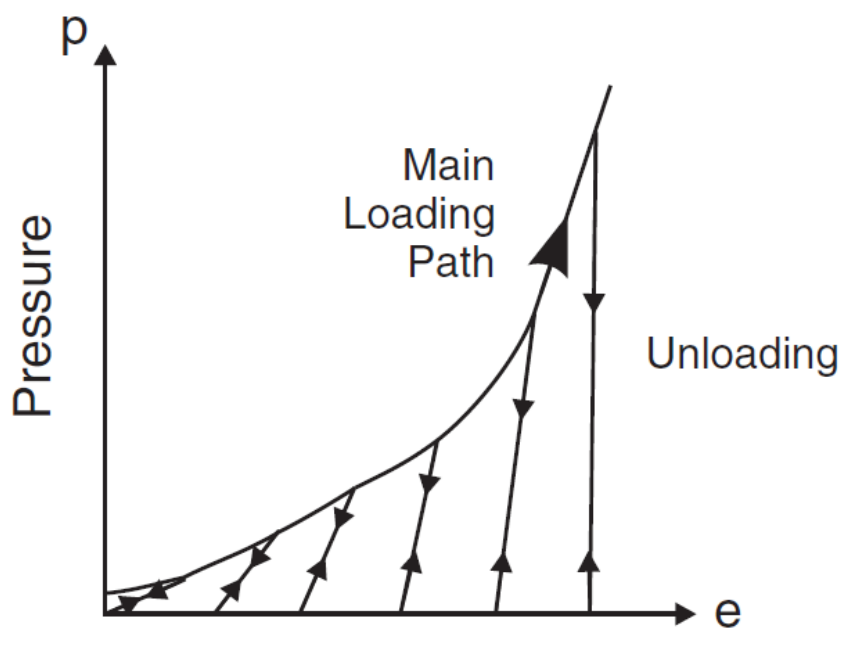

- Volumetric Strain

Figure 4-4 The relation between pressure and volumetric strain of double yielding model in FLAC (Itasca, 2011)

\subsubsection{Define the boundary condition}

As mentioned in Section 4.1.1(b), the geostatic state is modeled as a hydrostatic state in this model. The overburden pressure is caused by gravity within the defined strata. The left and right side of the model will be fixed in $\mathrm{X}$ direction ( $\mathrm{Y}$ direction is free). The bottom of the model is fixed in $\mathrm{Y}$ direction ( $\mathrm{X}$ direction is free). 


\subsection{Development of strain-softening coal material}

In this model, the strain-softening material is used to simulate the real behavior of coal pillars in bleeder entries. This property will be representative of full-scale coal pillars even under excessive loads. The determination of the strain-softening parameters is based on the tested pillars subjected to increasing loads while monitoring their stress-strain response. The response of tested pillars will also be compared to lab-tested data for the standard coal specimens.

Based on the previous studies (Su \& Hasenfus, 1999), the confirmation of empirical formulas results is up to $\mathrm{w} / \mathrm{h}$ ratio of 4 . Thus, four width-to-height ratios of pillars are tested and the peak strength of each pillar is obtained. Then Bieniawski's empirical pillar strength equation was used to compare the peak strength of the tested pillars in the model. The large scale coal strength used in Bieniawski's equation was set as the typical coal strength in U.S. coal mines, 900 psi.

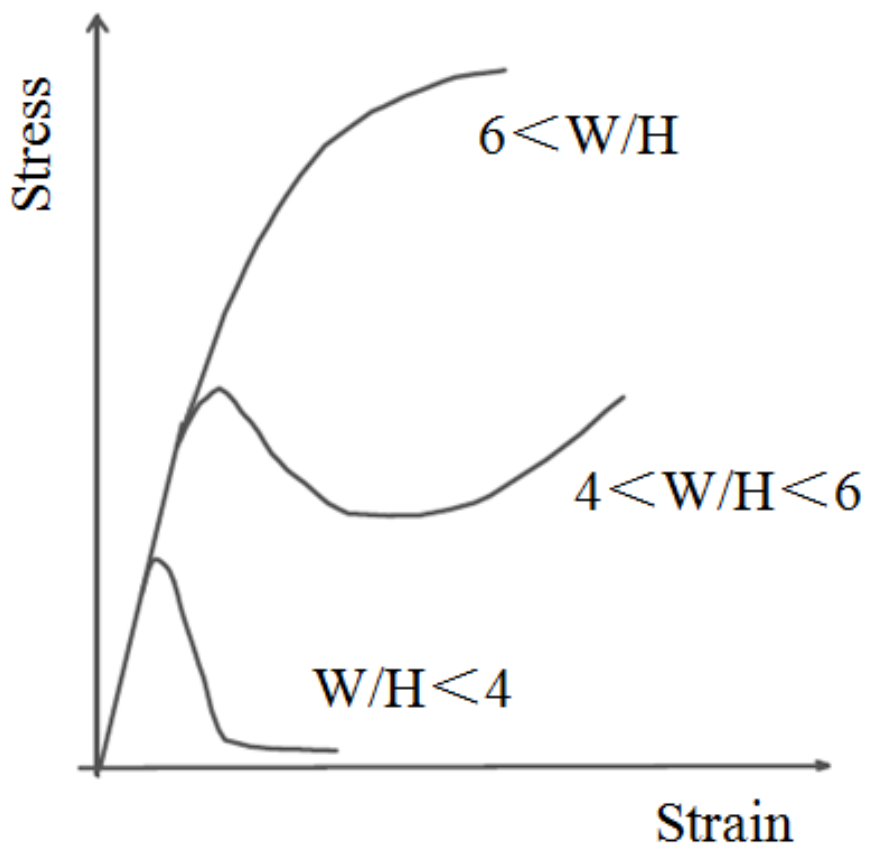

Figure 4-5 Typical stress-strain curves for coal under different width-to-height ratios

The test procedure in FLAC for different $\mathrm{W} / \mathrm{H}$ ratio of pillar is shown in Figure 4-5. The pillars are loaded by gradual compression from the top surface of the model in vertical 
direction. The rate of compression is controlled by velocity. As stress in the model increases, deformation and failure of tested pillar is monitored and recorded. The coal pillars of the model are tested up to limited working steps so the post failure behavior of pillars is clearly shown. Pillar behavior is monitored by FISH functions; the average of vertical stress at the middle of the pillar is calculated, which can be presented as the stress of the whole pillar. Pillar strain is obtained by averaging the displacement values between the top and bottom of the pillar, dividing the original length.

Table 4-2 The relation between strain and cohesion

\begin{tabular}{|c|c|}
\hline Strain & Cohesion $\left(\mathrm{lb} / \mathrm{ft}^{2}\right)$ \\
\hline 0 & 34000 \\
\hline 0.006 & 20000 \\
\hline 0.010 & 10000 \\
\hline 0.100 & 2700 \\
\hline 0.500 & 2700 \\
\hline
\end{tabular}

For the strain-softening model, the post-failure behavior is defined in the following way; the cohesion, friction angle, and dilation angle are piecewise-linear functions of plastic shear strain. The piecewise-linear relation is defined in the form of tables in command. Each table contains pairs of values: one for the parameter and one for the corresponding property value. In this case, the cohesion decreases from its peak value to the residual value of $8 \%$ of peak strength, shown in Table $4-2$, and the other two parameters remain original values. The tensile strength remains constant during the whole process. The dilation angle is zero in this modeling. In order to obtain reasonable input parameters for strain-softening coal, investigations were conducted and the published strain-softening coal parameters are shown in Table 4-3.

All these data in Table 4-3 are tested by trial and error to obtain reasonable input values with peak strength of tested pillar, which should be in satisfactory agreement with the empirical equation. Finally, the reasonable input parameters are obtained (Table 4-3) and the comparison of FLAC results and the empirical equation are shown in Figure 4-6. It is 
obvious that FLAC results range from the result of Bieniawski's equation to that of Salamon's formula, and these three results show similar patterns in which peak strength increases with increasing width-to-height ratio. This also demonstrates that the pillar with higher width-to-height ratio will obtain higher bearing capacity. The stress-strain curves for the tested pillars are shown in Figure 4-7.

Table 4-3 The mechanical properties of strain-softening coal

\begin{tabular}{|l|c|c|c|c|c|}
\hline & $\begin{array}{c}\text { Case 1 \& 2 } \\
(\mathrm{Essi}, 2011 ; \\
\mathrm{Li}, 2004)\end{array}$ & $\begin{array}{c}\text { Case 3 } \\
(\mathrm{Badr}, 2003)\end{array}$ & $\begin{array}{c}\text { Case 4 } \\
(\text { Mahadi, } \\
2012)\end{array}$ & $\begin{array}{c}\text { Case 5 } \\
\text { Esterhuizen, } \\
2005)\end{array}$ & $\begin{array}{c}\text { Model in this } \\
\text { thesis }\end{array}$ \\
\hline Density (slugs $\left./ \mathrm{ft}^{3}\right)$ & 2.55 & -- & 2.55 & 2.91 & $\mathbf{2 . 5 5}$ \\
\hline Shear modulus $\left(\mathrm{lbf} / \mathrm{ft}^{2}\right)$ & $1.93 \mathrm{E}+07$ & $1.99 \mathrm{E}+07$ & $2.51 \mathrm{E}+07$ & $1.34 \mathrm{E}+07$ & $\mathbf{1 . 8 0 E + 0 7}$ \\
\hline Bulk modulus $\left(\mathrm{lbf} / \mathrm{ft}^{2}\right)$ & $5.40 \mathrm{E}+07$ & $4.32 \mathrm{E}+07$ & $4.18 \mathrm{E}+07$ & $2.23 \mathrm{E}+07$ & $\mathbf{4 . 2 0 E}+\mathbf{0 7}$ \\
\hline Young's modulus & -- & $5.18 \mathrm{E}+07$ & $6.27 \mathrm{E}+07$ & $3.34 \mathrm{E}+07$ & $\mathbf{4 . 7 E}+\mathbf{0 7}$ \\
\hline Poison's ration & -- & 0.30 & 0.25 & 0.25 & $\mathbf{0 . 3 1}$ \\
\hline Friction angle $(\mathrm{degree})$ & 35 & 28 & 20 & 30 & $\mathbf{3 5}$ \\
\hline Cohesion $\left(\mathrm{lbf} / \mathrm{ft}^{2}\right)$ & 33840 & 27360 & 10445 & 66848 & $\mathbf{3 4 0 0 0}$ \\
\hline Tensile strength $\left(\mathrm{lbf} / \mathrm{ft}^{2}\right)$ & $3.17 \mathrm{E}+03$ & $2.09 \mathrm{E}+04$ & -- & -- & $\mathbf{2 . 9 0 E + 0 4}$ \\
\hline UCS $\left(1 \mathrm{bf} / \mathrm{ft}^{2}\right)$ & $1.30 \mathrm{E}+05$ & $3.47 \mathrm{E}+05$ & $1.59 \mathrm{E}+05$ & -- & -- \\
\hline
\end{tabular}

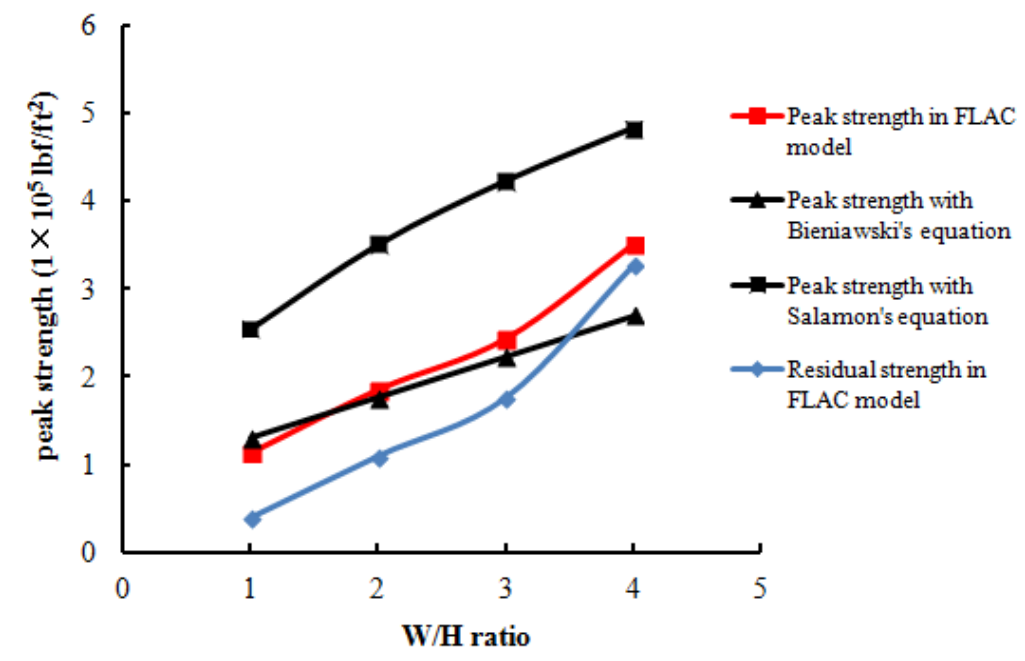

Figure 4-6 Comparison between the peak strength of pillar under various $\mathrm{W} / \mathrm{H}$ ratios with the results obtained by Bieniawski's equation and Salamon's equation 


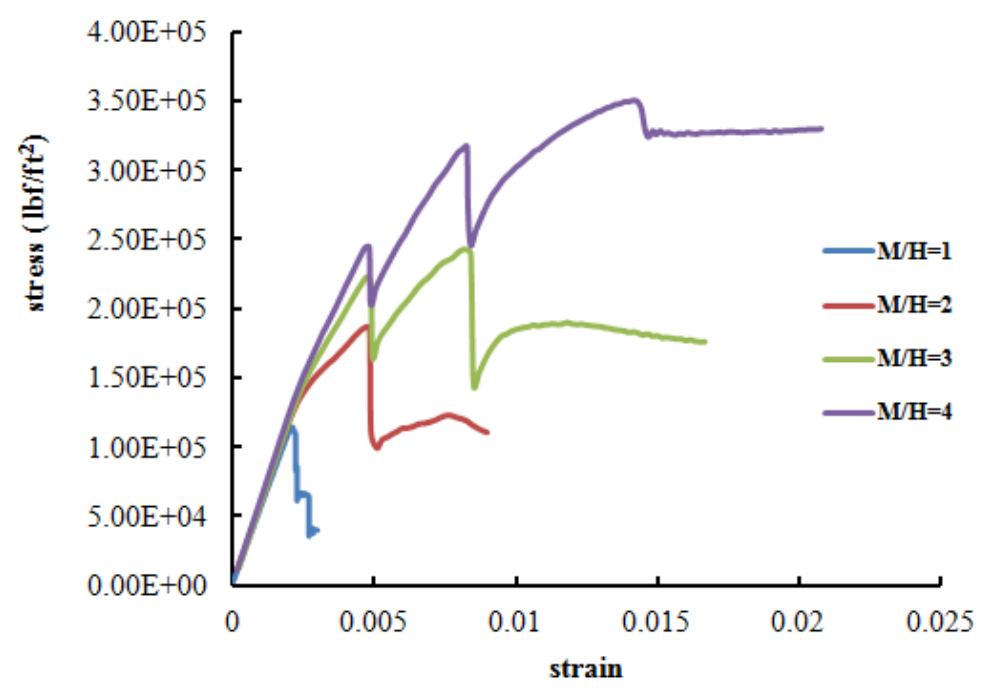

Figure 4-7 The stress-strain curves of pillars modeled by FLAC with various W/H ratios 


\subsection{Modeling gob behavior}

Longwall mining is one of the most widely used underground coal mining methods, valued for its high productivity and safety. During the longwall mining retreat process, the development of gob area and overburden movement determines the loading on the adjacent coal pillar around the gob area. The behavior of the gob is critical to understand the load transferred to the longwall face, pillars, and tailgate sections. When numerical modeling is employed to investigate the stress distribution of the longwall face, the behavior of gob material is very critical, which has great influence on the induced stress around gob area.

To properly model gob behavior in underground coal mines, the first step is to find the best constitutive equation for gob material. Salamon (1966) reported the relationship between porosity and pressure, which is the equivalent function with the mathematical proved relation between bulking factor and pressure (Salamon, 1990). Ryder and Wagner (1978) presented the similar reasonable stress-strain relation, describing the compaction characteristic of backfill materials independently. Terzaghi (Pappas and Mark, 1993) used the theoretical exponential stress-strain relation to describe the compaction process of soil, which can be used for gob material response.

Based on these constitutive relations, many researchers have tried different approaches to model gob behavior. Sandler and Rubin (1979) used the double-yielding model or "cap model" to describe the strain-hardening behavior of gob material. Peng (1980) performed three-dimensional finite element analyses to study gob behavior by isotropic, homogeneous, and elastic property of gob material, and divided the gob area into three zones towards into the gob center: loosely packed zone, packed zone, and well-packed zone. R. Trueman (1989) derived a parabolic stress-strain relation of gob material for longwall coal mining and then implemented this model to investigate the vertical stress development of the gob area. Xie (1999) presented gob material parameters (density, Young's modulus, and Poisson's ratio), varying with time to describe the progressively compressed behavior of the gob area. Morsy and Peng (2002) studied the gob loading mechanism using the Terzaghi's model of gob material based on the ABAQUS finite element code, and found that the result of the model showed the same loading behavior 
with in-situ measurements. H. Yavuz (2003) provided an estimation method for cover pressure reestablishment distance and pressure distribution in the gob of longwall coal mines. Jeromel (2010) analyzed the development of geo-mechanical process in the hanging wall and the footwall during sub-level coal excavation for thickness coal seam mining by FLAC, and confirmed that the caving process is reasonable and reliable by the equation derived by H. Yavuz.

Pappas and Mark (1993) evaluated the behavior of gob material by laboratory compaction tests using caving rock obtained from the mined-out area in underground coal mines. Based on their test results, they found that the nonlinear stress-strain relation was more reasonable to describe the strain-hardening behavior of gob material. Salamon's model was found to better represent the gob stress-strain constitutive relation than Terzaghi's model. Furthermore, Salamon's model was proved in a mathematical way based on the relation between porosity and pressure; each parameter in the model also has physical meaning. Thus, the Salamon's model is currently the most widely used one in gob modeling.

When FLAC is employed to analyze stress distribution during the retreat mining process, the double yielding model is one of the options to model the strain-hardening gob material. Since the double yielding model in FLAC is controlled by two group parameters, material properties and cap pressure, the Salamon's model needs to be converted to double yielding model. However, the final confirmed parameters of gob material in Salamon's model were quite different (S. Badr, 2003; Esterhuizen, 2005; Essie, 2011; Mahdi, 2012; Li, 2014), which makes it difficult to evaluate these published data. Furthermore, the convert approach for Salamon's model to double yielding model is not very clear, and to some extent it is time consuming to obtain reasonable input parameters for the double yielding model in FLAC.

This paper first discusses the physical meaning of each parameter in Salamon's model. Then the effective boundary of the equation is provided under current mining technology in U.S. The obtained boundary of the model is also tested by the published data. Finally, the process to calibrate the double yielding model is recommended. 


\subsubsection{The Ryder and Salamon's equation}

Ryder and Wagner (1978) reported the stress-strain relation to describe the compaction characteristic of backfill material,

$$
\delta=\frac{E_{0} \varepsilon}{1-\frac{\varepsilon}{\varepsilon_{m}}}
$$

where $\delta$ is vertical stress, $\varepsilon$ is vertical strain, $\mathrm{E}_{0}$ is the initial tangent modulus and $\varepsilon_{m}$ is the maximum possible strain. Salamon (1990) proved this equation mathematically and showed the maximum possible strain is $\varepsilon_{m}=\frac{b-1}{b}, \mathrm{~b}$ is the bulking factor. But Salamon did not show how to obtain the initial tangent modulus $\mathrm{E}_{0}$, which plays a significant role in determining the stress-strain behavior of gob material. In the following paragraphs, the determination of parameters in equation (1) is discussed.

Initial tangent modulus estimation. Pappas and Mark (1993) conducted twenty uniaxial compression tests to determine the material properties of the gob in a laboratory scale. They found that the modulus of gob material was the only function of vertical stress during the compaction test for gob material; this is seen in the approximately linear second modulus-stress relation and the second-order polynomial tangent modulus-stress relation. Even though this relation is reasonable and fits the data well, the gob modulus should be affected by another parameter, the bulking factor of gob material; the stiffness of gob material should be higher for strong rocks than for weak rocks. From this point of view, H. Yavuz (2003) built a new function to calculate the initial tangent modulus, taking both compressive strength of rock piece and bulking factor into consideration, according to the published data by Pappas and Mark(1993),

$$
E_{0}=\frac{10.39 \delta_{c}^{1.042}}{b^{7.7}}
$$

where $\delta_{c}$-compressive strength of rock pieces, psi, $\mathrm{E}_{0}$-initial gob modulus, psi, b-bulking factor. This relation clearly shows that the initial tangent modulus, $\mathrm{E}_{0}$, depends largely on 
the bulking factor and strength of rock fragments. The bulking factor of the stronger and harder rocks will be smaller because they will result in larger fragments; conversely, the weaker and softer rocks will result in smaller fragments and consequently a larger bulking factor (H. Yavuz, 2003). This relation shows the property of strain-hardening gob material; the material will be stiffer and the modulus will increase when the load is increased. However, $\mathrm{Su}$ (2013) reported that there is no relation between bulking factor and rock strength, but they did find that the bulking factor increased with the increase of particle size by the logarithmic relation. The bulking factor of rock varies with rock type, shape, and size of the caved rock fragments, and the way in which the caved rock fragments are piled up (Peng, 2007).

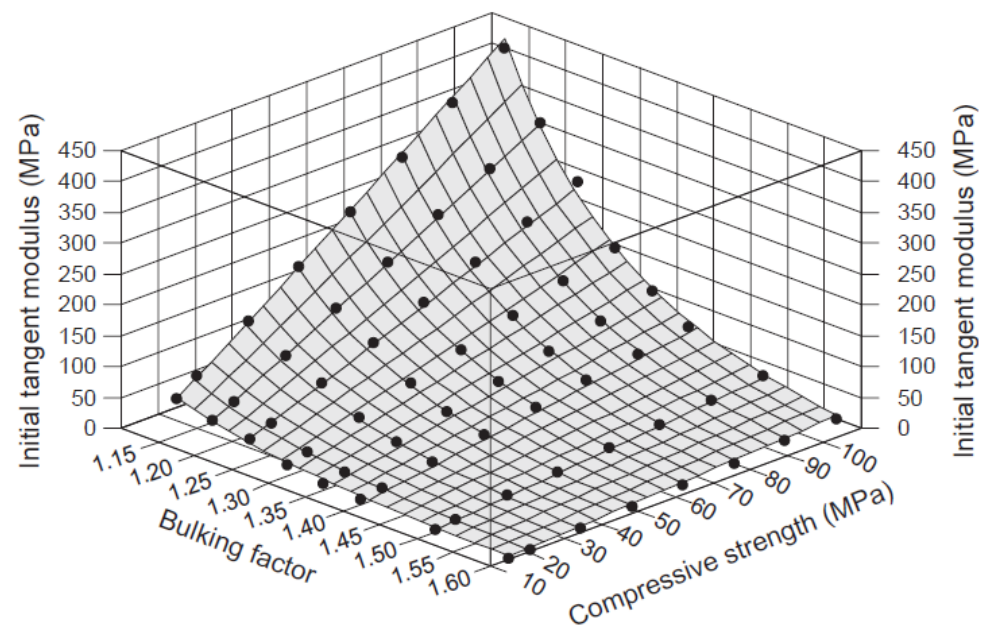

Figure 4-8 Variation of initial tangent modulus with rock strength and bulking factor $(\mathrm{H}$. Yavuz, 2003)

Bulking factor estimation in practice. In mining practice, the bulking factor can be obtained by the equation,

$$
b=\frac{h_{c a v}+H}{h_{c a v}}
$$

where, $\mathrm{h}_{\mathrm{cav}}$ is the height of caving zone (the immediate roof), and $\mathrm{H}$ is the mining height. To confirm the range of bulking factor, published data were intensively investigated and the minimum is 1.1 and the maximum is 1.8 (Table 4-4). Generally, the bulking factor estimated in mining practice is within this range from 1.1 to 1.8 . 
Table 4-4 Bulking factor of broken rock

\begin{tabular}{|l|l|l|l|l|}
\hline \multicolumn{1}{|c|}{ Case } & \multicolumn{1}{|c|}{$\begin{array}{c}\text { Peng } \\
\mathbf{( 1 9 8 0 a )}\end{array}$} & $\begin{array}{c}\text { Khair } \\
\mathbf{( 1 9 8 7 a )}\end{array}$ & $\begin{array}{c}\text { Listak } \\
\mathbf{( 1 9 8 6 )}\end{array}$ & Qian (2010) \\
\hline & & & & $\begin{array}{l}\text { Clay: }<1.2 \\
\text { Crushed coal: }<1.2 \\
\text { Bulking } \\
\text { factor }\end{array}$ \\
& $1.25-1.3$ & $\mathbf{1 . 1}-.1 .16$ & $1.23-1.72$ & $\begin{array}{l}\text { Clay shale: } 1.4 \\
\text { Sandy shale: } 1.6-1.8 \\
\text { Sandstone: } 1.5-1.8\end{array}$ \\
\hline & Shale roof; & field data & field data & ----- \\
\hline
\end{tabular}

\subsubsection{Discussion on the confidential interval of Salamon's equation}

Since the theoretical constitutive relation for the compaction process of gob material was obtained, the next step is to obtain the reasonable intervals of each parameter, show the effective boundary of the equation, and confirm the situations in which it can be properly employed.

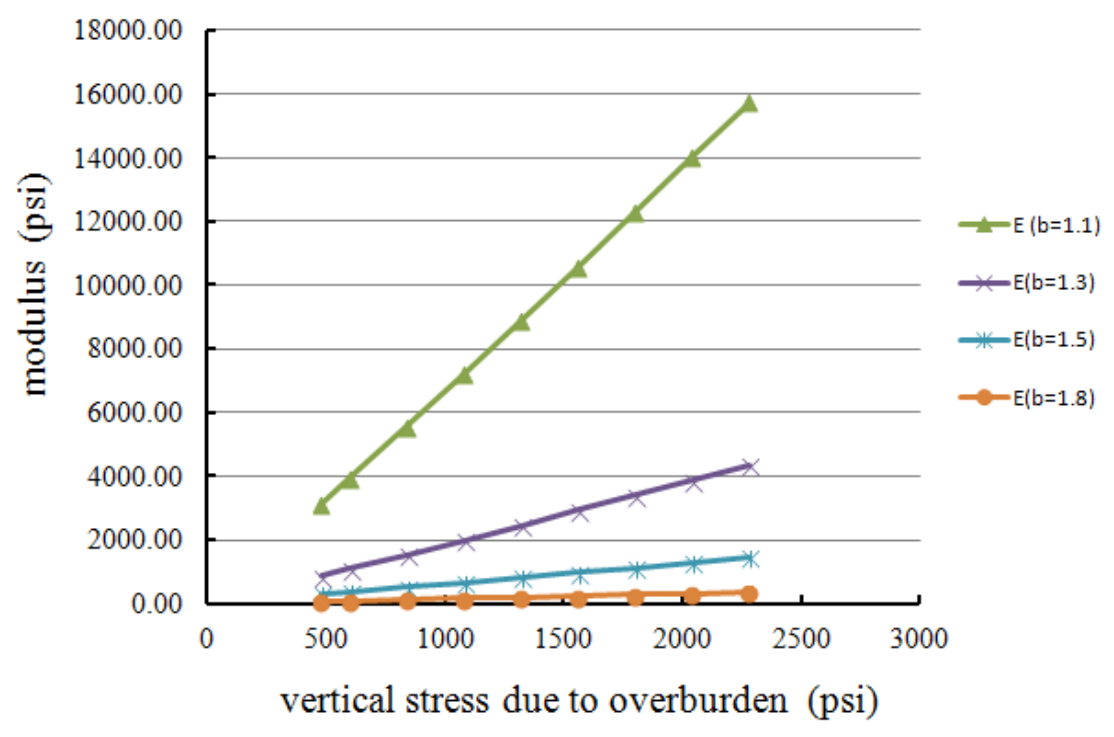

Figure 4-9 The relation between initial tangent modulus and vertical stress for different bulking factor (b) 
In order to confirm the initial tangent modulus $\left(\mathrm{E}_{0}\right)$ of equation (2), the vertical stress due to overburden is estimated by,

$$
\delta_{V}=1.2 h
$$

where $\delta_{V}$ is vertical stress due to overburden, psi and h is overburden cover, in $\mathrm{ft}$. Under current mining technology, most underground coal mine are deeper than 400 feet, and some mines reach depths beyond $1900 \mathrm{ft}$ in the U.S. Thus the relation between gob modulus and stress was investigated when vertical stress ranges from 480 psi to 2280 psi.

Table 4-5 Reasonable coefficient for Ryder and Salamon's equation

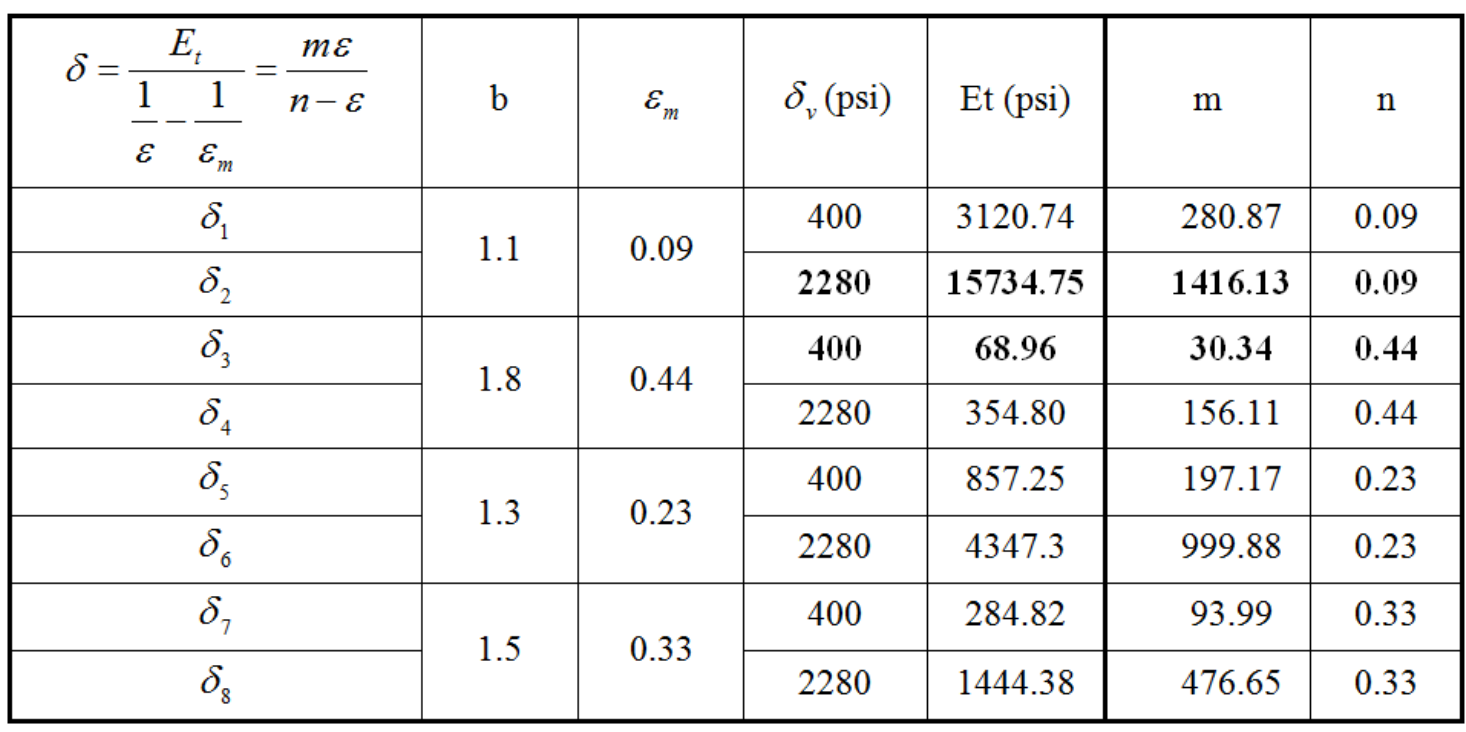

Based on the equation of initial tangent modulus and the range of gob material bulking factor, the boundary condition of Salamon's equation can be estimated. The ranges of each parameter in equation (1) are listed (Table 4-5). Based on these obtained values, the confidence interval of Salamon's equation is obtained (Figure 4-10). The confidence interval is actually the boundary condition of Salamon's model, which means the parameters within the confidence interval are effective and reliable. This also implies that when Salamon's equation is applied for the calibration of gob material, the bulking factor should vary between 1.1 and 1.8 and the initial tangent modulus should range from 68.96 psi to 15734.75 psi (Figure 4-9). The obtained Salamon's curve should be within the area between curve $\delta_{2}$ and curve $\delta_{3}$; the other six curves included are in this range. It should 
be pointed out that the stress-strain relation is dependent on two parameters ( $\varepsilon_{m}$ and $\mathrm{b}$, or $\mathrm{m}$ and $\mathrm{n}$ ), which means the two parameters have numerically innumerable combinations mathematically. Even though one or two of the parameters may beyond the ranges in practice, the final curve of Salamon's model must within the confidence interval or effective boundary.

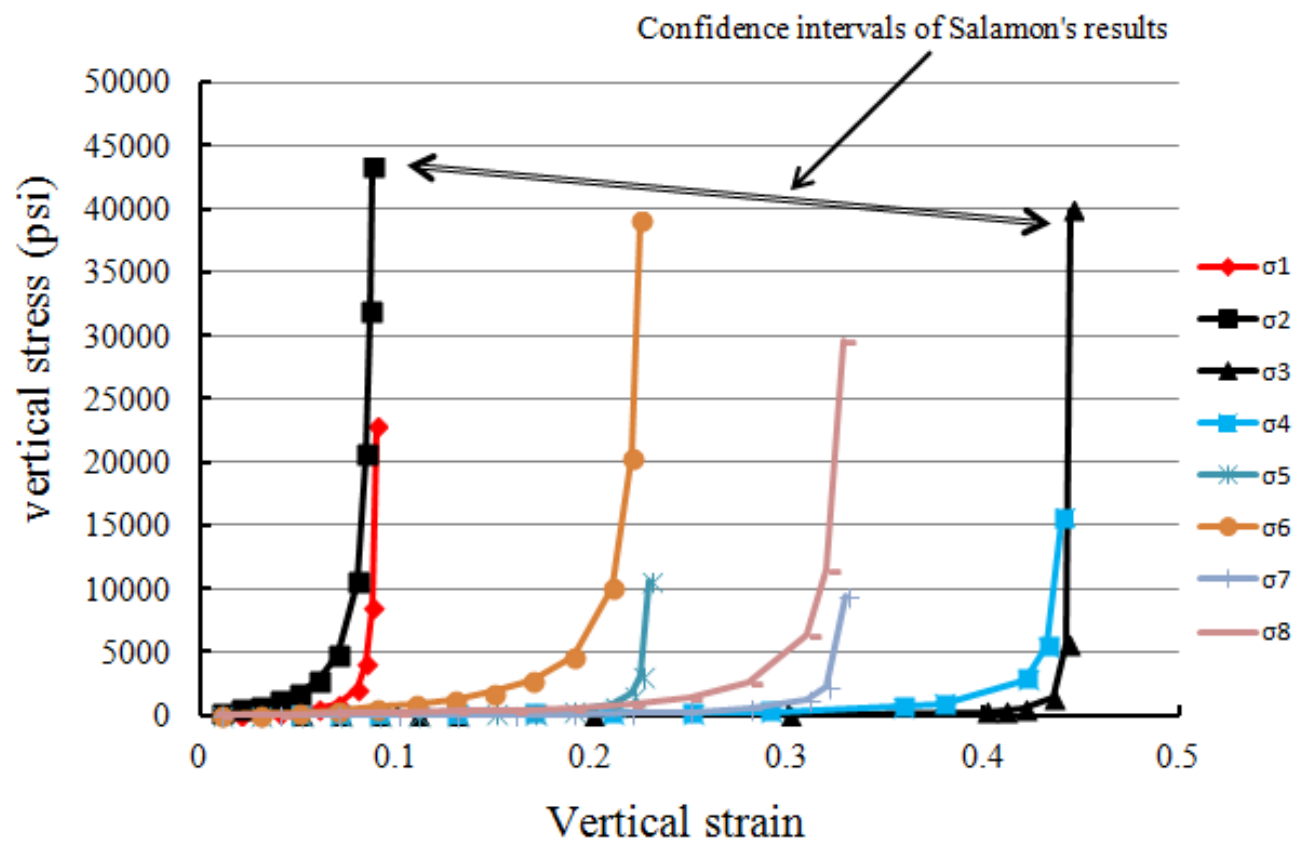

Figure 4-10 The confidence interval or boundary of Salamon's equation

\subsubsection{Confirmation of the confidence interval of Salamon's equation}

For the calibration process of the double yielding model in FLAC, two steps should be applied, as shown in Figure 4-11. The first step is theoretical calibration; the Salamon's equation or laboratory compaction tests will be used to determine input parameters of double yielding material in FLAC. The next step is field calibration, which means field monitoring data such as subsidence profile data or the distribution of vertical stress in the gob area will be used to test whether the outputs of the model are reasonable. If the double yielding models satisfy both two steps, the outputs of double yielding model should be reasonable and reliable. 


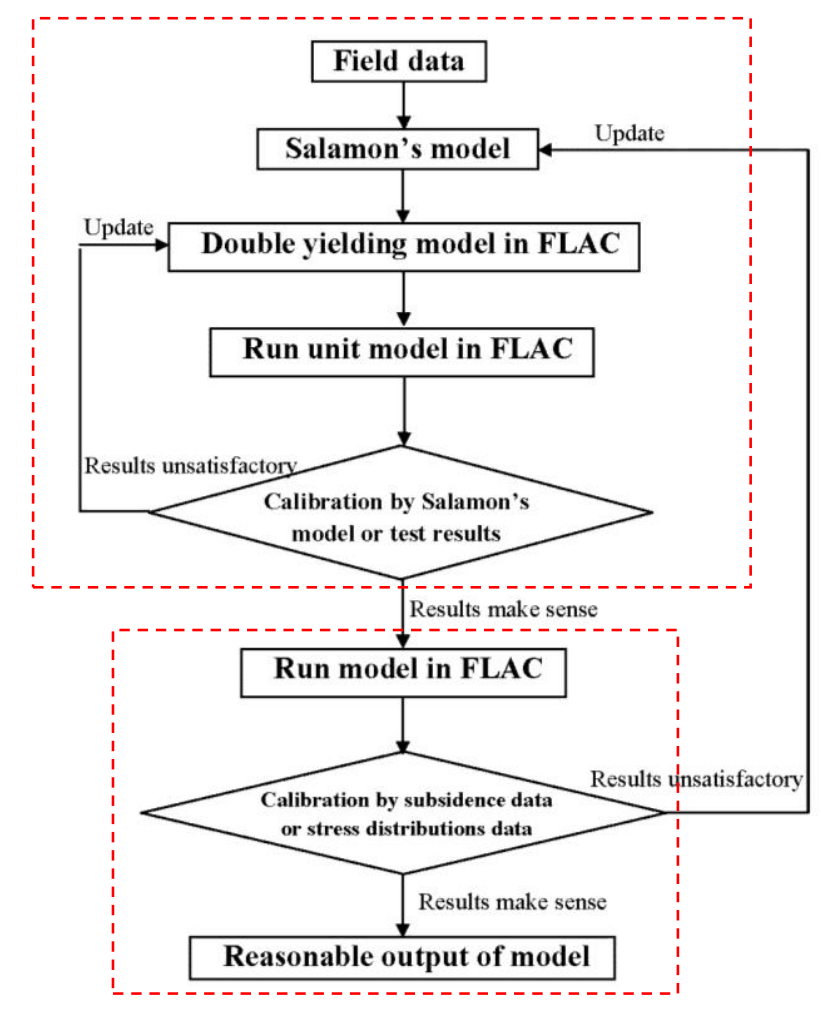

Figure 4-11 The calibration process of double yielding model in FLAC

In order to test whether the theoretical boundary of Salamon's equation is reasonable, the gob behavior modeled by double yielding model in FLAC were investigated intensively, using five cases (Table 4-6). In the first case, the authors showed a very clear and logical way to do numerical modeling by FLAC code. For gob calibration, the author employed two steps to calibrate the double yielding model and showed four kinds of double yielding material depending on the type of rock. For the second and fifth cases, the author also implied two steps to calibrate the double yielding model; Salamon's calibration and gob stress distribution calibration. In the third and fourth cases, the authors showed gob stress distribution during the mining process to reconfirm the gob behavior modeled by the double yielding model.

It is obvious that most of the calibration results are within the confidence interval of Salamon's equation except case-3 (Figure 4-12). The reason why case-3 is so different is that geological condition, panel plan, and pillar state are totally different. The final input parameters of the double yielding model contain both the theoretical and field calibration 
process case by case. These calibrated results are compatible with the theoretical boundary, which also means that the theoretical boundary of Salamon's model is reasonable.

Table 4-6 Five cases for calibrated double yielding model by FLAC

\begin{tabular}{|c|c|c|c|}
\hline \multirow{2}{*}{ Calibration process } & \multicolumn{2}{|c|}{ First Step } & \multirow{2}{*}{ Second step } \\
\hline & m or $\left(\varepsilon_{m} b\right)(\mathbf{p s i})$ & n or b & \\
\hline \multirow{4}{*}{ Case 1 (Essie,2011) } & 855.5 & 0.44 & \multirow{4}{*}{ Subsidence data } \\
\hline & 1247.0 & 0.44 & \\
\hline & 1856.0 & 0.44 & \\
\hline & 3654.0 & 0.44 & \\
\hline Case $2(\mathrm{Li}, 2014)$ & 3150.85 & 0.17 & Gob stress distribution \\
\hline Case 3 (S. Badr, 2003) & 507.5 & 0.5 & Gob stress distribution \\
\hline Case 4 (Mahadi S., 2012) & 3480 & 0.3 & Subsidence data \\
\hline Case 5 (Esterhuizen, 2005) & \multicolumn{2}{|c|}{ calibrated by laboratory tests } & / \\
\hline
\end{tabular}

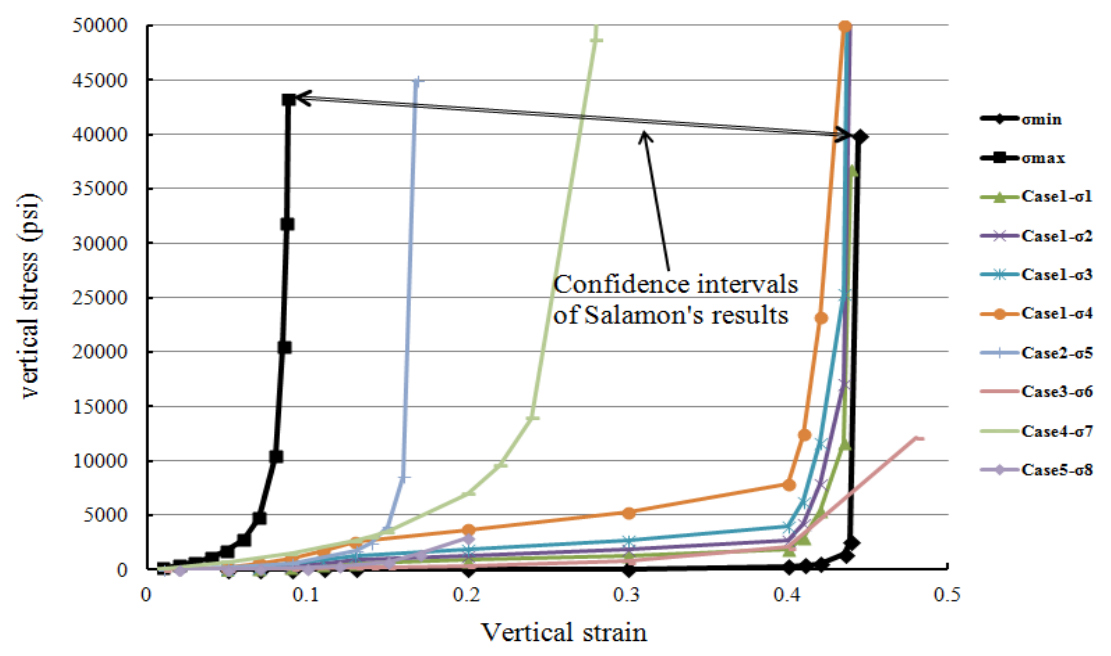

Figure 4-12 The conformation process of double yielding model in FLAC

\subsubsection{Case study}

The coal mine is located in the Upper Freeport coal seam area. The overburden of the coal seam is $1046 \mathrm{ft}$. The immediate roof is $3.28 \mathrm{ft}$ of gray clayshale and the immediate 
floor is also $3.28 \mathrm{ft}$ of gray clayshale. The $62.32 \mathrm{ft}$ thick rock layer (including 52.48 thick sandstone rock, $6.56 \mathrm{ft}$ thick siltshale and $3.28 \mathrm{ft}$ thick immediate roof layer) lying above the coal seam is assumed to be the height of caving in the gob area.

The first step is to obtain the maximum strain value,

$$
\begin{gathered}
b=\frac{h_{c a v}+H}{h_{c a v}}=\frac{62.34+6.56}{62.34}=1.11 \\
\varepsilon_{m}=\frac{b-1}{b}=\frac{1.11-1}{1.11}=0.099
\end{gathered}
$$

The next step is to obtain the vertical stress,

$$
\delta_{V}=1.2 h=1.2 \times 1046.32=1255.58 p s i
$$

So the initial tangent modulus can be obtained,

$$
E_{0}=\frac{10.39 \delta_{v}^{1.042}}{b^{7.7}}=7881.81 p s i
$$

The constitutive model for gob material will be obtained by Salamon's model,

$$
\delta=\frac{7881.81 \times \varepsilon}{1-\frac{\varepsilon}{0.099}}
$$

Since the Salamon's model is obtained, the next step is to convert Salamon's model to double yielding model in FLAC. The trial and error technique is used to match the stressstrain relation of Salamon's model to that of the double yielding model.

Table 4-7 Physical-mechanical parameter of double yielding model in FLAC

\begin{tabular}{|l|c|c|c|c|c|}
\hline Property & $\begin{array}{c}\text { Density } \\
(\mathrm{lb} / \mathrm{ft} 3)\end{array}$ & $\begin{array}{c}\text { Shear Modulus } \\
(\mathrm{psi})\end{array}$ & $\begin{array}{c}\text { Bulk Modulus } \\
(\mathrm{psi})\end{array}$ & $\begin{array}{c}\text { Friction angle } \\
(\mathrm{deg} .)\end{array}$ & $\begin{array}{c}\text { Dilation angle } \\
(\mathrm{deg} .)\end{array}$ \\
\hline Value & 100 & $5.25+\mathrm{E} 5$ & $3.15+\mathrm{E} 5$ & 40 & 5 \\
\hline
\end{tabular}

The converted stress-strain behavior of the double yielding model for the gob material is tested by $1 \mathrm{ft}$ cubic model in FLAC. The unit gob model is loaded by gradual compression from the top surface of the model in vertical direction. The rate of compression is controlled by velocity. As the stress in the model increases, deformation of the tested pillar is monitored and recorded. The pillar behavior is monitored by FISH 
functions; the average of vertical stress at the middle of the pillar is calculated, which can be presented as the stress of the whole model. The pillar strain is obtained by averaging the displacement values between the top and bottom of the pillar, dividing the original length.

Model results are shown in Figure 4-13. It is obvious that modeling result fits the Salamon's model very well, which is within the confirmed confidential interval of the Salamon's model in the previous section. So the converted double yielding model is valid and can be used in the numerical model to model the gob behavior in underground coal mines.

Table 4-8 Relation between plastic volumetric strain and cap pressure of double yielding model in FLAC

\begin{tabular}{|c|c|}
\hline $\begin{array}{c}\text { Plastic Volumetric } \\
\text { Strain }\end{array}$ & Cap pressure (psi) \\
\hline 0.01 & $8.77 \mathrm{E}+01$ \\
\hline 0.02 & $1.98 \mathrm{E}+02$ \\
\hline 0.03 & $3.39 \mathrm{E}+02$ \\
\hline 0.04 & $5.29 \mathrm{E}+02$ \\
\hline 0.05 & $7.96 \mathrm{E}+02$ \\
\hline 0.06 & $1.20 \mathrm{E}+03$ \\
\hline 0.07 & $1.88 \mathrm{E}+03$ \\
\hline 0.08 & $3.29 \mathrm{E}+03$ \\
\hline
\end{tabular}

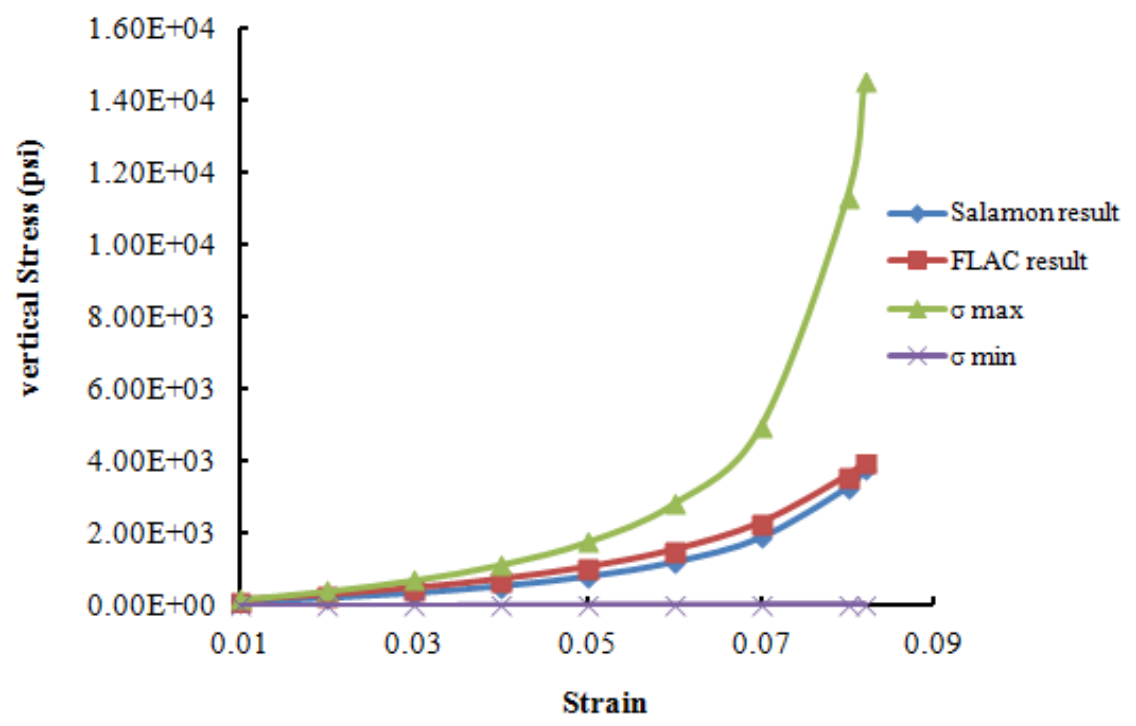

Figure 4-13 Comparison between model results and Salamon's model for gob material 


\subsection{Roof deformation analysis in bleeder entries}

\subsubsection{Model development}

In Chapter 3, the stability of bleeder pillars is evaluated, and it is clear that the bleeder pillar of $60 \times 40 \mathrm{ft}$ remains stable during the retreat mining stage when the overburden ranges from $500 \mathrm{ft}$ to $1500 \mathrm{ft}$. However, because of the limitation of the LaModel program, the roof deformation of the bleeder entry cannot be monitored. Thus the FLAC model is used to study the roof deformation during the retreat mining process. Based on the input parameters obtained from Sections 4.1 and 4.4, the model is created with the strain-softening coal material and double-yielding gob material. In this section, the roof and floor displacement analysis of bleeder entries will be further studied.

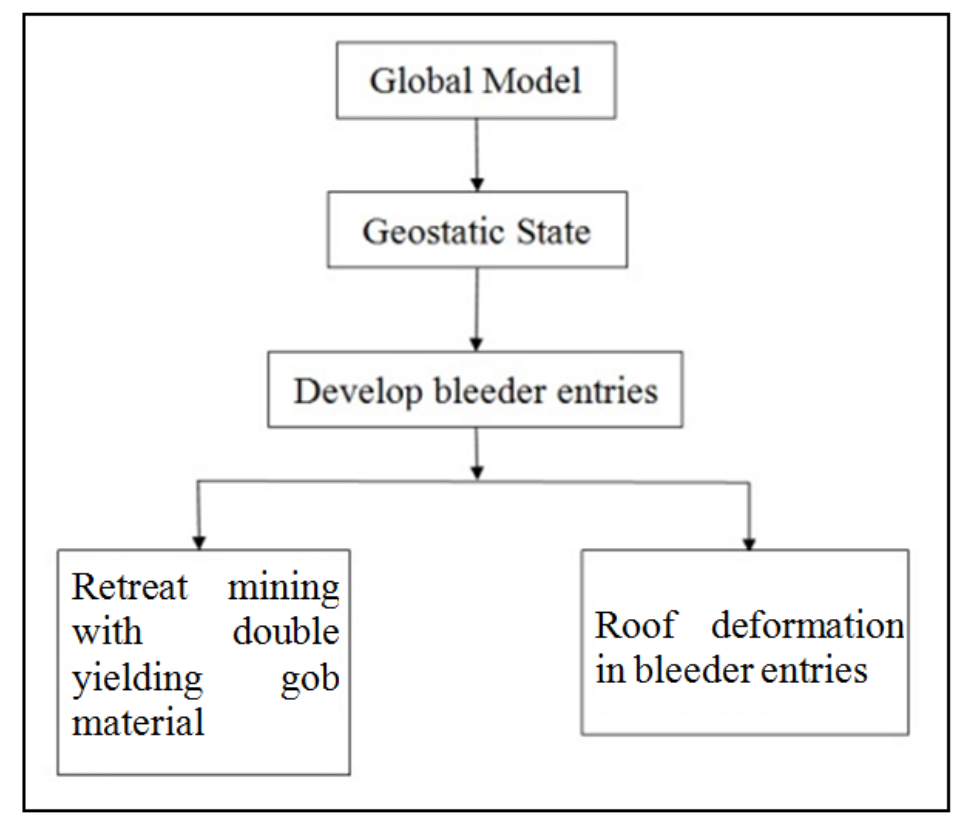

Figure 4-14 Modeling procedures

The model follows three steps (Figure 4-14), which is similar to longwall mining practice. In the first step, the global model will be generated based on the simplified geological condition and representative physico-mechanical properties of the overburden rock strata. The horizontal sides of model are fixed only in X direction and the bottom side is fixed in both $\mathrm{X}$ and $\mathrm{Y}$ directions. In the second step, the geostatic state is obtained, simulating the stress state of the virgin coal seam without mining disturbance. Next, three bleeder entries and set-up room are developed. In the last step, the retreat longwall process is 
modeled by ten mining steps (Figure 4-15); the longwall face is advanced by $16.4 \mathrm{ft}$ in each step. During the retreat mining process, the displacement of roof and floor will be monitored; the monitor points are shown in Figure 4-16.

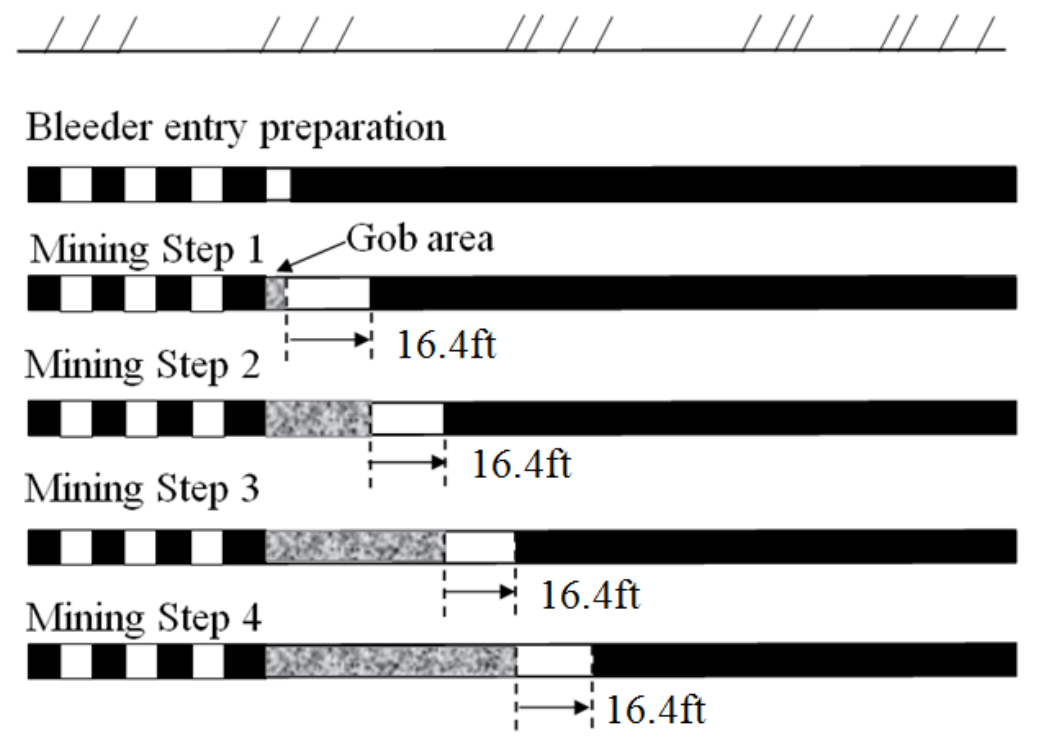

Figure 4-15 First four steps in mining scenario two
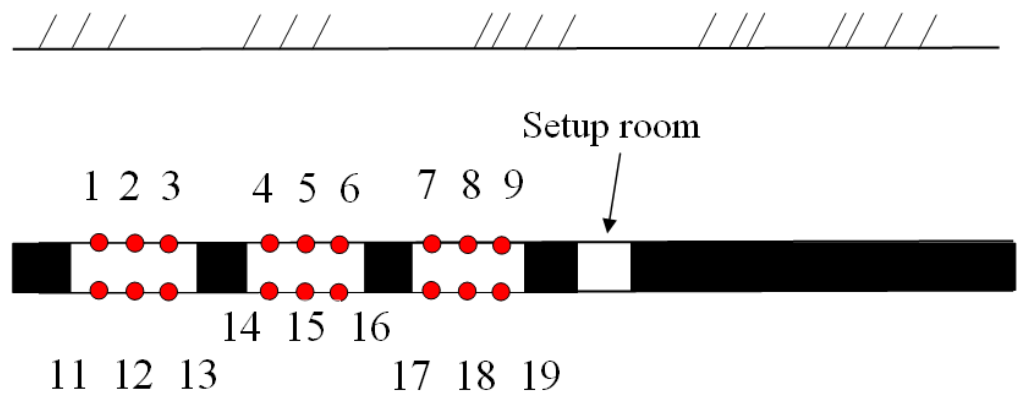

Figure 4-16 Displacement monitoring point of bleeder roof during retreat mining process

\subsubsection{Modeling steps}

According to the modeling procedure, the model is first generated (Figure 4-18) and then run to initial equilibrium state, also called geostatic state (Figure 4-19). Then the bleeder entries and setup room are excavated and the coal seam is modeled by strain-softening material. This is done instantly and the model is subsequently run to equilibrium state (Figure 4-20). Finally, the excavation process begins by simulating longwall mining in practice (Figure 4-21). The caving area or gob behavior is simulated by double-yielding 
gob materials. The displacements of these monitoring points (Figure 4-17) are measured and recorded to evaluate the roof deformation during mining process.

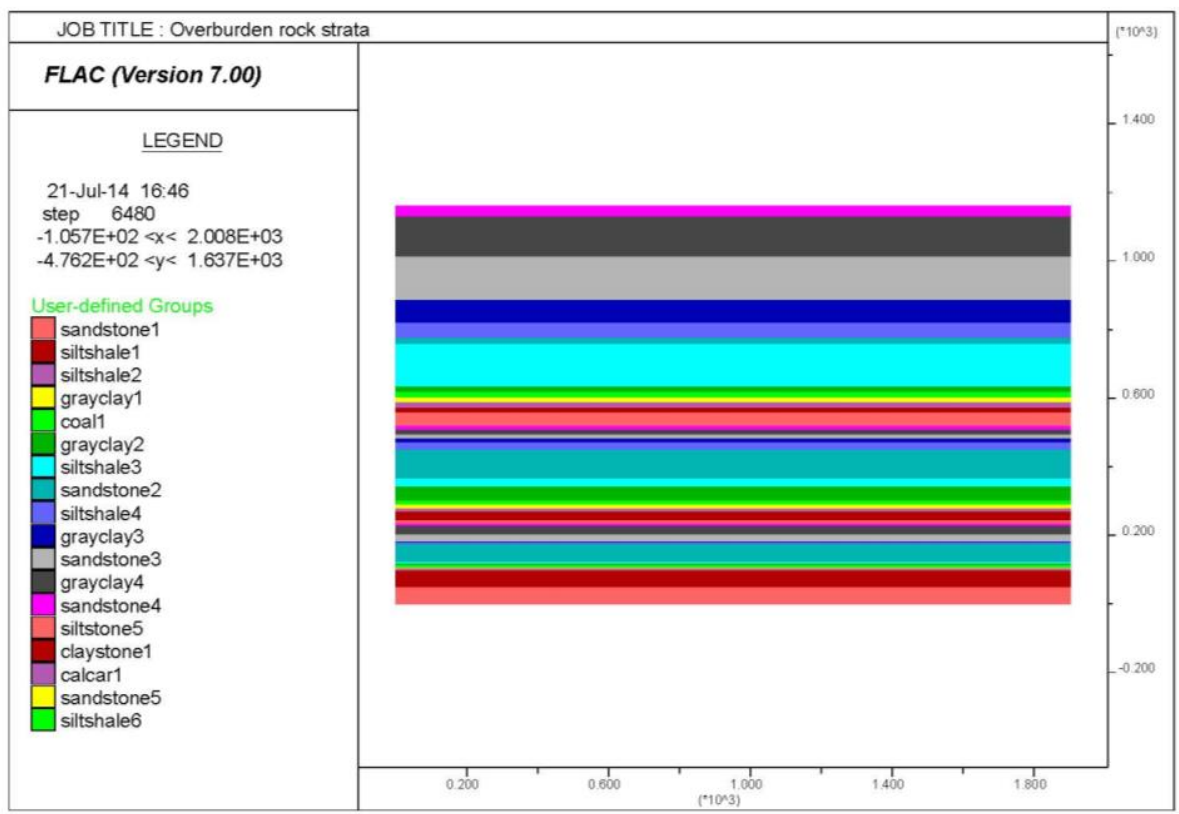

Figure 4-17 The physico-mechanical properties of the overburden rock strata

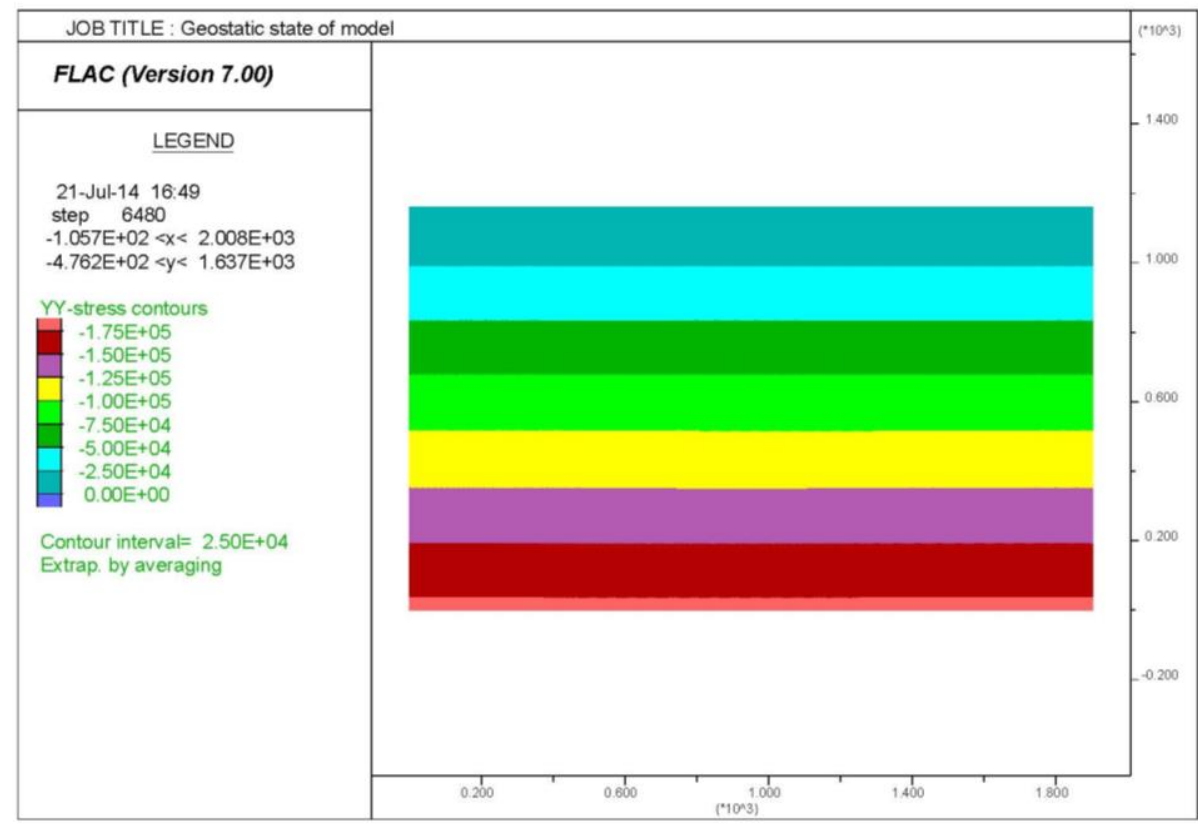

Figure 4-18 The geostatic state of model-YY stress contour 


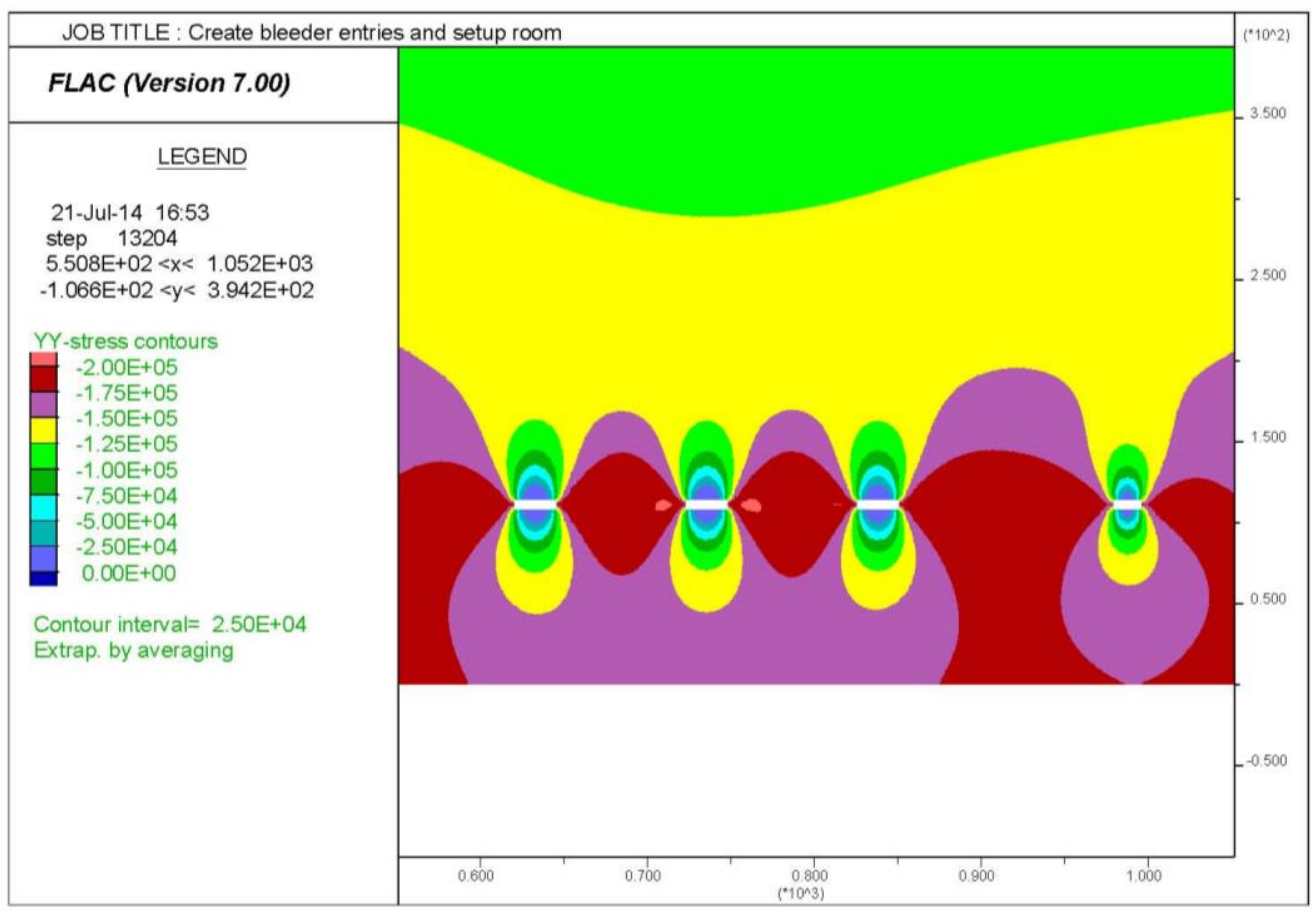

Figure 4-19 The YY stress contour after creating bleeder entries and setup room

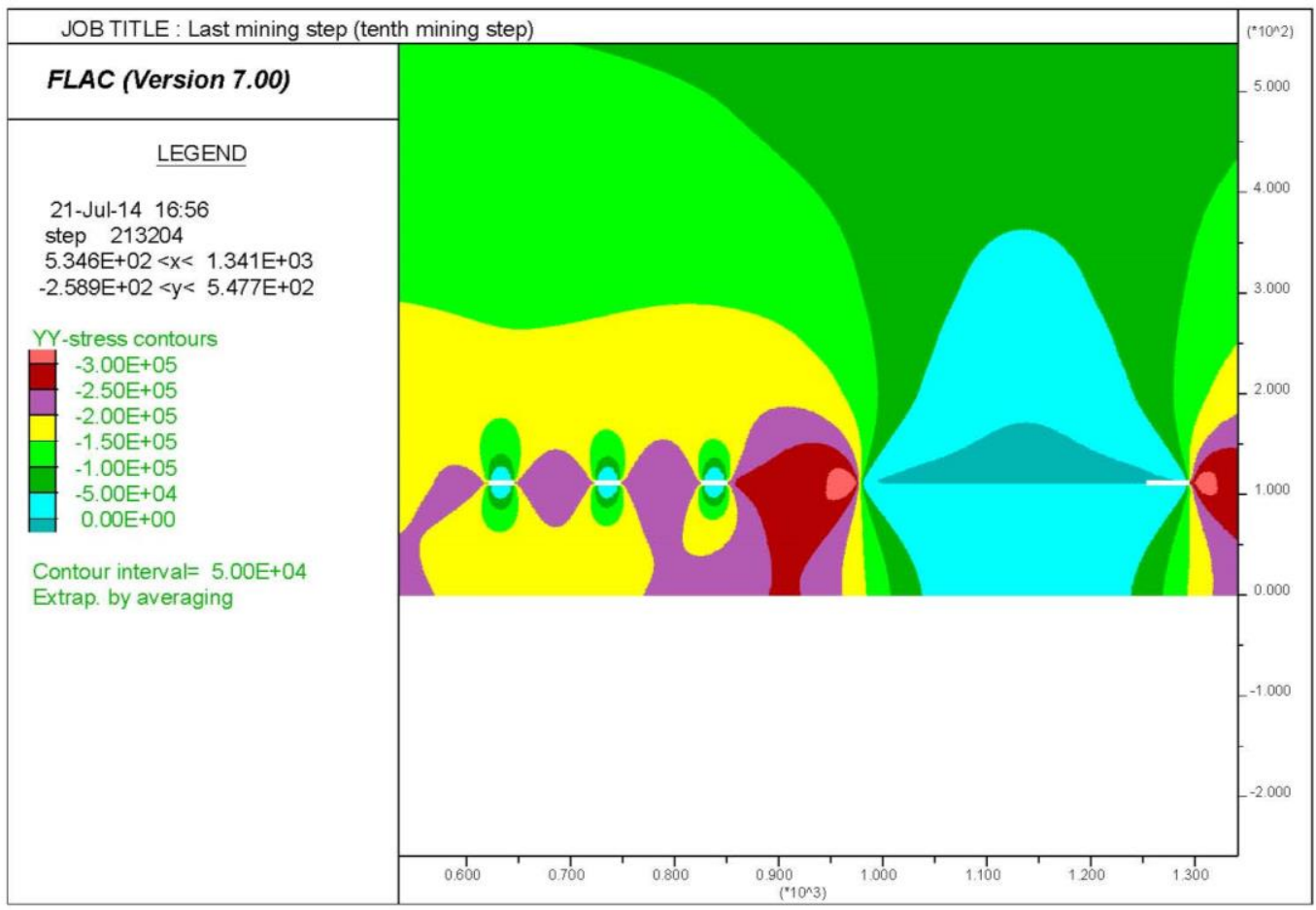

Figure 4-20 The YY stress contour in tenth mining steps 


\subsubsection{Roof and floor displacement analysis of bleeder entries}

In this model, the retreat mining process is completed within ten steps. In the first six steps, the mining distance of each step is 16.4 and then $32.8 \mathrm{ft}$ for the following four steps; in each step, the previous caving area is modeled by double-yielding material and the longwall face is created as a $16.4 \mathrm{ft}$ width entry. In each mining step, the model is run to reach equilibrium state, and roof displacements of monitoring points are monitored and recorded. The displacements of roof and floor in each step are shown in Figure 4-21 and Figure 4-22. The displacement vectors around the three bleeder entries are shown in Figure 4-23. It is clear that roof displacement increases when the longwall face moves forward, and maximum roof displacement appears at MP3 (monitor point 3), MP6, and MP9, instead of the middle point MP2, MP5, and MP8. Roof displacement in the bleeder entry nearer the gob area is the greatest compared to roof displacement in the other two entries.

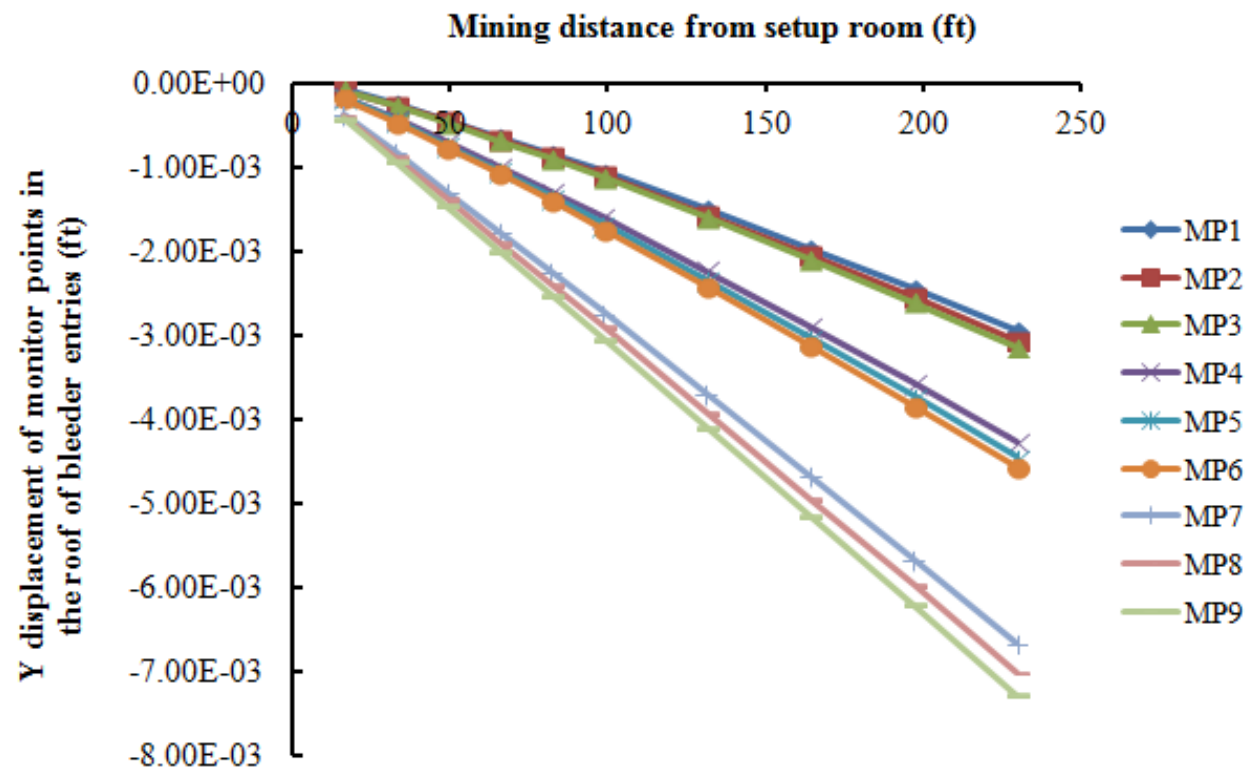

Figure 4-21 Y displacement of each monitor point in the roof in bleeder entries during the retreat mining process 


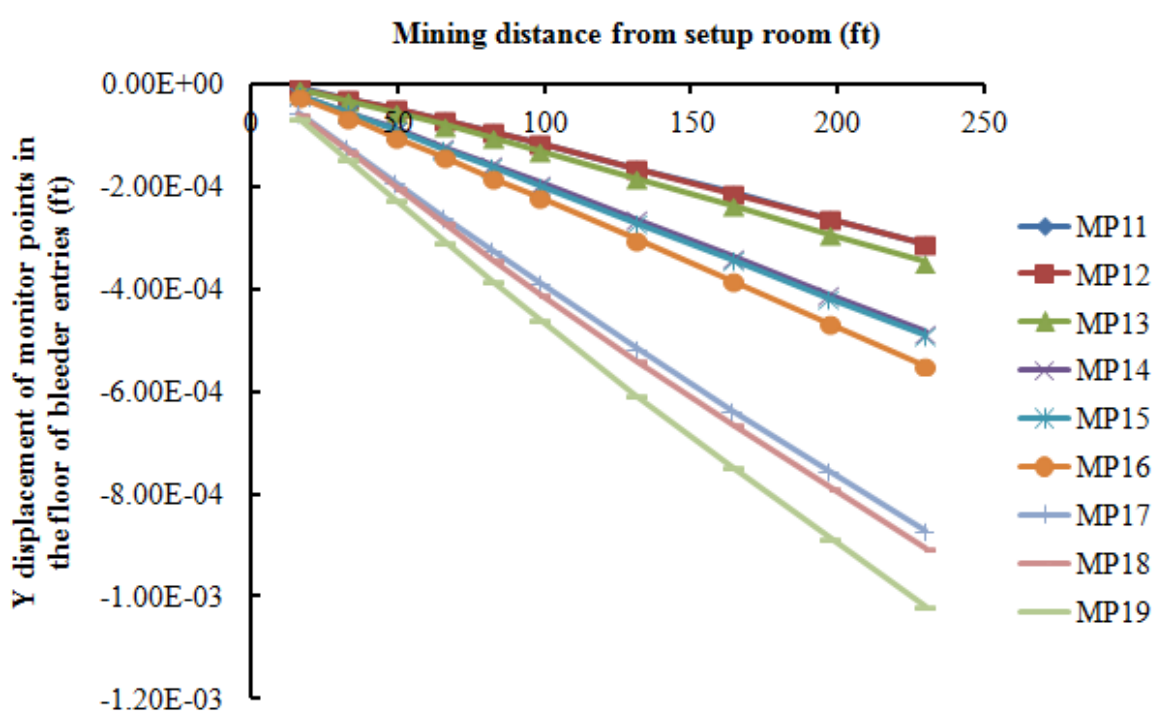

Figure 4-22 Y displacement of each monitor point in the floor in bleeder entries during the retreat mining process
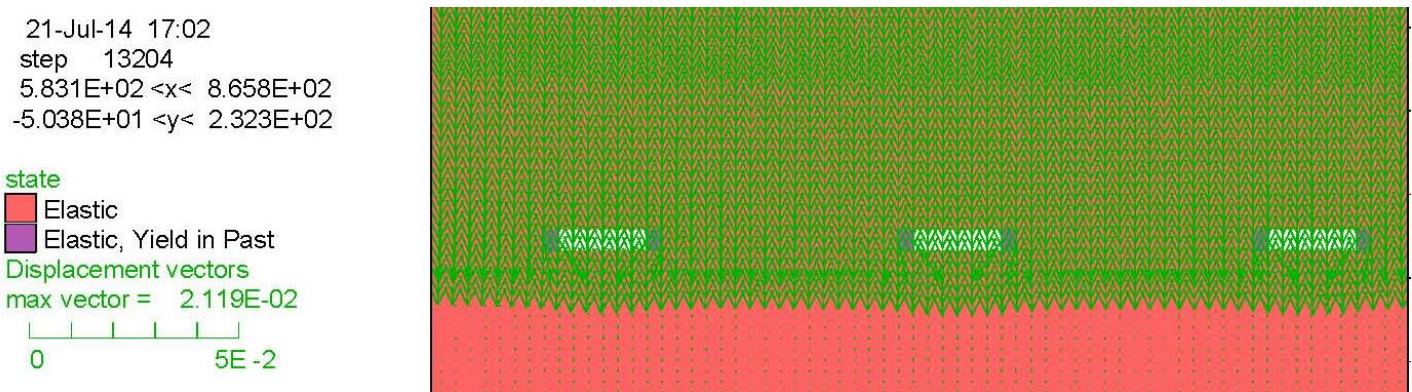

Figure 4-23 Displacement vectors around three bleeder entries

\subsubsection{Discussion}

In a typical longwall panel, bleeder entries connect the far end of gateroads. The setup room at the most outby side of the bleeder entries is used for installing the longwall face equipment. After the panel is prepared, including tailgates, headgates, bleeder entries and setup room, the longwall face equipment is installed and then the retreat mining process starts. Consequently, bleeder entries are frequently disturbed during the underground mining process. At first, the excavation of bleeder entries will disturb the initial geostatic state of the virgin area. After the bleeder entries are excavated, the induced stress around the bleeder entries will reach a new equilibrium state. Then when the longwall face moves forward, the new equilibrium will be disturbed because of the creation of the gob area and overburden movement; in this stage the stress around bleeder entries will be 
dynamic because of the moving longwall face. Finally, the induced stress around the bleeder entries will reach a second equilibrium state after the longwall moves a certain distance and the compacted gob area has the ability to support the overburden, which means the movement of longwall does not affect the stress state in the bleeder entries.

The maximum principal stress distribution around bleeder entries and setup room is shown in Figure 8(a). The surrounding rock mass of bleeder entries are in a stress relief state. The bleeder pillar rib is at yield in shear state (Figure 8(b)), which means that the potential failure zone. Because of the close distance of bleeder entries, the induced stresses around each entry interact with each other.
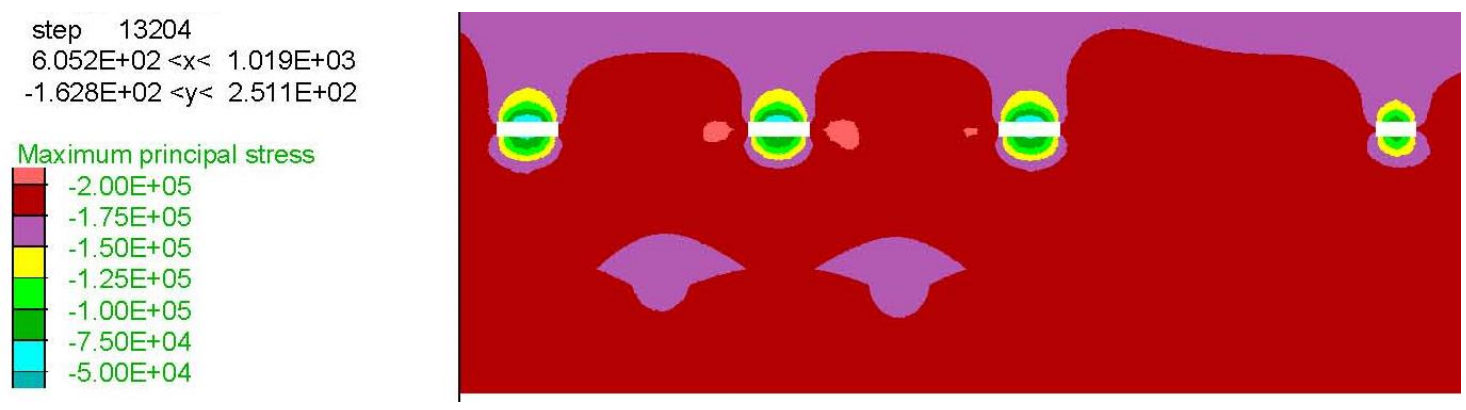

(a) Maximum principal stress around the bleeder entries and setup room

21-Jul-14 17:12

step 13204

$6.007 \mathrm{E}+02<\mathrm{x}<1.015 \mathrm{E}+03$

$-1.872 E+02<y<2.267 E+02$

state
$\square$ Elastic
$\square$ Elastic, Yield in Past

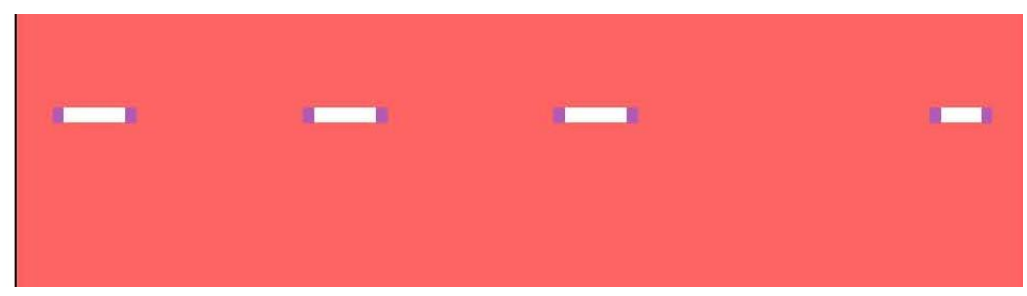

(b) The zone status around the bleeder entries and setup room

Figure 4-24 Stress state around bleeder entries and setup room during panel preparation

The roof and floor displacement with time steps in FLAC are shown in Figure 4-25 and 4-26. It is clear that roof and floor displacement increases with the increase of time steps in FLAC. It should be noted that time step in FLAC is not the real time, but one parameter for mathematical calculation. The inclined curve means the model is processed to equilibrium while the horizontal curve means the model has already reached 
equilibrium state. These also confirm that the final displacement in section 4.4 .3 is reasonable.

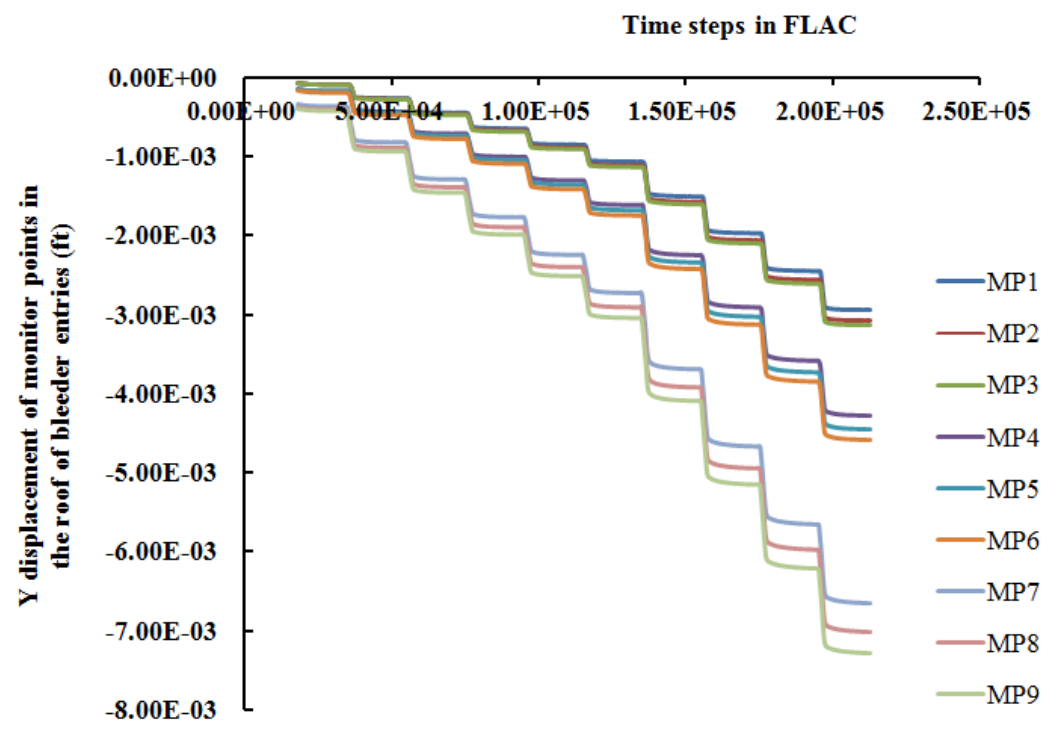

Figure 4-25 Y displacement of each monitor point of the roof in bleeder entries with FLAC steps during the retreat mining process

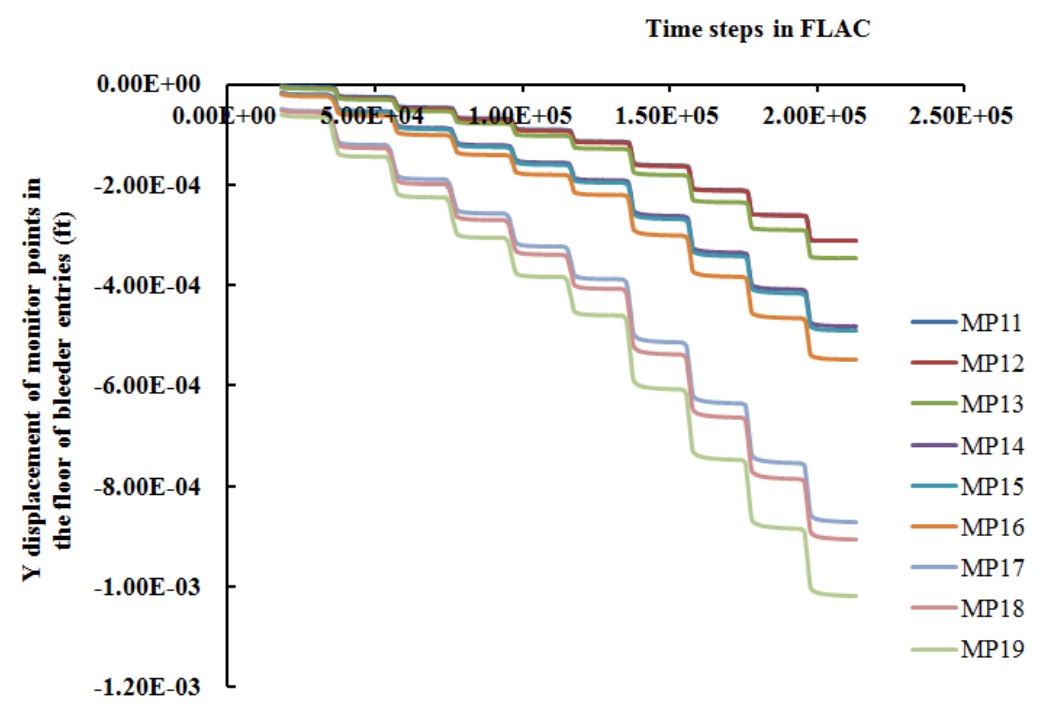

Figure 4-26 Y displacement of each monitor point of the roof in bleeder entries with FLAC steps during the retreat mining process 

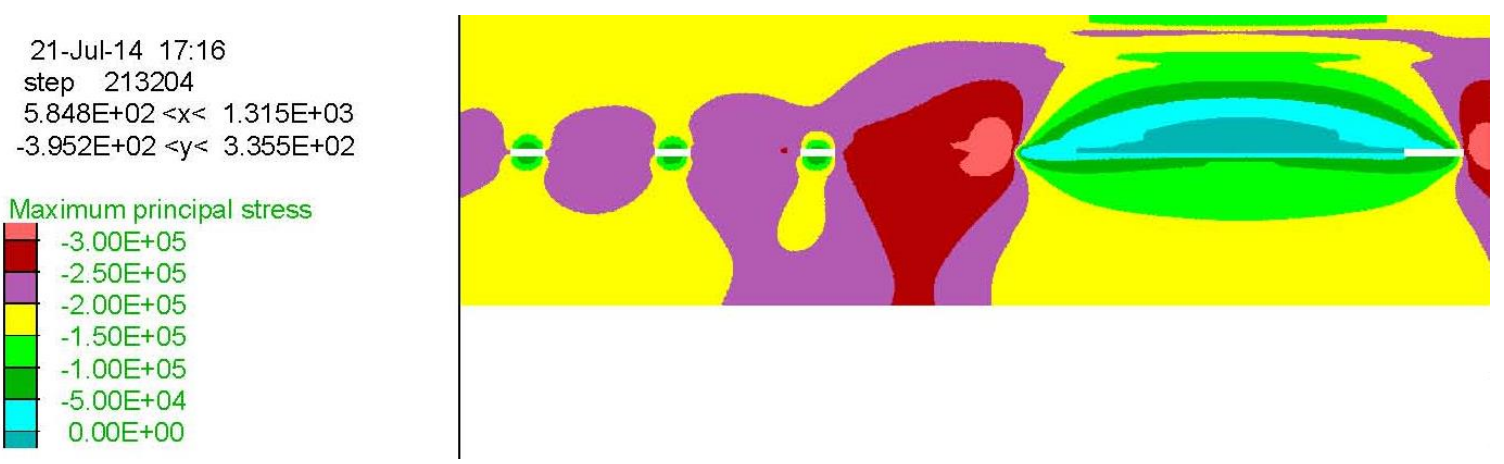

(a) Maximum principal stress around the bleeder entries and setup room
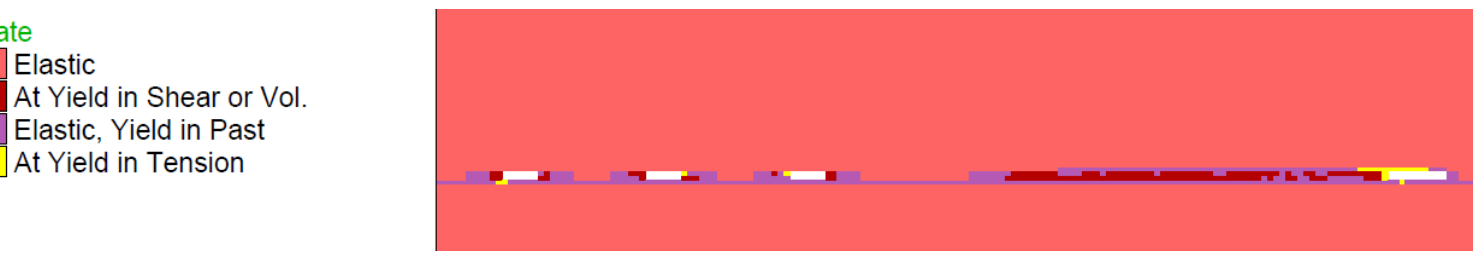

(b) The zone stress status around the bleeder entries and setup room.

Figure 4-27 Stress state around bleeder entries in retreat mining step 10

Figure 4-27(a) and 4-27(b) shows the stress state around bleeder entries in retreat mining step 10. Comparing Figures 4-27(b) and 4-24(b), it is found that there is no major difference in zone state around the bleeder area except in the case of the longwall face area. In Figure 4-27(b), the roof of mining face is in tension, which has potential for failure. The edges of the bleeder pillar are in shear state, implying the appearance of rib spalling.

\subsubsection{Conclusion}

In this section, one global model is created using the double-yielding gob material and strain-softening coal material to study the disturbance of the active longwall face on the roof and floor deformation in bleeder entries.

For underground coal mines operated in the Upper Freeport coal seam, the longwall face moves forward with an immediately unstable roof over the mine-out area, which means the immediate roof will fall, fill up the gob area, and finally support the overburden during the retreat mining process. In this model the gob and coal behavior are modeled by double-yielding material and strain-softening material. Based on the modeling results, it is found that roof displacement increases with mining distance. A similar pattern is 
followed in relation to floor displacement. For the three monitor points in the bleeder roof, the maximum displacement occurs at the right-side entry nearer the gob area instead of the middle of the entry. This is contradicted by common sense. There are no potential floor heave problems in this mining scenario. Rib spall failure may occur as a result of the high stress state of pillars in bleeder entries. 


\section{Conclusion and recommendation}

In this research, the stability of bleeder entries in underground coal mines was studied by the displacement-discontinuity LaModel code and finite-difference-based FLAC program. Using LaModel, the stability of bleeder pillars was evaluated, which emphasizes the effects of overburden thickness, multi-panel, and the size effect of bleeder pillars. Then the roof stability of bleeder entries was investigated by FLAC, using strain-softening coal material and double-yielding gob material.

\subsection{Conclusion}

Numerical modeling results obtained from LaModel and FLAC models show the following conclusions:

(1) The vertical stresses in bleeder pillars first increase and then remain unchanged during the retreat longwall process. The increase of vertical stress in bleeder pillars under deep cover is higher than that under shallow cover when the longwall face moves forward.

(2) Safety factors of bleeder pillars are determined for each case, and it is found that pillars in bleeder areas are stable.

(3) The active longwall face did not influence the stress and safety factors in the bleeder pillars in the adjacent mined-out panel.

(4) Bleeder pillars suffer different stress states during the retreat mining process because of the arrangement of bleeder pillars; induced vertical stress in bleeder pillars perpendicular to the longwall face is usually higher than that in bleeder pillars parallel to the longwall face.

(5) When different sizes of bleeder pillars are employed in the same bleeder area, the bleeder pillar nearest the longwall face is the most prone to fail because of the higher induced vertical stress upon it.

(6) The procedure using double-yielding material to model gob rock behavior was presented, and gob behavior was modeled by Salamon's constitutive equation. The 
confidence interval of Salamon's model was given; most of the known published data using Salamon's model are within this interval.

(7) Roof displacement in bleeder entries increases during the retreat mining process. The bleeder entry closest to the gob area is the most easily disturbed one. Rather than the middle point of the entry, maximum roof displacement occurs in the roof area nearer to the gob area.

\subsection{Future research recommendation}

Based on the investigations conducted in this research, the following work need to be updated:

(1) Up until now, there have been no published filed data monitoring the stress of bleeder pillars and roof deformation in bleeder entries. Even though the numerical models can give us some heuristic results, these results need to be confirmed by field test data.

(2) The time effect on the stability of bleeder pillars and bleeder roofs requires extensive research, including both field monitoring data and laboratory tests of coal measure rocks. 


\section{Reference}

Akinkugbe, O. O. (2004). A Simple Two-Dimensional Boundary Element Program for Estimating Multiple Seam Interaction (Master thesis, West Virginia University).

Badr, S. A. (2003) Numerical Analysis of coal yield pillars at deep longwall mines. Ph .D. Department of Mining Engineering, Colorado School of Mines, Golden, Colorado.

Barczak, T. M., \& Tadolini, S. C. (2005). Pumpable roof supports: an evolution in longwall roof support technology.

Barczak, T.M,Tadolini, S.C. (2006). Standing support alternatives in western united states longwalls. Mining Engineering, 58(2), 49-55.

Barczak, T.M,Tadolini, S.C. (2008). Pumpable roof supports: An evolution in longwall roof support technology. (pp. 208-220)

Barczak, T. M. (2000). Optimizing secondary roof support with the NIOSH Support Technology Optimization Program (STOP). In Proceedings of 19th International Conference on Ground Control in Mining, Morgantown, WV (pp. 74-84).

Barczak, T. M., Tadolini, S. C., \& McKelvey, P. (2004). Hydraulic Prestressing Units: An Innovation in Roof Support Technology. In Proceedings, 23rd International Conference on Ground Control in Mining, Morgantown, WV (pp. 286-294).

Barczak, T. M., \& Gearhart, D. F. (1995). Assessment of wood and alternative materials for supplemental roof support construction. In International Journal of Rock Mechanics and Mining Sciences and Geomechanics Abstracts (Vol. 32, No. 8). Elsevier Science.

Becker, A. A. (1992). The boundary element method in engineering: a complete course. McGraw-Hill Companies.

Beckett, L. A. and Madrid, R S (1988). MULSIM/NL - a structural analysis computer program for mine design, USBM IC 9168, $302 \mathrm{p}$.

Cacas, M.C., Ledoux E., de Marsily G., Tille B., Barbreau A, Durand E, Feuga B, Peaudecerf P.(1990). Modeling fracture flow with a stochastic discrete fracture network: calibration and validation. I. The flow model. Water Resource Res 26(3):479-89. 
Cluster prop. (n.d.). Retrieved May 20, 2014, from http://www.strataworldwide.com/sites/default/files/products/Edit\%20Products\%20Cluste r\%20Prop/brochure/StrataClusterProp.pdf

Code of Federal Regulations Title 30 (CFR-30)-Mineral Resources (2001). Washington DC: U.S. Government printing office, Office of the Federal Register.

Dershowitz W, Miller I. (1995) Dual porosity fracture flow and transport. Geophys Res Lett, 22(11):1441-4.

Esterhuizen E., Mark C., Murphy M. (2010) Numerical model calibration for simulation coal pillars, gob and overburden response. In: Proceeding of the 29th international conference on ground control in mining, Morgantown, WV, pp 46-57.

Esterhuizen, G.S. \& Karacan, C.O. (2005) Development of numerical models to investigate permeability changes and gas emission around longwall mining panels. Proceedings Alaska Rocks. $40^{\text {th }}$ US symposium on rock mechanics, Anchorage,25-26 June.

Grossbach, I., Chlan, L., \& Tracy, M. F. (2011). Overview of mechanical ventilatory support and management of patient-and ventilator-related responses.Critical care nurse, 31(3), 30-44.

Geromel, G., Medved,M., and Likar, J. (2010) An analysis of the geomechanical processes in coal mining using the Velenje mining method. Acta Geotechnica Slovenica, $1: 31-45$.

Dhatt, G., Lefrançois, E., \& Touzot, G. (2012). Finite element method. John Wiley \& Sons.

Heasley, KA. LaModel Timeline. (n.d.). Retrieved May 20, 2014, from http://web.cemr.wvu.edu/ kheasley/LaModelDownloads/Documents/Details/LaModelTi meline2.pdf

Heasley, K. A. (2008). Some thoughts on calibrating LaModel. In Proceedings: 27th International Conference on Ground Control in Mining (pp. 29-31). 
Heasley, K A (1998). Numerical modeling of coal mines with a laminated displacementdiscontinuity code, $\mathrm{PhD}$ thesis, Colorado School of Mines, Golden, $187 \mathrm{p}$.

Hoek, E., Kaiser, P. K., \& Bawden, W. F. (2000). Support of underground excavations in hard rock. CRC Press.

Insitu and induced stresses. (n.d.). Retrieved May 20, 2014, from http://www.rocscience.com/hoek/corner/10_In_situ_and_induced_stresses.pdf

Itasca (2011). FLAC User's guide: A Computer Program for Fast Lagrangian Analysis of Continua. Version 7.0. p.1-1, 2-53.

Jing, L. (2003). A review of techniques, advances and outstanding issues in numerical modelling for rock mechanics and rock engineering. International Journal of Rock Mechanics and Mining Sciences, 40(3), 283-353.

Jing, L., \& Hudson, J. A. (2002). Numerical methods in rock mechanics.International Journal of Rock Mechanics and Mining Sciences, 39(4), 409-427.

Li W., Bai J. \& Peng SS et al (2014) Numerical modeling for yield pillar design: a case study. J Rock Mechanics and Rock Engineering, http://dx.doi.org/10.1007/s00603-0130539-8.

Leach, B., J.R. (2012). Timber cribbing use. Fire Engineering, 165, 18-23. Retrieved from http://search.proquest.com/docview/1080966420?accountid=2837

Mark, C. (2002). "The introduction of roof-bolting to US underground coal mines (19481960): a cautionary tale." Proceedings of the 21st International Conference on Ground Control in Mining.

Mark, C., \& Chase, F. E. (1997). Analysis of retreat mining pillar stability (ARMPS). In Proceedings-New Technology for Ground Control in Retreat Mining. Pittsburgh, PA: US Department of Health and Human Services, Public Health Service, Centers for Disease Control and Prevention, National Institute for Occupational Safety and Health, DHHS (NIOSH) Publication (No. 97-122, pp. 17-34). 
Morsy, K. and Peng,SS. (2002) Numercial modeling of the gob loading mechanism in longwall coal mines. In: Proceeding of the 21 th international conference on ground control in mining, Morgantown, WV, pp 58-67.

Mucho T.P., Diamond W.P., \& Garcia F et al. (2000) Implications of recent NIOSH tracer gas studies on bleeder and gob gas ventilation design. SME Annual Meeting. Salt Lake City, UT, pp 1-17.

Mukherjee, S,Liu, Y.J. (2013). The Boundary Element Method. International Journal of Computational Methods, 10(6) doi:10.1142/S0219876213500370

Kalarsky J.D., Krikovic S. (1973) Ventilation of pillared areas by bleeder systems or equipment means, Trans. Soc. Min. Eng. AIME, December, Vol. 254, pp 284-291.

Kriakov N.P., and Melvin M.T. (1983) A computer procedure to simulate progressive rock failure around coal mine entries. Proceeding of the first conference on use of computers in the coal industry, West Virginia University, Morgantown, WV, pp.487-502.

Krickovic S., TD Moore Jr \& Carpetta JE (1973) Bleeder system in virgin area in a Pittsburgh coalbed mine, Report, U.S. Bureau of Mines.

Oswald N.L., Prosser B.S. (2006) Ventilation surveying and modeling of longwall bleeder and gob areas. 11th US/North American Mine Ventilation Symposium, pp: 587 590.

Pappas D.M., Mark C. (1993) Behavior of simulated longwall gob material. Bureau of Mines, RI.

Peng SS (2008) Coal mine ground control. Peng SS publisher, Morgantown, WV, pp. 12, 226, 319-334, 336-337, 324-325.

Peng S.S., Chiang H.S. (1984) Longwall mining, Peng SS publisher, Morgantown, WV, pp.36-50.

Peng S.S. (2010) Understanding the Chinese Coal Industry. (n.d.). Retrieved May 20, 2014, from http://www.coalage.com/features/593-understanding-the-chinese-coalindustry.html\#.U3wPwvldXlp 
Peng, S.S., Matsuki,K., and Su, W.(1980), 3-D structural analysis of longwall panels, Proceeding $21^{\text {st }}$ U.S. Symposium on Rock Mechanics, University of Missouri Rolla, pp. 44-56.

Propsetter. (n.d.). Retrieved May 20, 2014, from http://www.strataworldwide.com/sites/default/files/products/brochure/StrataPropsetter.pd f

R. Stefanko, R. V.Ramani (1972). pplication of Computer Methods in the Mineral Industry: Proceedings of the Tenth International Sympsium, Johannesburg, South Africa, 10-14 April 1972. http://www.saimm.co.za/Conferences/Apcom72/311-Stefanko.pdf

Ryder, J.A. and H.Wagner. (1978) 2D analysis of backfill as means of reduction energy release rates at depth. Chamber of Mines of South Africa, Research Organization, research report, No. 47/788, 22.

Salamon, M. D. G (1990), Mechanism of Caving in Longwall Coal Mining. Paper in Rock Mechanics Contributions and Challenges: Proceedings of the 31st U.S. Symposium, ed, by W, A, Hustrulid and G. A. Johnson (Denver, CO, June 18-20). A. A. Balkema, 1990, pp. 161-168.

Salamon, M.D.G. (1966) Reconsolidation of caved areas. Chamber Mines of South Africa, Research Organization, research report, No. 58/66, 25p.

Salamon M.D.G (1990) Mechanism of caving in longwall coal mining. Rock mechanics contribution and challenges: proceedings of the 31 st US symposium of rock mechanics, Golden, Colorado, pp 161-168.

Shabanimashcool, M. and C.LI, Charlie (2012) Numerical modeling of longwall mining and stability analysis of the gates in a coal mine. International journal of rock mechanics and mining science, 51:24-34.

Sears, M. M. (2013) Calibrating the LaModel Program for Shallow Cover Multiple-Seam Mines (Doctoral dissertation, WEST VIRGINIA UNIVERSITY), Morgantown, WV.

Sandler I.S., Rubin D. (1979) An algorithm and a modular subroutine for the cap model. Int J Numer Anal Methods Geomech 3:173-186. 
Smelser, T.W,Henton, L.N. (1983). Concrete Crib Design and Field Testing. Report of Investigations - United States, Bureau of Mines.

Sinha, K. P. (1979). Displacement discontinuity technique for analyzing stresses and displacements due to mining in seam deposits (Doctoral dissertation, University of Minnesota.).

Starfield, A. M., \& Cundall, P. A. (1988). Towards a methodology for rock mechanics modelling. In International Journal of Rock Mechanics and Mining Sciences \& Geomechanics Abstracts (Vol. 25, No. 3, pp. 99-106). Pergamon.

Su C. Gu M. and Tang X. et al. (2012) Experiment study of compaction characteristics of crushed stone from coal seam roof. Chinese Journal of rock mechanics and engineering. 31(1): 18-26. (in Chinese).

Tisdale J. (1996) Bleeder and gob ventilation systems. United States Department of Labor, Mine Safety and Health Administration, Arlington, VA.

Trueman R.(1989) A finite element analysis for the establishment of stress development in coal mine caved waste, Mining Science and Technology, No.10, 1990, pp. 247-252.

Ulery, J. P. (2008). Explosion hazards from methane emissions related to geologic features in coal mines. Department of Health and Human Services, Centers for Disease Control and Prevention, National Institute for Occupational Safety and Health, Pittsburgh Research Laboratory.

Urosek J.E., Francart W.J. (2002) Bleeder systems in underground coal mines. Proceedings of the North American/Ninth U.S. Mine Ventilation Symposium (Kingston, Ontario, Canada). DOI: 10.1201/9781439833742.ch63.

Vermeer, P. A., \& De Borst, R. (1984). Non-associated plasticity for soils, concrete and rock.

Xie,H., Chen Z. and Wang, J. (1999) Three-dimensional numerical analysis of deformation and failure during top coal caving. International Journal of Rock Mechanics and Mining Science, 36: 651-658. 
Yavuz, H. (2003) An estimation method for cover pressure re-establishment distance and pressure distribution in the goaf of longwall coal mines. International Journal of Rock Mechanics and Mining Science, 41: 193-205.

Zhang, P. (2014) Integrating the LaModel and ARMPS Programs (ARMPS-LAM) (Doctoral dissertation, West Virginia Univeristy), Morgantown, WV.

Zienkiewicz, O. C., \& Morice, P. B. (1971). The finite element method in engineering science (Vol. 1977). London: McGraw-hill. 


\section{About the author}

\section{Xu TANG}

\section{EDUCATION}

\section{Master of Science in Mining Engineering}

West Virginia University (WVU), U.S. (August, 2014)

"Stability Analysis of Bleeder Entries for Underground Coal Mines Using Displacement Discontinuity and Finite Difference Program".

Advisor: Brijes Mishra, Ph.D.

Master of Engineering in Safety Engineering

Henan Polytechnic University (HPU), China (July, 2013)

"Experimental research on effects of temperature and moisture upon gas

diffusion kinetic properties of crushed coal".

Advisor: Zhaofeng Wang, Ph.D.; co-advisor: Zhiqiang Li, Ph.D.

\section{Bachelor of Engineering in Mining Engineering}

Henan Polytechnic University, China (July, 2011)

"Experimental Study on mechanical property and compression deformation characteristics of broken rock".

Advisor: Ming Gu; co-advisor: Prof. Chengdong Su

\section{EXPERIENCE}

Graduate Research Assistant (Aug. 2012- Aug.2014)

Department of Mining Engineering, WVU

Interests: Rock mechanics, Numerical modeling, Ground control

Graduate Research Assistant (Sep. 2011- July, 2012)

College of Safety Science and Engineering, HPU

Interests: Coal and gas outburst control, Coal and gas interaction, Geo-mechanics

Undergraduate Research Assistant (Sep. 2010- June, 2011)

School of Energy Science and Engineering, HPU

Interests: Rock mechanics, Underground mining system 